\title{
Mechanisms of skeletal muscle dysfunction in lysosomal glycogen storage disease : observations in acid 1-4 [Alpha]-glucosidase deficient mice
}

Citation for published version (APA):

Hesselink, R. P. (2004). Mechanisms of skeletal muscle dysfunction in lysosomal glycogen storage disease : observations in acid 1-4 [Alpha]-glucosidase deficient mice. [Doctoral Thesis, Maastricht University]. Universiteit Maastricht. https://doi.org/10.26481/dis.20040129rh

Document status and date:

Published: 01/01/2004

DOI:

10.26481/dis.20040129rh

Document Version:

Publisher's PDF, also known as Version of record

Please check the document version of this publication:

- A submitted manuscript is the version of the article upon submission and before peer-review. There can be important differences between the submitted version and the official published version of record.

People interested in the research are advised to contact the author for the final version of the publication, or visit the DOI to the publisher's website.

- The final author version and the galley proof are versions of the publication after peer review.

- The final published version features the final layout of the paper including the volume, issue and page numbers.

Link to publication

\footnotetext{
General rights rights.

- You may freely distribute the URL identifying the publication in the public portal. please follow below link for the End User Agreement:

www.umlib.nl/taverne-license

Take down policy

If you believe that this document breaches copyright please contact us at:

repository@maastrichtuniversity.nl

providing details and we will investigate your claim.
}

Copyright and moral rights for the publications made accessible in the public portal are retained by the authors and/or other copyright owners and it is a condition of accessing publications that users recognise and abide by the legal requirements associated with these

- Users may download and print one copy of any publication from the public portal for the purpose of private study or research.

- You may not further distribute the material or use it for any profit-making activity or commercial gain

If the publication is distributed under the terms of Article 25fa of the Dutch Copyright Act, indicated by the "Taverne" license above, 


\section{Mechanisms of skeletal muscle dysfunction in lysosomal glycogen storage disease}

Observations in acid 1-4 $\alpha$-glucosidase deficient mice 
(C) Reinout Hesselink, Maastricht, 2004

Printed by: Datawyse, Universitaire Pers Maastricht

The studies described in this thesis were performed at the Cardiovascular Research Institute Maastricht (CARIM), Maastricht University, the Netherlands.

The Prinses Beatrix Fonds and foundation "De Drie Lichten" in The Netherlands financially supported the studies 


\section{Mechanisms of skeletal muscle dysfunction in lysosomal glycogen storage disease}

Observations in acid 1-4 $\alpha$-glucosidase deficient mice

\section{PROEFSCHRIFT}

Ter verkrijging van de graad van doctor aan de Universiteit Maastricht, op gezag van de Rector Magnificus, Prof. mr. G.P.M.F. Mols volgens het besluit van het College van Decanen, in het openbaar te verdedigen op donderdag 29 januari 2004 om 14.00 uur

door

Reinout Pepijn Hesselink

geboren op 14 juni 1973 te Enschede 


\section{Promotores:}

Prof. dr. G.J. van der Vusse

Prof. dr. A.J.M. Wagenmakers

Co-promotor:

Dr. ir. M.R. Drost

\section{Beoordelingscommisie:}

Prof. dr. H. Kuipers

Prof. dr. M. Borgers

Prof. dr. K. Nicolay

(voorzitter)

Dr. A. van der Ploeg

(Technische Universiteit Eindhoven)

Prof. dr. L. Snoeckx

(Erasmus Universiteit Rotterdam) 
GENERAL INTROOUCTION

BACKGROUND AND AMS OF THE STUDY

CHAPTER 2

LYSOSOMAL DYSFUNCTION IN MUSCLE WITH SPECIAL REFERENCE TO GLYCOGEN STORAGE DISEASE TYPE \|

CHAPTER 3

IMPAIRED PERFORMANCE OF SKELETAL MUSCLE

IN ACID $\alpha$-GLUCOSIDASE KNOCKOUT MICE

CHAPTER 4.

PROGRESSION OF MUSCLE DYSFUNCTION IN ACID $1.4 \alpha$-GLUCOSIDASE KNOCKOUT MICE

DURING ISOMETRIC AND SHORTENING CONTRACTIONS

CHAPTER 5

MORPHOLOGICAL AND STRUCTURAL CHANGES IN SKELETAL. MUSCLE

OF MICE LACKING ACID $\alpha$-GLUCOSIDASE

CHAPTER 6

EFFECTS OF NON-CONTRACTILE INCLUSIONS

ON MECHANICAL PERFORMANCE OF SKELETAL MUSCLE

CHAPTER 7 .

PROTEIN METABOLISM, REGENERATION AND APOPTOSIS:

AN EXPLORATIVE STUDY IN MUSCLE OF MICE LACKING ACID $\alpha$-GLUCOSIDASE

CHAPTER 8.

GENERAL DISCUSSION

SUMMARY

SAMENVATTING

DANKWOORD.

LIST OF PUBLICATIONS

CURRICULUM VITAE 

Chapter 1

General Introduction Background and aims of the study 


\section{General background}

Lysosomal storage diseases have in common that a wide variety of organs are affected, in most cases resulting in severe patho-physiology. Generally, a lysosomal storage disease is the outcome of an inborn genetic defect that causes insufficient function of one or more lysosomal proteins. At present, over 40 pathologies have been described which are associated with the dysfunction of lysosomal enzymes or proteins (for a recent reviews see $[1,2])$. In the majority of these diseases, both the substance accumulating inside the lysosomes or as cellular debris and the dysfunctional enzyme or protein have been characterised.

In 1932, the Dutch physician Jan C. Pompe described a syndrome that is now known as glycogen storage disease type II (GSD II) or Pompe disease [3]. This syndrome is hallmarked by skeletal muscle weakness and enlargement of the heart [3, 4]. In 1963, Hers showed that the cause of this disease was a lack of functional acid $1-4 \alpha$ glucosidase (E.C. 3.2.1.20), a lysosomal enzyme that degrades glycogen to glucose [5]. As a result of the deficient enzyme activity, a progressive accumulation of glycogen within the lysosome occurs, affecting predominantly skeletal and cardiac muscle function [6]. This condition generally leads to death as a consequence of cardio-respiratory insufficiency [7].

Since the first case reports in the early 1930 's, the pathological features of the disease have been described in detail. It has become clear that the severity of the disease depends on the residual activity of the enzyme. Depending on the locus of the genetic alteration, this residual activity varies from patient to patient. Extensive research on GSD II patients by Reuser and co-workers has established a large number of genetic alterations and the associated residual activity of acid 1-4 $\alpha$-glucosidase [8]. Usually, patients with over $25 \%$ residual enzyme activity do not show overt clinical symptoms or derangements $[9,10]$. Patients completely lacking enzyme activity commonly die before they reach the age of 2 years [11]. However, as most case reports are concerning patients in progressed stages of the disease, or are descriptions of post mortem obtained material, only little is known about the sequel of patho-physiological alterations in muscles of GSD II patients. As effective therapies can optimally be developed when the underlying pathogenic mechanisms and their time course are well understood, the need for an experimental animal model for GSD II was present. Moreover, such a model allows for testing the efficacy of potentially successful therapies. This need resulted in the generation of a knockout mouse model (AGLU mice) with a genetic defect that has identical functional effects as the most frequently occurring deletions in most Caucasian patients [12].

In this thesis, the mouse model generated by Bijvoet and co-workers was used to study in more detail the pathological alterations that occur in skeletal muscle cells lacking acid $1-4 \alpha$-glucosidase. 


\section{Objectives of the thesis}

To be able to unravel the sequel of pathological changes that take place in skeletal muscle cells lacking acid 1-4 $\alpha$-glucosidase, a number of research aims was addressed. The main objective of this thesis was to gain insight in the time course of the decline in muscle mechanical performance in AGLU- mice. For everyday life, two types of muscle contraction are vital. To be able to maintain posture, isometric contractions must be performed. For locomotion, breathing and cardiac function, (isokinetic) shortening contractions are important. Therefore, special attention should be paid to the extent and nature of the changes in isometric and isokinetic contractile behaviour of the diseased skeletal muscle. In close co-operation with the division of Biomechanical Engineering of the Technical University Eindhoven, two devices were developed that enable in vivo assessment of both types of muscle contractions in mice $[13,14]$.

The second aim was to obtain information on the mechanisms that lead to the decline in muscle performance. This includes alterations in muscle mass and quality of the remaining muscle tissue. To this end, the following assessments of metabolic processes and (ultra)structural changes have been performed:

- Quantification of glycogen accumulation in muscles of AGLU mice.

- Estimation of the impact of the physical presence of glycogen filled lysosomes and their interference with myofibrillar structure on muscle mechanical performance.

- Assessment of the time course of accumulation of cell debris in general and lipofuscin in particular in the affected muscle cells as a consequence of disturbed lysosomal function.

- Assessment of the muscle content of high-energy phosphates, i.e., ATP and phosphocreatine, and the maximal activity of a number of enzymes involved in muscle energy conversion.

- Elucidation of alterations in cytoskeletal proteins, with special reference to titin and desmin, as it has been shown that these proteins are involved in intracellular force transmission in skeletal muscle cells.

- Assessment of changes in the intracellular and cell-to-cell differences in myofibrillar structure of skeletal myocytes during the course of the disease.

The third aim of this thesis was to identify mechanisms underlying muscle wasting that occurs in GSD II. To this end, we investigated a number of potential causes of muscle wasting in AGLU mice, i.e., changes in protein turnover, the activity of the ubiquitin proteasome complex and apoptotic activity.

\section{Outline of the thesis}

In Chapter 2 of this thesis, a literature survey on lysosomal storage diseases is given, with special reference to mechanisms that may play a causative role in muscle dysfunction commonly observed in GSD II. Then, a study is presented in which muscle mechanical performance, a number of biochemical muscle characteristics, including high 
energy phosphates stores, and muscle cell micro-morphology were assessed in aged, severely affected AGLU - mice (Chapter 3). This study provided insight in the degree and nature of the loss of muscle mechanical function. The hypothesis put forward at the end of Chapter 3 was used as a starting point for further research. In the following chapter, muscle mechanical performance, both maximal torque produced during isometric contractions and peak power output calculated from isokinetic contractions, were assessed in three groups of mice at different ages and, hence, stages of the disease. The data on muscle mechanical performance were compared with muscular glycogen and protein content (Chapter 4). This study was extended in Chapter 5, where a detailed study on muscle morphological changes and content of cytoskeletal proteins involved in intracellular force transmission is described. In Chapter 6, mathematical modelling was applied to estimate the quantitative contribution of the physical presence of glycogen filled lysosomal structures to the decline in muscle mechanical performance. Chapter 7 explores whether there are evident changes in protein synthesis and degradation in the skeletal muscle of AGLU mice. Protein synthesis rates were assessed from the incorporation rate of an isotopically labelled amino acid, while the activity of the ubiquitin proteasome system was studied as a measure of protein degradation. Moreover, the localisation of the proteasome complex was monitored and apoptotic activity in muscle of AGLU mice was analysed. In the last chapter of this thesis, the major findings of the experimental chapters are summarised, and directions for further research are provided (Chapter 8). 


\section{References}

1 Hesselink, R.P., Wagenmakers, A.J.M., Drost, M.R. and Van der Vusse, G.J. (2003) Biochim Biophys Acta 1637, 164-170.

2 Scriver, C.R., Beaudet, A.L., Sly, W.S. and Valle, D., eds. (2001)The Metabolic and Molecular Basis of Inherited Disease McGraw-Hill, New York.

3 Pompe, J.C. (1932) Ned Tijdsch Geneesk 76, 304-311.

4 Putschar, W. (1932) Beitr Pathol Anat 90, 222- 232.

5 Hers, H.G. (1963) Biochem J 86, 11-16.

6 Hers, H.G. and De Barsy, T. (1973) in Lysosomes and storage diseases (Hers, H.G. and Van Hoof, F., eds.), pp. 197 -217, Academic Press, New York.

7 Van den Hout, J.M., Reuser, A.J.J., De Klerk, J.B., Arts, W.F., Smeitink, J.A. and Van der Ploeg, A.T. (2001) J Inherit Metab Dis 24, 266-274.

8 Reuser, A.J.J. GSD mutation database (2002).

9 Wokke, J.H., Ausems, M.G., Van den Boogaard, M.J., Ippel, E.F., Van Diggelene, O., Kroos, M.A., Boer, M., Jennekens, F.G., Reuser, A.J.J. and Ploos-van Amstel, H.K. (2001) Ann Neurol 38, 450-454.

10 Ausems, M.G., Lochman, P., Van Diggelen, O.P., Ploos-van Amstel, H.K., Reuser, A.J.J. and Wokke, J.H. (1999) Neurology 52, 851-853.

11 Hirschhorn, R, Reuser A.J.J. (2001) in The Metabolic and Molecular Basis of Inherited Disease (Scriver, C.R., Beaudet, A.L., Sly, W.S. and Valle, D., eds.), pp. 3389-3420, McGraw-Hill, New York.

12 Bijvoet, A.G.A., Van der Kamp, E.H.M., Kroos, M.A., Ding, J-H., Yang, B.Z., Visser, P., Bakker, C.E., Verbeet, M.P., Oostra, B.A., Reuser A.J.J. and Van der Ploeg A.T. (1998) Hum Mol Gen 7, 53-62.

13 Gorselink, M., Drost, M.R., de Louw, J., Willems, P.J., Rosielle, N., Janssen, J.D. and Van der Vusse, G.J. (2000) Pflugers Arch 439, 665-670.

14 Gorselink, M., Drost, M.R., de Louw, J., Willems, P.J., Hesselink, M.K.C., Dekkers, E.C., Rosielle, N. and Van der Vusse, G.J. (2001) Pflugers Arch 442, 304-311. 
Chapter 2

\section{Lysosomal dysfunction in muscle with special reference to glycogen storage disease type II}

Reinout P. Hesselink, Anton J.M. Wagenmakers, Maarten R. Drost and Ger J. van der Vusse

Published in:

Biochimica Biophysica Acta, 2003; 1637; 164-170 


\section{Summary}

The importance of proper lysosomal activity in cell and tissue homeostasis is underlined by "experiments of nature", i.e., genetic defects in one of the at least 40 lysosomal enzymes/protein present in the human cell. Life threatening is the complete lack of acid $1-4 \alpha$-glucosidase (GSD II or Pompe disease). Patients suffering from GSD II commonly die before the age of 2 years because of cardio-respiratory insufficiency. Striated muscle cells appear to be particularly vulnerable in GSD II. The high cytoplasmic glycogen content in muscle cells most likely gives rise to a high rate of glycogen engulfment by the lysosomes. The polysaccharides become subsequently trapped in these organelles when acid 1-4 $\alpha$-glucosidase activity is absent. During the course of the disease muscle wasting occurs. It is hypothesised that the gradual loss of muscle mass is caused by a combination of disuse atrophy and lipofuscin mediated apoptosis of myocytes. Moreover we hypothesise that in the remaining skeletal muscle cells longitudinal transmission of force is hampered by swollen lysosomes, clustering of non-contractile material and focal regions with degraded contractile proteins, which results in muscle weakness. 


\section{Introduction}

Lysosomal storage diseases are a group of inborn metabolic disorders characterised by accumulation of non-metabolised material inside lysosomes. In the majority of these diseases the pathology is severe, leading to disabilities and often to death. In general, each of the approximately 40 lysosomal enzymes can be affected by a genetic defect [1. 3]. Table 2.1 provides an overview of lysosomal enzymes currently known and of pathological conditions due to impaired synthesis and/or activity.

Table 2.1: Lysosomal enzymes and related storage diseases.

Based on Gieselmann [1] Bijvoet [71] and Michalski and Klein [80]

\begin{tabular}{l|l}
\hline Lysosomal enzyme & Disease \\
\hline Lipid metabolism & \\
\hline cathepsin A & Galactosialidosis \\
$\beta$-galactosidase & GM1-gangliosialidosis (Landing) \\
hexosaminidase A and B ( $\beta$-chain) & GM2-gangliosialidosis (Sandhoff) \\
hexosaminidase A and S ( $\alpha$-chain) & GM2-gangliosialidosis (Tay-Sachs) \\
$\beta$-galactocerebrosidase & Galactocerebrosidosis (Krabbe) \\
glucocerebrosidase & Glucocerebrosidosis (Gaucher) \\
sphingomyelinase & Sphingomyelin lipidosis (Niemann-Pick A, B) \\
acid lipase & Cholesteryl ester storage disease (Wolman) \\
aryisulfatase A & Metachromatic leukodystrophy \\
$\alpha$-galactosidase A & Fabry \\
\hline Glycoprotein metabolism & \\
\hline aspartylglucosaminidase & Aspartylglucosaminuria \\
$\alpha$-L-fucosidase & Fucosidosis \\
$\alpha$-N-acetylneuraminidase & Sialidosis / Mucolipidosis I \\
$\alpha$-N-acetylgalactosaminidase & Schindler disease \\
$\beta$-galactosidase & Galactosialidosis \\
$\alpha$-neuraminidase & Galactosialidosis \\
$\alpha$-mannosidase & $\alpha$-mannosidosis \\
$\beta$-mannosidase & $\beta$-mannosidosis \\
\hline Mucopolysaccharide metabolism & \\
\hline$\alpha$-L-iduronidase & MPS I (Hurler/ Scheie) \\
iduronate-sulfate sulfatase & MPS II (Hunter) \\
heparansulfate sulfatase & MPS IIIA (Sanfilippo A) \\
$N$-acetyl-a-D-glucosaminidase & MPS IIIB (Sanflippo B) \\
acetyl transferase & MPS IIIC (Sanflippo C) \\
$\alpha$-N-acetylglucosamine 6-sulfatase & MPS IIID (Sanfilippo D) \\
$N$-acetylgalactosamidase-6-sulfate & MPS IV (Morquio A) \\
sulfatase & \\
$\beta$-galactosidase & MPS IVB (Morquio B) \\
arylisulfatase B & MPS VI (Maroteaux-Lamy) \\
&
\end{tabular}




\begin{tabular}{l|l}
\hline B-glucuronidase & MPS VII (Sly) \\
\hline Various lysosomal functions & \\
\hline $\begin{array}{l}\text { acid } 1-4 \alpha \text {-glucosidase } \\
\text { cathepsin K }\end{array}$ & Glycogenosis type II (Pompe) \\
prosaposin (sphingolipid activator) & Complex lipidosis \\
GM2 activator (sap3) & GM2-gangliosialidosis / AMB variant \\
palmitoyl-protein thioesterase & Infantile neuronal ceroid lipofuscinosis \\
pepstatin-insensitive peptidase & Juvenile neuronal ceroid lipofuscinosis \\
(deficient) cholesterol recycling & Cholesterollipidosis (Niemann-Pick C) \\
\hline Other lysosomal enzymes & \\
\hline acid phosphatase (LAP) & No pathology described in humans \\
cathepsin B & No pathology described in humans \\
cathepsin D & No pathology described in humans \\
cathepsin L & No pathology described in humans \\
tartrate-resistant acid phosphatase & No pathology described in humans \\
(TRAP) & \\
\hline
\end{tabular}

In one of the most frequently occurring lysosomal storage diseases, i.e. lysosomal glycogen storage disease type II (GSD II), muscle tissue is primarily affected. The hallmarks of this syndrome are skeletal muscle weakness and hypertrophy of the heart as described for the first time in 1932 by the Dutch physician Jan C. Pompe [4]. In 1963 it was convincingly shown that GSD II is caused by deficiency of the enzyme acid $1-4 \alpha$ glucosidase (EC 3.2.1.20) [5]. This defect results in accumulation of glycogen inside the lysosome in a variety of tissues including smooth and striated muscle. As both heart and skeletal muscle are functionally affected, patients eventually suffer from cardiorespiratory failure [6]. The pace of progression of this disease is primarily determined by the residual activity of acid 1-4 $\alpha$-glucosidase. Patients with a complete lack of enzyme activity die before they are two years old [7]. In contrast, patients with more than $25 \%$ residual activity show no clinical symptoms [8]. The frequency of the various forms of GSD II is estimated to be 1 out of 40,000 births [9].

In this review, attention will be paid to the structure and function of lysosomes in general, to the assembly of lysosomes and the synthesis of lysosomal enzymes, and to the biological activity of lysosomes. Moreover, lysosomal storage disease as a consequence of a genetic defect will be discussed, with special emphasis on GSD II. Finally, a novel hypothesis will be presented explaining the impairment of muscle mechanical function of patients suffering from GSD II.

\section{Structure and function of lysosomes}

Lysosomes are organelles originating from the endoplasmatic reticulum [10]. Usually, the diameter of a mature lysosome varies from 400 to 500 nanometer. The lysosomal membrane consists of a phospho-lipid bilayer that envelops an acidic environment ( $\mathrm{pH}$ 
4-5) in which at least 40 enzymes/proteins are active. To avoid autolysis of the lysosomal membrane, the internal side of the membrane is protected by various forms of lysosome-associated membrane proteins (LAMPs), which contain numerous sialic acidrich oligosaccharides $[11,12]$. Vacuolar $\left(\mathrm{H}^{*}\right)$-ATP-ases maintain the low internal $\mathrm{pH}$ of the lysosomes [13].

The main function of the lysosomal system is to engulf and subsequently digest macromolecules. In general, these are either damaged or non-functional compounds from endogenous origin, or exogenous substances and microorganisms that penetrated the cell membrane. Each of the lysosomal enzymes is able to break a specific chemical bond of the enguifed material. Although spatial separation of metabolic activity within the lysosomes is most likely absent, it is believed that the lysosomal enzymes are able to coagulate to form enzyme hypercomplexes that effectively degrade the internalised macromolecules [14]. The degradation products are actively or passively transferred back from the lysosomal interior into the cytoplasm, and can be re-utilised for the synthesis of functional molecules. Recent studies indicate that LAMPs might also be involved in the transport of lysosomal degradation products through the lysosomal membrane [11]. It is tempting to speculate that in the phagocytic process some macromolecules, such as cytoplasmic glycogen, are inadvertently engulfed by the lysosome. To get rid of this 'by catch', the polysaccharides have to be hydrolysed by acid 1-4 $\alpha$-glucosidase and the glucose molecules produced must be transported back into the cytoplasm, most likely by the facilitating action of LAMP2 [15].

Initially it was assumed that lysosomes were largely involved in the hydrolysis of tissue proteins [16]. However, in the last decade several studies have provided evidence that also the cytoplasmic ubiquitin proteasome system substantially contributes to the degradation of contractile and cytoskeletal proteins in muscle tissue [17-23]. There are indications that lysosomes are preferentially involved in the degradation of mitochondrial and sarcolemmal proteins, and in the process of membrane turnover [24, 25]. In addition, ligand/receptor uncoupling is accomplished by engulfment of the entire complex and subsequent intra-lysosomal proteolysis [26].

\section{Lysosome assembly}

Like any cellular structure, the assembly of lysosomes starts with the transcription of genes encoding their specific proteins. Transcription of genes and translation of mRNA encoding for the different lysosomal enzymes is inherently complex [27-29]. Most of the lysosomal genes described so far lack the specific TATA and CAAT motifs adjacent to the transcription start site. The absence of these motives in the promoter region is characteristic for mammalian "housekeeping" genes [30]. The expression of the individual lysosomal enzymes is not mutually linked, and the lysosomal content of distinct enzymes may differ between tissues and metabolic situations [31]. Information on the regulatory mechanisms underlying lysosomal protein expression is still very 
fragmented, but points towards a multitude of factors that are able to influence gene transcription and mRNA translation of the distinct lysosomal enzymes [28, 32-35]. These include, among others, hormones (e.g. growth hormone and insulin) and metabolically challenging situations such as starvation [36].

Though the precise regulation of gene expression of lysosomal proteins is still incompletely understood, detailed information on post-translational handling of lysosomal enzymes is available [37-39]. Precursors of lysosomal enzymes are synthesised in the cytoplasm at the endoplasmatic reticulum. Substantial posttranslational modification occurs in subsequent steps required for the transport of (pro)enzymes to the lysosomes. Maturation of the precursors of lysosomal enzymes involves processes in the endoplasmatic reticulum and the Golgi complex, where protein folding and chemical modification through the addition of carbohydrate chains (i.e. attachment of mannose 6-phosphate (M6P) groups) take place. These M6P groups are in the trans-Golgi network recognised by M6P receptors and subsequently bound. These receptor/ligand complexes are packaged into clathrin-coated vesicles that fuse with endosomes, where the ligand is released. The M6P receptor returns to either the transGolgi network or the cell surface. To avoid autolysis lysosomal pro-enzymes usually contain a pro-peptide region, i.e. a polypeptide chain that blocks their active site as long as the enzyme is not transferred into the lysosome. In general, the above mentioned polypeptide chain is removed by proteolytic processing by cathepsins. This step subsequently results in the activation of the lysosomal enzyme.

\section{Biological activity of lysosomes}

Lysosomes are present in all eukaryotic cells. Their specific activity appears to differ between tissues and species, and is age dependent [40]. In spleen and liver lysosomal activity is reported to be high, in differentiated muscle tissue it is low [12]. During cellular differentiation, lysosomes appear to be of importance, as the activity of at least a number of lysosomal enzymes is increased in differentiating tissue [41]. Moreover, the activity of lysosomal enzymes, particularly the cathepsins, is high during development of muscle tissue [42], while during ageing the activity diminishes [40].

Whereas the activity of the lysosomal system differs between tissues, it also depends on the metabolic status of the organ or organism. Several stimuli have been identified that regulate lysosomal activity, none of which however is exclusively targeting the lysosome. In starvation and other catabolic situations, the activity of lysosomal enzymes in the muscle, especially cathepsin-L, is increased $[43,44]$. This resulted in enhanced proteolysis, most likely due to an increased lysosomal contribution to protein degradation $[43,44]$. In inflammation, cancer cachexia, hyperthyroidism and various neuromuscular disorders the activity of a selected number of lysosomal enzymes was found to be increased as well [16, 45-49]. A variety of hormonal stimuli (e.g. insulin, growth hormone, catecholamines, and clenbuterol) are exerting a negative effect on lysosomal 
activity $[48,50]$. Experimental studies have revealed that pharmacological agents are able to decrease the activity of the lysosomal system in vitro [51- 54].

Due to the complexity of the system, it is comprehensible that the majority of factors capable of influencing lysosomal activity have not yet been fully identified. In the cases mentioned above, little information is available on the cellular signalling pathway through which lysosomal activity is modulated. Moreover, it is not clear whether the observed changes in activity could be ascribed to an altered number of lysosomes in the cells or to a specific change in the activity of the lysosomal enzymes under investigation.

\section{Common features in lysosomal storage diseases}

Lysosomal storage diseases comprise a group of over 30 different syndromes. Commonly a division in lipidoses, mucopolysaccharidoses and disorders of glycoprotein degradation is made (Table 1). The common denominator of these syndromes is a deficiency of one lysosomal enzyme/protein, usually the result of a genetic disorder. If either an enzyme or a transport protein is affected, progressive accumulation of the corresponding, non-metabolised substrate within the lysosome occurs. The lack of activity is usually generalised, and accumulation of material is observed in lysosomes of all tissues.

The consequences of the lack of activity of one specific lysosomal enzyme on the overall lysosomal function is only partially understood. Commonly, the dimensions of the lysosomes appreciably increase in lysosomal storage syndromes [55]. While the volume increases, the intra-lysosomal pH must be kept low to ensure proper function of the lysosomal enzymes. However, it is unlikely that the proton pumps in the lysosomal membrane are able to entirely cope with a substantial increase in lysosomal volume [56]. This may imply that in lysosomal storage diseases lysosomal pH gradually rises and that the actual activity of originally unaffected lysosomal enzymes declines with the progression of the disease.

As indicated above in more detail, the formation of lysosomes is a complex process, which involves a number of steps (transcription, translation, trafficking of primary proteins, post-translational modification). Therefore, the molecular origin of the lysosomal dysfunction can differ even within a particular storage syndrome. In GSD II, for instance, over 40 mutations are described [57]. In the majority of lysosomal storage disorders the relationship between genotype and phenotype is poorly understood. Almost all lysosomal storage diseases show an appreciable variability in clinical progression, and the onset and progression of symptoms vary with the residual activity of the affected enzyme. In many lysosomal storage diseases, a distinction in a severe infantile, an intermediate juvenile and a mild adult form is made. This classification is somewhat arbitrary as it represents a continuum of clinical severity, and it is safe to assume that the accumulation of undigested material already starts during the foetal stage in all patients. 
A common feature observed in lysosomal storage disorders is the formation of lamellar, roundly shaped, electron dense structures within cells. These structures are indicated by a variety of names such as ceroid, myelin figures, electron dense bodies or lipofuscin. Since lipofuscin accumulation is typical in lysosomal storage disorders the mechanism underlying and the functional consequences of lipofuscin formation are discussed in more detail below.

\section{Mechanisms underlying lipofuscin formation}

Lipofuscin is formed in the lysosomes, most likely after peroxidation of autophagocytised material [58]. The chances that this material becomes peroxidised in the free-radical rich environment of the lysosome rise when the amount of undigested material and/ or its dwelling time inside the lysosome increase. In lysosomal storage diseases, the size of the lysosomes can increase several fold as a result of accumulation of undigested material. In addition, osmotic swelling might occur. In case of lysosomal glycogen storage the hygroscopic properties of glycogen will also promote lysosomal swelling. As indicated above, swelling of lysosomes most likely increases the intra-lysosomal pH when the proton pumps in the lysosomal membrane fail to maintain the $\mathrm{H}^{*}$ gradient over the membrane [59]. Since lysosomal enzymes are less active at elevated $\mathrm{pH}$, passage time of the enguifed material will increase. This in turn most likely ieads to increased formation and deposition of lipofuscin. In tissue with a high cell turnover, enhanced deposition of lipofuscin may not harm the cell, as the cells are most likely removed before lipofuscin accumulation becomes detrimental. In tissues with a relatively stable cell population such as liver, muscle and nerve tissue, lysosomal lipofuscin formation might exert large effects. As the regenerative capacity of these tissues is relatively limited, damaged cells are not, or not in sufficient numbers, replaced in time. This consideration may explain why, despite the fact that the lysosomal dysfunction is usually generalised, the pathological features are most prominent in tissues with relatively stable cell populations.

Experiments exploring the effect of a decline in lysosomal activity have been performed in a variety of cultured cell types $[52,54,60,61]$. In all experiments where lysosomal activity was diminished, cells rapidly develop an abnormal appearance. In general, lipofuscin accumulation is a common and prominent feature. It is of interest to note that in senescent cells, where lysosomal activity also declines, lipofuscin accumulation becomes apparent as a typical feature of physiological ageing $[62,63]$.

\section{Putative functional consequences of lipofuscin accumulation}

Though the pathological significance of accumulation of lipofuscin in the cells is not fully understood, several studies strongly suggest that cellular accumulation of this material is 
a trigger for cell death [64-66]. Nakae and co-workers [67] found a significant correlation between lipofuscin accumulation and apoptosis in the diaphragm muscle of mdx mice, a well-established model for Duchenne muscle dystrophy. They hypothesised that lipofuscin accumulation was caused by elevated oxidative stress. Since satellite cells in the diaphragm of $m d x$ mice also showed lipofuscin granules as well as apoptosis, it was concluded that the regenerative capacity of the diaphragm muscle was severely depressed. As a consequence, overall diaphragm function is impaired, which might eventually cause respiratory insufficiency.

As tissue degeneration readily occurs in lysosomal storage diseases, the question remains whether the cells become jeopardised due to improper functioning of the lysosomal system in general, or due to cellular accumulation of lipofuscin in particular. Since exposure to mild oxidative stress triggers lipofuscin formation, this experimental condition can be used to discriminate between these two options. The mortality rate both of cells with blocked lysosomal function and of cells exposed to mild oxidative stress was found to be high. This finding might suggest that accumulation of lipofuscin rather than improper functioning of the lysosomes per se causes cell death.

It has been shown that accumulation of lipofuscin is reversible, when the extent of accumulation is relatively small, and lysosomal function is restored in due time [68]. Since the mortality rates of the rescued cells returned to normal, these findings may have important clinical implications. It can be inferred that therapies aiming to restore proper lysosomal function, such as enzyme replacement therapy, should be started before a critical amount of lipofuscin has been accumulated in the affected cell.

\section{Muscular dysfunction in GSD ॥}

Glycogen storage disease type II (GSD II) is the result of a genetic defect in the acid 1.4 $\alpha$-glucosidase gene resulting in an insufficient degradation of glycogen inside the lysosomes. From an energetic point of view, the amount of glycogen accumulating within the lysosomes is inconsequential. It is unlikely that it creates a shortage of glucose required for glycolytic and oxidative energy conversion. This notion is supported by the observation that the muscle content of high-energy phosphates in an experimental knockout mouse model for GSD II was equal to that in non-affected controls [69].

As the genetic defect is generalised, the question remains why in GSD II in particular muscular tissue is severely affected. A major cause is most likely the high concentration of glycogen in the cytoplasm of cardiac and skeletal muscle cells. As pointed out above, cytoplasmic glycogen is most likely inadvertently engulfed by the lysosome and, hence, lysosomal sequestration of this carbohydrate is most pronounced in muscle cells when 1-4 $\alpha$-glucosidase activity is impaired. Since hepatocytes also contain relatively high levels of cytoplasmic glycogen it is of interest to note that despite the fact that glycogen accumulates in hepatic lysosomes to the same extent as in myocytes [6], patients suffer from muscular insufficiency rather than from liver malfunction in GSD II. 
Both clinical studies in GSD II patients [70,71] and experimental investigations in $1-4 \alpha$ glucosidase null mice (AGLU*) [72] show that impaired muscle function is a prominent feature of this disease. Developed force by hind limb muscles of AGLU - mice fell by approximately $50 \%$, when the animals reach the age of 18 months [69]. This decline in mechanical function could be partially explained by loss of muscular mass. Compared to age-matched controls, the wet weight of the hind limb muscle was on the order of $25 \%$ less in AGLU mice. The precise cause of muscle wasting in GSD II is unknown, but one may speculate that lipofuscin-mediated apoptosis contributes to this process. Recent findings in AGLU mice are in support of this notion. In regions of the affected muscle cell with marked lipofuscin deposits, nuclei with typical apoptotic features were readily observed (Hesselink, unpublished findings). Under normal conditions, these regions could regenerate by the action of satellite cells [73, 74], but in GSD II satellite cells may be affected as well. In this respect, it is worth to mention that in the diaphragm of $m d x$ mice, the presence of lipofuscin precipitates was associated with satellite cell apoptosis and, hence, a substantial decline in regenerative capacity [75]. If a similar process occurs in satellite cells in GSD II patients and AGLU* mice, muscle wasting is inevitable.

Since the loss of skeletal muscle mass cannot fully account for the decline in muscular developed force [69], additional factors exerting a negative effect on mechanical performance should be considered. Recently we hypothesised that direct mechanical effects of the non-contractile inclusions impair muscle strength [69]. Already in early stages of GSD II, lysosomal volume is substantially increased. These swollen lysosomes (Figure 2.1) disturb the highly organised architecture of the contractile machinery by interruption of myofibrils.

Lysosomes do not contribute to the generation of force and are unlikely to be attached to the contractile machinery. Therefore, shortening of sarcomeres of the interrupted myofibrils near the site of interruption is likely to occur. As force can be transmitted from interrupted to non-interrupted myofibrils by shearing, elongation of sarcomeres of the non-interrupted myofibrils adjacent to the lysosome will occur at the same time. This will decrease the total force of a bundle of myofibrils centred around an inclusion because in-homogeneities in sarcomere length develop during contraction. These inhomogeneities diminish the force generating capacity of the entire bundle.

By means of a recently developed numerical model of contracting muscle which makes use of the Finite Element Method [76], the loss of mechanical performance was calculated as a function of the volume density of glycogen-filled lysosomes. At a density of $15 \%$, reflecting the situation in muscles of 12 month old AGLU mice, the loss in mechanical performance was calculated to be about $25 \%$ (Drost, unpublished results). This implies that about half of the observed loss in muscle function may be caused by hampering of mechanical activity by the swollen lysosomes.

When GSD II progresses, also deposits of extra-lysosomal material become apparent in the affected muscle cells (Figure 2.1) [77, 78]. Electron microscopical analysis revealed that at the borders of the large inclusions degradation of myofibrillar material occurred 
Chapter 2

Lysosomal dystunction in muscle

and that degraded myofibrils were often present inside these inclusions. This focal myofibrillar degradation will directly affect mechanical performance.

Figure 2.1: Muscle fiber of an AGLU- mouse in an advanced stage of GSD I| Arrows indicate swollen lysosomes

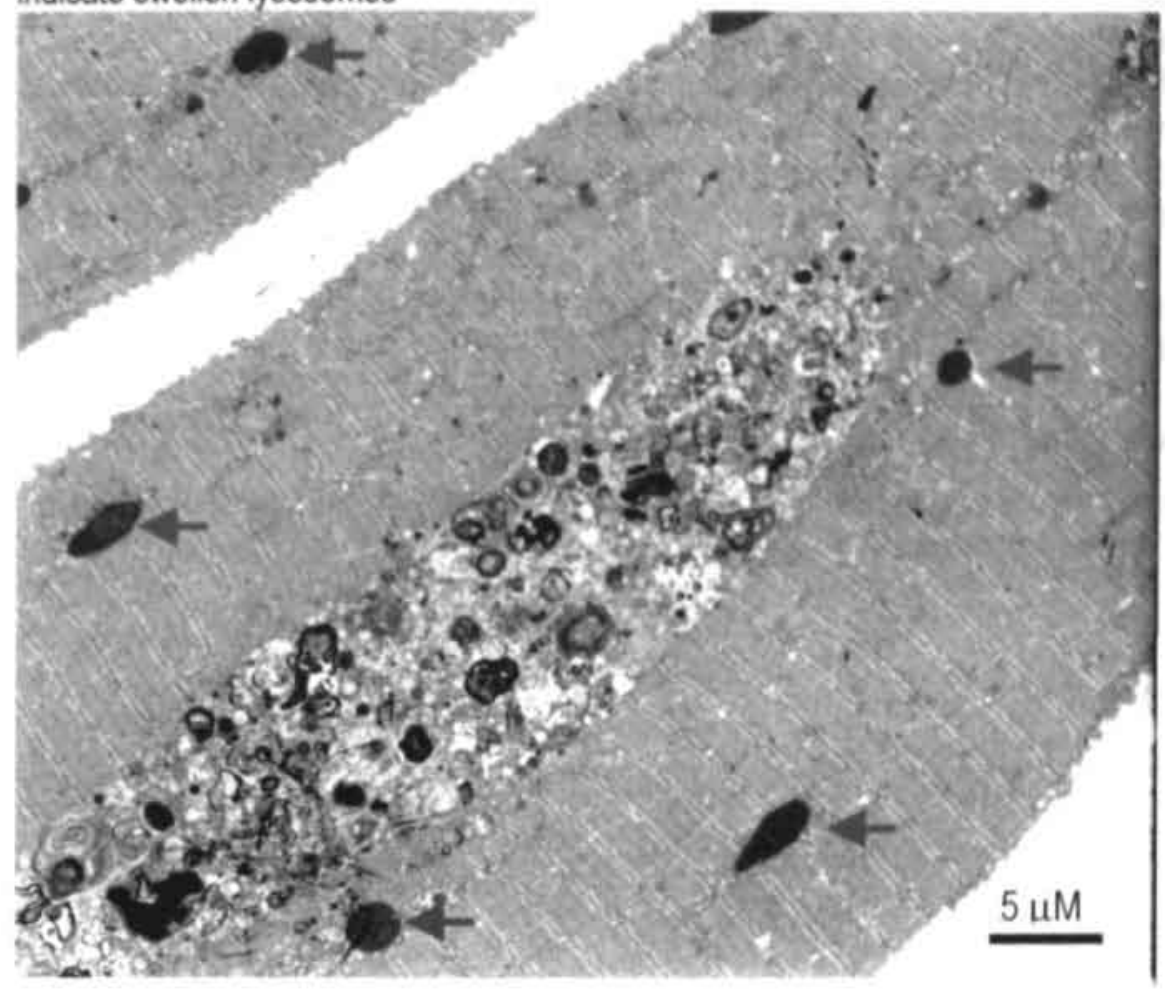

In more progressed stages of GSD II, short cell segments show degeneration over their entire cross section. Apoptotic nuclei are present in these regions and the contractile material is in complete disarray while the basal membrane remains intact. In this situation, force is most likely transmitted to adjacent cells. Though cell-to-cell transmission of forces has been shown to be very effective in healthy muscles [79] it remains to be seen whether this is also the case in muscles of which most fibres are structurally in disarray.

Although all striated muscles are affected, the decline in mechanical function in cardiac and respiratory muscle is most life threatening. In the clinical situation, patients suffering from a complete lack of $1-4 \alpha$-glucosidase activity commonly die before the age of 2 years, because of cardio-respiratory insufficiency. In the past, all therapeutic measures to relieve the severity of the disease failed. Very recently, a breakthrough was reached by treatment of a limited number of very young patients with recombinant human $1-4 \alpha$ - 
glucosidase $[70,71]$. In the 2 youngest of the four children, included in the study at an early stage of their disease, clinical signs of GSD II remained absent and patients showed a normal development after treatment with recombinant human $1-4 \alpha$ glucosidase $[70,71]$.

In summary, a brief overview has been provided on the structure, assembly and biological function of lysosomes. Special attention was paid to one particular kind of lysosomal dysfunction due to a genetic defect, i.e., acid 1-4 $\alpha$-glucosidase deficiency. Lack of this enzyme affects particularly the cardio-respiratory system since mechanical performance of striated muscle is severely depressed. Skeletal muscle wasting, either a result of apoptosis or disuse atrophy, substantially contributes to the loss of force generation. Furthermore, it has been hypothesised that longitudinal force transmission inside the remaining myocytes is hampered by increased lysosomal dimensions, cytoplasmic deposition of non-contractile material and focal regions of contractile protein degradation.

\section{Acknowledgements}

This study was supported by the Prinses Beatrix Fonds and Foundation "De Drie Lichten" in The Netherlands. 


\section{References}

Gieselmann, V. (1995) Biochim Biophys Acta 1270, 103-136.

Kaye, E.M. (2001) J Physiol 3, 249-256.

Walkley, S.U. (1998) Brain Pathol 8, 175-193.

Pompe, J.C. (1932) Ned Tijdsch Geneesk 76, 304-311.

Hers, H.G. (1963) Biochem J 86, 11-16.

Hirschhom, R. (1995) in The Metabolic and Molecular Basis of Inherited Disease (Scriver, C.R., Beaudet, A.L., Sly, W.S. and Valle, D., eds.), pp. 24432464, McGraw-Hill, New York.

Hers, H.G. and DeBarsy, T. (1973) in Lysosomes and storage diseases (Hers, H.G. and Van Hoof, F., eds.), pp. 197-217, Academic Press, New York.

Felice, K.J., Alessi, A.G. and Grunnet, M.L. (1995) Medicine 74, 131-135.

Ausems, M.G., Verbiest, J., Hermans, M.P., Kroos, M.A., Beemer, F.A., Wokke, J.H., Sandkuiil, L.A., Reuser, A.J.J. and Van der Ploeg, A.T. (1999) Eur J Hum Genet 7, 713-716.

De Duve, C., Pressman, B.C., Gianetto, R., Wattiaux, R. and Appelmans, F. (1955) Biochem J 60, 604-617.

Winchester, B.G. (2001) Europ J Paediatr Neurol 5, 11-19.

Bird, J.W. (1975) Front Biol 43, 75-109.

Van Dyke, R.W. (1996) Subcell Biochem 27, 331-360.

4 Achyuthan, K.E. and Achyuthan, A.M. (2001) Comp Biochem Physiol B Biochem Mol Biol 129, 29-64.

5 Saftig, P., Tanaka, Y., Lullmann-Rauch, R. and Von Figura, K. (2001) Trends Mol Med 7, 37-39.

6 Libelius, R., Jirmanova, I., Lundquist, I. and Thesleff, S. (1978) J Neuropathol Exp Neurol 37, 387-400.

Lecker, S.H., Solomon, V., Mitch, W.E. and Goldberg, A.L. (1999) J Nutr 129 , 227S-237S.

Mitch, W.E. and Goldberg, A.L. (1996) N Engl J Med 335, 1897-1905.

Mitch, W.E., Bailey, J.L., Wang, X., Jurkovitz, C., Newby, D. and Price, S.R. (1999) Am J Physiol 276, C1132-C1138.

Taillandier, D., Aurousseau, E., Meynial-Denis, D., Bechet, D., Ferrara, M., Cottin, P., Ducastaing, A., Bigard, X., Guezennec, C.Y., Schmid, H.P. and et al. (1996) Biochem J 316, 65-72.

1 Tawa, N.E., Jr., Odessey, R. and Goldberg, A.L. (1997) J Clin Invest 100, 197 203.

2 Voisin, L., Breuille, D., Combaret, L., Pouyet, C., Taillandier, D., Aurousseau, E., Obled, C. and Attaix, D. (1996) J Clin Invest 97, 1610-1617.

DeMartino, G.N. and Ordway, G.A. (1998) Exerc Sport Sci Rev 26, 219-252.

Elmore, S.P., Qian, T., Grissom, S.F. and Lemasters, J.J. (2001) Faseb J 15. 2286-2287.

5 Klionsky, D.J. and Emr, S.D. (2000) Science 290, 1717-1721. 
26 Moats, R.K., 2nd and Ramirez, V.D. (2000) J Endocrinol 166, 631-647.

27 Tournu, C., Obled, A., Roux, M.P., Deval, C., Ferrara, M. and Bechet, D.M. (1998) Arch Biochem Biophys 360, 15-24.

28 Olsen, I., Adams, G., Watson, G., Chain, B. and Abraham, D. (1993) Biochem Biophys Res Commun 195, 327-335.

29 Qian, F., Chan, S.J., Gong, Q.M., Bajkowski, A.S., Steiner, D.F. and Frankfater, A. (1991) Biomed Biochim Acta 50, 531-540.

30 Eklund, L., Muona, A., Lietard, J. and Pihlajaniemi, T. (2000) Matrix Biol 19, 489-500.

31 Seglen, P.O., Berg, T.O., Blankson, H., Fengsrud, M., Holen, I. and Stromhaug, P.E. (1996) Adv Exp Med Biol 389, 103-111.

32 Blommaart, E.F., Luiken, J.J. and Meijer, A.J. (1997) Contrib Nephrol 121, 101108.

33 Blommaart, E.F., Luiken, J.J. and Meijer, A.J. (1997) Histochem J 29, 365-385.

34 Katunuma, N. (1989) Revis Biol Celular 20, 35-61.

35 Stromhaug, P.E. and Klionsky, D.J. (2001) Traffic 2, 524-531.

36 Inubushi, T., Shikiji, M., Endo, K., Kakegawa, H., Kishino, Y. and Katunuma, N. (1996) Biol Chem 377, 539-542.

37 Von Figura, K. and Hasilik, A. (1986) Annu Rev Biochem 55, 167-193.

38 Kornfeld, S. and Mellman, I. (1989) Annu Rev Cell Biol 5, 483-525.

39 Braulke, T. (1996) Subcell Biochem 27, 15-49.

40 Vittorini, S., Paradiso, C., Donati, A., Cavallini, G., Masini, M., Gori, Z., Pollera, M. and Bergamini, E. (1999) J Gerontol A Biol Sci Med Sci 54, B318-B323.

41 Bird, J.W., Roisen, F.J., Yorke, G., Lee, J.A., McElligott, M.A., Triemer, D.F, and St John, A. (1981) J Histochem Cytochem 29, 431-439.

42 Ebisui, C., Tsujinaka, T., Morimoto, T., Fujita, J., Ogawa, A., Ishidoh, K., Kominami, E., Tanaka, K. and Monden, M. (1995) J Biochem (Tokyo) 117, 1088-1094.

43 Tawa, N.E., Jr. and Goldberg, A.L. (1992) Am J Physiol 263, E317-E325.

44 Tawa, N.E., Jr., Kettelhut, I.C. and Goldberg, A.L. (1992) Am J Physiol 263, E326-E334.

45 Kawai, H., Yoneda, K., Naruo, T., Nishida, Y., Kashiwagi, S., Kunishige, M. and Saito, S. (1995) Muscle Nerve 18, 1009-1015.

46 Gelman, B.B., Davis, M.H., Morris, R.E. and Gruenstein, E. (1981) J Cell Biol 88, 329-337.

47 Kumamoto, T., Ito, T., Horinouchi, H., Ueyama, H., Toyoshima, I. and Tsuda, T. (2000) Muscle Nerve 23, 1686-1693.

48 Tsujinaka, T., Ebisui, C., Fujita, J., Morimoto, T., Ogawa, A., Ishidoh, K., Kominami, E., Yano, M., Shiozaki, H. and Monden, M. (1995) Biochem Biophys Res Commun 208, 353-359. 
Tsujinaka, T., Kishibuchi, M., Yano, M., Morimoto, T., Ebisui, C., Fujita, J., Ogawa, A., Shiozaki, H., Kominami, E. and Monden, M. (1997) J Biochem (Tokyo) 122, 595-600.

50 Svanberg, E., Powell-Braxton, L., Ohisson, C., Zachrisson, H. and Lundholm, K. (1998) Endocrinology 139, 4906-4910.

51 Blok, J., Ginsel, L.A., Mulder-Stapel, A.A., Onderwater, J.J. and Daems, W.T. (1981) Cell Tissue Res 215, 1-12.

52 Bursztajn, S. and Libby, P. (1981) Cell Tissue Res 220, 573-588.

53 Ohkuma, S., Chudzik, J. and Poole, B. (1986) J Cell Biol 102, 959-966.

54 Decker, R.S., Decker, M.L., Thomas, V. and Fuseler, J.W. (1985) J Cell Sci 74, 119-135.

55 Carpenter, S. and Karpati, G. (1986) Hum Pathol 17, 683-703.

56

Luiken, J.J., Aerts, J.M. and Meijer, A.J. (1996) Eur J Biochem 235, 564-573.

Reuser, A.J.J. (2002) GSDII mutation database

Yin, D. (1996) Free Radic Biol Med 21, 871-888.

Busch, G.L., Lang, H.J. and Lang, F. (1996) Pflugers Arch 431, 690-696.

60 Baron, P.L., Meola, G., Scarpini, E., Moggio, M., Santilli, I. and Scarlato, G. (1991) Eur J Basic Appl Histochem 35, 423-432.

61 Lembcke, B., Lamberts, R., Wohler, J. and Creutzfeldt, W. (1991) Res Exp Med 191, 389-404.

62 Porta, E.A. (2002) Ann N Y Acad Sci 959, 57-65.

63 Cuervo, A.M. and Dice, J.F. (1998) Front Biosci 3, D25-D43.

64 Kieseier, B.C., Wisniewski, K.E., Park, E., Schuller-Levis, G., Mehta, P.D. and Goebel, H.H. (1997) Brain Dev 19, 317-322.

65 Suter, M., Reme, C., Grimm, C., Wenzel, A., Jaattela, M., Esser, P., Kociok, N., Leist, M. and Richter, C. (2000) J Bioi Chem 275, 39625-39630.

66 Farina, F., Cappello, F., Todaro, M., Bucchieri, F., Peri, G., Zummo, G. and Stassi, G. (2000) J Histochem Cytochem 48, 57-62.

67 Nakae, Y., Stoward, P.J., Shono, M. and Matsuzaki, T. (2001) Histochem Cell Biol 115, 205-214.

68 Yin, D., Yuan, X. and Brunk, U.T. (1995) Mech Ageing Dev 81, 37-50.

69 Hesselink, R.P., Gorselink, M., Schaart, G., Wagenmakers, A.J.M., Kamphoven, J., Reuser, A.J.J., Van der Vusse, G.J. and Drost, M.R. (2002) Muscle Nerve 25, 873-883.

70 Van den Hout, J.M., Reuser, A.J.J., Vulto, A.G., Loonen, M.C., CrommeDijkhuis, A. and Van der Ploeg. A.T. (2000) Lancet 356, 397-398

71 Van den Hout, J.M., Reuser, A.J.J., de Klerk, J.B., Arts, W.F., Smeitink, J.A. and Van der Ploeg, A.T. (2001) J Inherit Metab Dis 24, 266-274.

72 Bijvoet, A.G.A. (1999) Department of Clinical Genetics,Thesis, Erasmus Universiteit, Rotterdam.

73 Goldring, K., Partridge, T. and Watt, D. (2002) J Pathol 197, 457-467.

74 Partridge, T.A. (2002) Gene Ther 9, 752-753. 
75 Luz, M.A., Marques, M.J. and Santo Neto, H. (2002) Braz J Med Biol Res 35, 691-695.

76 Gielen, A.W., Oomens, C.W., Bovendeerd, P.H., Arts, T. and Janssen, J.D. (2000) Comput Methods Biomech Biomed Engin 3, 231-244.

77 Griffin, J.L. (1984) Virchows Arch B Cell Pathol Incl Mol Pathol 45, 51-61.

78 Cardiff, R.D. (1966) Pediatrics 37, 249-259.

79 Monti, R.J., Roy, R.R., Hodgson, J.A. and Edgerton, V.R. (1999) J Biomech 32 , 371-380.

80 Michalski, J-C., Klein, A. (1999) Biochim Biophys Acta 1455, 69-84 
Chapter 3

\section{Impaired performance of skeletal muscle in acid $\alpha$-glucosidase knockout mice}

Reinout P. Hesselink, Marchel Gorselink, Gert Schaart, Anton J.M. Wagenmakers, Joep Kamphoven, Arnold J.J. Reuser, Ger J. van der Vusse, Maarten R. Drost

Published in:

Muscle \& Nerve, $2002 ; 25 ; 873-883$ 


\section{Abstract}

Glycogen storage disease type II (GSD II) is an inherited progressive muscular disease in which lack of functional acid $\alpha$-glucosidase (AGLU) results in lysosomal accumulation of glycogen. We report on the impact of a null mutation of the acid 1-4 $\alpha$-glucosidase gene (AGLU) in mice on the force production capabilities, contractile mass, oxidative capacity, energy status, morphology, and desmin content of skeletal muscle. Muscle function was assessed in halothane anaesthetised animals, using a recently designed murine isometric dynamometer. Maximal torque production during single tetanic contraction was $50 \%$ lower in the knockout mice than in wild type. Loss of developed torque was found to be disproportionate to the $20 \%$ loss in muscle mass. During a series of supramaximal contractions, fatigue, expressed as percentile decline of developed torque, did not differ between AGLU* mice and age-matched controls. Muscle oxidative capacity, energy status, and protein content (normalised to either dry or wet weight) were not changed in knockout mice compared to control. Alterations in muscle cell morphology were clearly visible. Desmin content was increased, whereas $\alpha$-actinin was not. As the decline in muscle mass is insufficient to explain the degree in decline of mechanical performance, we hypothesise that the large clusters of non-contractile material present in the cytoplasm hamper longitudinal force transmission, and hence muscle contractile function. The increase in muscular desmin content is most likely reflecting adaptations to altered intracelluiar force transmission. 


\section{Introduction}

Glycogen storage disease type II (GSD II, acid maltase deficiency or Pompe disease) is caused by mutations of the acid $\alpha$-glucosidase gene $[1,2]$. The lack of functional enzyme results in accumulation of glycogen in the lysosomal compartment [3]. Both early- and late-onset forms of GSD II have been reported. In the early, infantile form of this disease, both heart and skeletal muscles are affected. Patients die before the age of 2 years because of cardio-respiratory failure [3]. The milder, late-onset forms of GSD ॥ are characterised by impaired skeletal muscle performance without overt signs of cardiac malfunctioning [4]. The incidence of the disease has been estimated as 1 in 40,000 , but exact numbers are not known as patients are frequently misdiagnosed as having muscular dystrophy [5-7]. Although both forms of GSD II lead to progressive muscle wasting and weakness, until now the decline in muscular force has not been quantified.

To allow detailed studies of the functional consequences of the enzymatic defect, an acid $\alpha$-glucosidase knockout mouse model (AGLU) was generated by Bijvoet and coworkers [8]. A recently developed and custom-built device allows us to evaluate in detail in situ muscle function in mice, accurately measuring produced torque and temporal parameters during isometric contractions of ankle plantar and dorsal flexors [9].

In the past, at least three causes for impaired muscle performance have been considered [10]: (1) decline in contractile mass, i.e., muscle mass and contractile protein content; (2) decrease in oxidative capacity resulting in insufficient amounts of ATP available for muscle contraction; and (3) impaired innervation of the muscle resulting in submaximal activation. In all reports of patients suffering from GSD II, muscle protein wasting is supposed to occur, but detailed information on alterations in lean body mass or muscle protein content is lacking. In a number of cases, muscular dystrophies have been associated with a decreased oxidative capacity [10-15], but for GSD ॥ this information is not available. Despite glycogen storage in nervous tissue, electromyography (EMG) findings in patients with GSD $\|$ are inconclusive $[16,17]$. Therefore, changes in electro-physiological properties of either muscle or nerves, probably play only a minor role in the impaired muscle performance.

A fourth mechanism for muscle dysfunction may be specific to GSD II. Pioneering studies of Cardiff [18] and Griffin [19] have shown that, in the cytoplasm of muscle fibres of GSD II patients, numerous non-contractile inclusions, including glycogen-filled lysosomes, are present. These inclusions could compromise muscle function of GSD II patients. As the inclusions interrupt and displace myofibrils, they most likely hamper longitudinal force transmission. As a consequence, force should be transferred around the inclusions to adjacent myofibrils. In response to this situation, the expression of cytoskeletal proteins involved in transverse force transmission (e.g., desmin) [20] may be altered. The observation that the concentration of desmin is increased in the vicinity of the intracellular inclusions in muscle fibres of GSD II patients [21] supports this hypothesis. So far, this phenomenon has not been related to possible alterations in muscle function. 
The main goal of this study was to quantify alterations in muscle force production in mice with a disrupted acid $\alpha$-glucosidase gene. Measurements were performed on mice showing overt clinical symptoms of muscle weakness, such as a splayed posture of the hind limbs and impaired gait [22]. Furthermore, we explored a number of potential causes of impaired force production. To this end, changes in force production were related to changes in contractile mass. Moreover, the activity of a variety of enzymes that play a key role in energy conversion and levels of high-energy phosphates were assessed. Finally, micro-morphological changes in muscle cells were determined to explore whether myofibrilar inclusions or disruptions of myofibrilar structure play a role in the impaired force production. Special attention was paid to the amount of desmin protein in the affected muscles, as this protein is involved in transverse force transmission.

\section{Materials and methods}

\section{Mouse characteristics}

Measurements were performed on 8 mice, $4 \alpha$-glucosidase knockout mice (AGLU) completely lacking acid $\alpha$-glucosidase activity in all tissues [8]. The AGLU\% mice included in this study were kindly provided by Dr. Reuser and were generated as described by Bijvoet and colleagues [8]. Four unaffected littermates (both wild type and heterozygous) served as control. All animals were 2 times backcrossed on their original strain. Littermates of two different offspring, i.e., three FVB mice 17 months of age (2 control and $1 \mathrm{AGLU}^{-}$) and five $\mathrm{C} 57 \mathrm{BI}$ mice 18 months of age (2 control and $3 \mathrm{AGLU}^{-*}$ ) were included in the study. All experimental procedures were approved by the Institutional Animal Care and Use Committee of Maastricht University and complied with the principles of proper laboratory animal care.

\section{Preparation procedures}

The routine followed for the contraction protocol was comparable for dorsal and plantar flexors. After weighing, mice were anaesthetised with 1.5 to $2.0 \%$ halothane (Fluothane, Zeneca, Ridderkerk, The Netherlands) which was mixed with $\mathrm{O}_{2}$ and $\mathrm{N}_{2} \mathrm{O}(2: 1,3.0 \mathrm{~L} \cdot \mathrm{min}$ 1), and delivered via a facemask through a flow-meter system (Medec, Montvalle, N.J.). The mouse was attached via the hip to a thermostatic platform. The foot was cast in dental cement and rigidly connected to the specifically designed murine torque transducer [9]. After shaving the skin locally, a small incision was made in either the lateral part or the hollow of the knee to expose the peroneal nerve for stimulation of the dorsal flexor complex (tibialis anterior and extensor digitorum longus muscles) or the tibial nerve for stimulation of the plantar flexor complex (gastrocnemius, plantaris and soleus muscles). A bipolar hook electrode, with an inter-pole distance of $0.8 \mathrm{~mm}$, was carefully placed around the nerve. The muscle complex was stimulated via a pulse 
generator (HSE 215/1Z, Freiburg, Germany). To prevent electrode displacement due to contraction, the electrode was attached to the skin by cyano-acrylate glue. The torque around the ankle was measured with a sample frequency of $1000 \mathrm{~Hz}$.

\section{Stimulation protocol}

In general, the procedure during the stimulation protocol was similar to that described in detail by Gorselink and co-workers [9]. To achieve maximal muscle performance, supramaximal current was determined in steps of $0.1 \mathrm{~mA}$ and subsequently ankle angle was optimised for torque in steps of $5^{\circ}$ using 7 twitches interspersed by 60 -s rest. All experiments were performed at optimal ankle angle, supramaximal current, and a stimulation frequency of $125 \mathrm{~Hz}$ (dorsal flexors) or $100 \mathrm{~Hz}$ (plantar flexors).

First, a single tetanic contraction was performed. After 3-min rest, a strenuous contraction protocol was performed involving 2 series of 12 isometric tetanic contractions separated by 60 -s recovery. Each contraction consisted of a 170-ms electrical stimulation followed by $95-\mathrm{ms}$ rest (tour duty cycle 0.64 ). Total time span of a stimulation series was 3-s. In the experimental procedure dorsal flexors were stimulated first.

\section{Sampling and processing of the tissue}

After the stimulation protocol, muscles were dissected in the following order. First the dorsal, then the plantar flexor complex of the exercised leg was dissected, followed by the contra-lateral dorsal and plantar flexor complex. Thereafter, quadriceps femoris muscles of the stimulated leg were harvested. Muscles were dissected from the bone or the visible start of the tendon. The contra-lateral dorsal and plantar flexor complexes were weighed and frozen in liquid nitrogen within 10-s of dissection for biochemical analysis. An approximately $1 \mathrm{~mm}^{3}$ tissue sample was taken from the mid-belly region of the stimulated gastrocnemius medialis and the tibialis anterior muscle, treated with a $2.5 \%$ glutaraldehyde fixative in phosphate buffer, and processed by standard procedures for morphological analysis by electron microscopy. The remaining mid-belly portions were frozen in melting isopentane for light microscopic analysis. Mice were subsequently sacrificed by cervical dislocation. Samples were stored at $-80^{\circ} \mathrm{C}$ until analysis.

Contralateral plantar and dorsal flexor complexes were used for biochemical analysis. Prior to analysis, samples were freeze-dried at $-30^{\circ} \mathrm{C}$ for $24-\mathrm{h}$. Freeze-dried muscle tissue was split lengthways. Half of the tissue was used for assessment of glycogen as described by Passonneau and Lauderdale [23]. The other half was used for analysis of high-energy phosphates and related substances by a high-pressure liquid chromatography (HPLC) method according to Van der Vusse and colleagues [24].

The alkali soluble protein fraction was assessed in the quadriceps femoris muscle of the stimulated leg. Approximately $20 \mathrm{mg}$ wet weight of muscle tissue was incubated in $1 \mathrm{ml}$ $1 \mathrm{~N} \mathrm{NaOH}$ at $37^{\circ} \mathrm{C}$ for $3 \mathrm{~h}$, neutralised in $1 \mathrm{~N} \mathrm{HCl}$, and centrifuged at $800 \mathrm{~g}$ for $5 \mathrm{~min}$. Protein content of the supernatant was measured using the Pierce BCA protein assay (Pierce, Rockford, IL) and expressed as $\mathrm{mg} \cdot \mathrm{g}^{-1}$ wet weight of tissue. 
Remaining quadriceps femoris muscle was homogenised in ice-cold sucrose-EDTA-tris (SET) buffer ( $\mathrm{pH} 7.4$ ) using an ultraturrax and then centrifuged at $1000 \mathrm{~g}$ for $5 \mathrm{~min}$. The activity of citrate synthase (CS), $\beta$-hydroxy acylCoA dehydrogenase (HAD), phosphofructokinase (PFK), and creatine kinase (CK) was measured in the supernatant using methods described by Bergmeyer [25] and modified for automated analysis with the use of a COBAS FARA (Roche, Basel, Switzerland).

Desmin protein content was assessed in stimulated muscles. Proteins were separated in a $10 \%$ sodium dodecylsulphate-polyacrylamide gel electrophoresis (SDS-PAGE) gel by standard methods according to Laemmli [26], and transferred to nitrocellulose paper using Western blotting [27]. Equal amounts of protein were loaded onto the gel as was confirmed by digital image processing and analysis after staining of the gels with coomassie brilliant blue. Desmin and $\alpha$-actinin were then identified using chemiluminescence immunodetection [28] after incubation with the mouse monoclonal desmin antibody DER-11 [29] (Dako, Glostrup, Denmark) and the rabbit polyclonal antiserum $\alpha$-653 directed against $\alpha$-actinin [30]. Muscle desmin and $\alpha$-actinin content of AGLU mice were determined relative to control mice by digital image processing and analysis.

To assess muscle morphology and localisation of glycogen, 5- $\mu \mathrm{m}$ thick longitudinal and transverse muscle tissue sections were stained with periodic acid Schiff (PAS) after formalin/ ethanol fixation (9:1). Sirius red and ATPase staining also were performed by standard procedures.

\section{Data analysis and statistics}

Data are represented as mean \pm standard deviation. From filtered data (11 points moving average) of both single and repeated stimulation, maximal torque was determined. Temporal parameters such as rise time (10-50\% of maximal torque) and half-relaxation time ( 50 to $25 \%$ of maximal torque) were calculated from unfiltered data using the Matlab 5.3 software package (The Math Works Inc., Natick, MA). Fatigue was defined as the decline in maximal torque from the first to the twelfth contraction within a series, expressed as percentage of the first contraction of the first series.

For statistical analysis of the contraction parameters, a paired (comparison of the first and second stimulation series) and unpaired (comparison between the two groups) one way Mann-Whitney-U test was used. Percentile changes in torque and half-relaxation time both within and between contraction series were analysed using a signed rank test. An unpaired one-way Mann-Whitney-U test was used to statistically analyse the biochemical data. The level of significance was set at $P<0.05$. Statistical analysis was performed using the SPSS 8.0 software package (SPSS Inc., Chicago, IL). 


\section{Results}

\section{Body and muscle mass}

Both plantar and dorsal flexor muscle mass was approximately $20 \%$ lower in AGLU mice than in control (Table 3.1). In contrast, body mass was not significantly different between groups, and showed a large within-group variability. As some animals in both groups showed clear signs of obesity, the large variability in animal mass was most likely caused by differences in body composition rather than body dimensions.

Table 3.1: Body mass and muscle mass of control and AGLU mice.

\begin{tabular}{l|c|c}
\hline & Control $(n=4)$ & AGLU $(n=4)$ \\
\hline Body mass (g) & $38.5 \pm 9.3$ & $34.1 \pm 6.7$ \\
\hline Plantar flexor muscle mass (mg) & $145 \pm 20$ & $109 \pm 3^{\circ}$ \\
\hline Dorsal flexor muscle mass (mg) & $68.8 \pm 6.5$ & $56.3 \pm 6.9^{\circ}$ \\
\hline
\end{tabular}

Mean $\pm S D,{ }^{*}=p<0.05$, control vs. AGLU

\section{Muscle contractile performance}

Representative tracings of the single tetanic contraction of plantar (left panel) and dorsal (right panel) flexor muscle of both AGLU and control mice are shown in Figure 3.1.

Figure 3.1: Representative example of maximal torque development during a single tetanic contraction of plantar (left panel) and dorsal (right panel) flexors of control and AGLU. Thick horizontal bar on $x$-axis indicates the time interval of electrical stimulation.

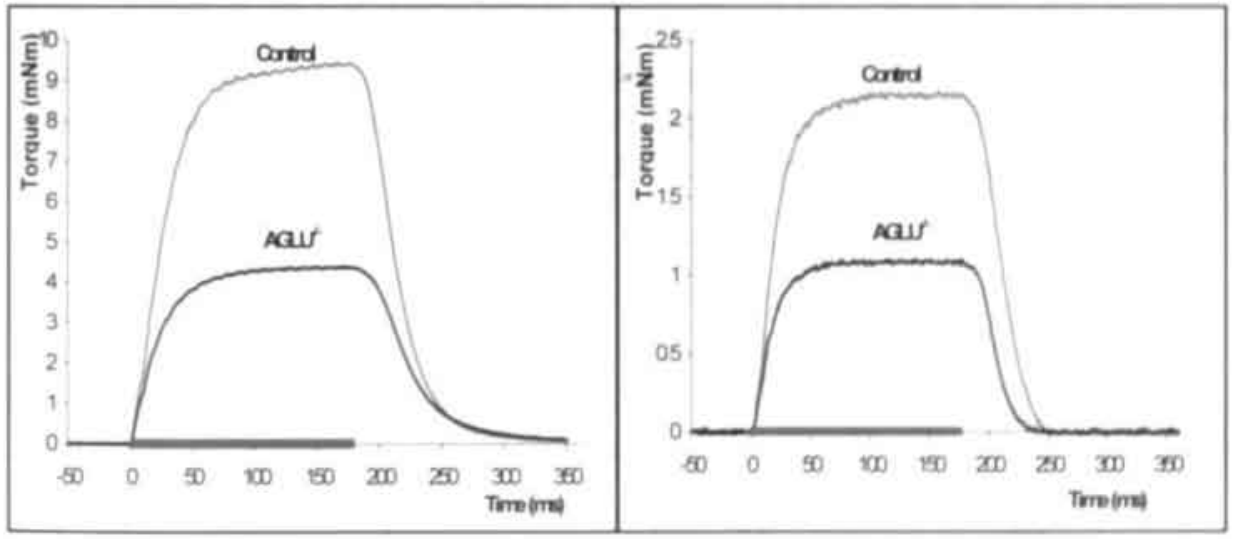

Absolute maximal plantar and dorsal flexor torque during a single tetanic contraction was $53 \%$ and $49 \%$ lower in AGLU mice than control, respectively (Table 3.2). When normalised to muscle mass, the decline in maximal torque of plantar and dorsal flexors of AGLU mice amounted to $39 \%$ and $36 \%$, respectively. Plantar flexors of AGLU mice 
showed shorter rise times and longer relaxation times than control. In dorsal flexors, these temporal parameters did not differ.

Table 3.2: Contractile parameters of a single tetanic isometric contraction of the plantar and dorsal flexor muscles of control and AGLU* mice.

\begin{tabular}{l|c|c|c|c}
\hline & \multicolumn{2}{|c|}{ Plantar flexion } & \multicolumn{2}{c}{ Dorsal flexion } \\
\cline { 2 - 5 } & Control $(n=4)$ & AGLU $*(n=4)$ & Control $(n=4)$ & AGLU $(n=4)$ \\
\hline Maximal torque $(\mathrm{mN} \cdot \mathrm{m})$ & $10.6 \pm 1.1$ & $5.0 \pm 1.4^{*}$ & $2.1 \pm 0.8$ & $1.1 \pm 0.2^{*}$ \\
\hline $\begin{array}{l}\text { Normalised maximal } \\
\text { torque }(\mathrm{mN} \cdot \mathrm{m} / \mathrm{g} \text { ww) }\end{array}$ & $74.4 \pm 16.7$ & $45.4 \pm 12.3^{*}$ & $29.6 \pm 9.0$ & $18.8 \pm 3.1^{*}$ \\
\hline Rise time $(\mathrm{ms})$ & $21.4 \pm 5.0$ & $14.3 \pm 2.5^{*}$ & $11.8 \pm 1.9$ & $9.6 \pm 2.4$ \\
\hline Relaxation time $(\mathrm{ms})$ & $11.6 \pm 3.6$ & $17.0 \pm 3.2^{*}$ & $10.3 \pm 1.2$ & $8.9 \pm 0.9$ \\
\hline
\end{tabular}

Mean $\pm \mathrm{SD},{ }^{*}=p<0.05$, control vs. AGLU

uw refers to wet weight of muscle complex

A significant decline in maximal torque was found during the series of 12 contractions, indicating that the muscles became fatigued when forced to contract repeatedly (see Figure 3.2 for typical example). No differences in fatigue between either control and AGLU mice or plantar and dorsal muscles were observed (Table 3.3). The $60 \mathrm{~s}$ resting period was sufficient to allow the muscles to recover to at least $90 \%$ of initial torque in each animal (see Figure 3.2 for a typical example). Within a series, the pattern of torque produced during a single stimulation period changed. In the first contraction of a series, maximal torque was reached at the end of the $170 \mathrm{~ms}$ stimulation period, whereas in the last contraction of the series the maximum was reached earlier and torque had already declined already during the electrical stimulation (Figure 3.2). This phenomenon was observed in both groups of mice. Changes in temporal parameters developed gradually between contraction 1 and contraction 12 (data not shown). 
Table 3.3: Maximal torque and temporal parameters measured at the 12th contraction, expressed as percentage of the first contraction of each contraction series in plantar and dorsal flexors of control and AGLU* mice.

\begin{tabular}{l|c|c|c|c}
\hline & \multicolumn{2}{|c|}{ Series 1 } & \multicolumn{2}{c}{ Series 2 } \\
\cline { 2 - 5 } & Control $(n=4)$ & AGL $(n=4)$ & Control $(n=4)$ & AGLU $(n=4)$ \\
\hline Plantar flexor torque & $-21 \pm 6^{\circ}$ & $-22 \pm 6^{\circ}$ & $-27 \pm 5^{\circ}$ & $-18 \pm 9^{\circ}$ \\
\hline Dorsal flexor torque & $-19 \pm 5^{\circ}$ & $-23 \pm 3^{\circ}$ & $-23 \pm 5^{\circ}$ & $-16 \pm 10^{\circ}$ \\
\hline $\begin{array}{l}\text { Plantar flexor } \\
\text { relaxation time }\end{array}$ & $+82 \pm 39^{\circ}$ & $+50 \pm 5^{\circ}$ & $+69 \pm 31^{\circ}$ & $+59 \pm 12^{\circ}$ \\
\hline $\begin{array}{l}\text { Dorsal flexor } \\
\text { relaxation time }\end{array}$ & $+24 \pm 20^{\circ}$ & $+25 \pm 8^{\circ}$ & $+31 \pm 18^{\circ}$ & $+24 \pm 4^{\circ}$ \\
\hline
\end{tabular}

Mean $\pm \mathrm{SD},{ }^{*}=p<0.05$, contraction 1 vs. contraction 12 of the same series, - and + refer to decrease and increase respectively. None of the differences between control and AGLU mice reached the level of significance $(p>0.05)$

Differences between the first and the last (12th) contraction of a series are presented in Table 3.3. Relaxation times significantly increased between the first and the twelfth contraction of both series of either muscle group in control as well as AGLU+ mice. In a number of cases, relaxation times of intermediate contractions were increased to such extent that rise times could not be calculated. Therefore changes in rise time are not presented

Figure 3.2: Typical example of the pattern of torque production in plantar (A) and dorsal (B) flexors of control and plantar (C) and dorsal (D) flexors of AGLU mice, expressed as percentage of the first contraction of contraction series 1 . Break in $x$-axis represents $60 \mathrm{~s}$ resting period.

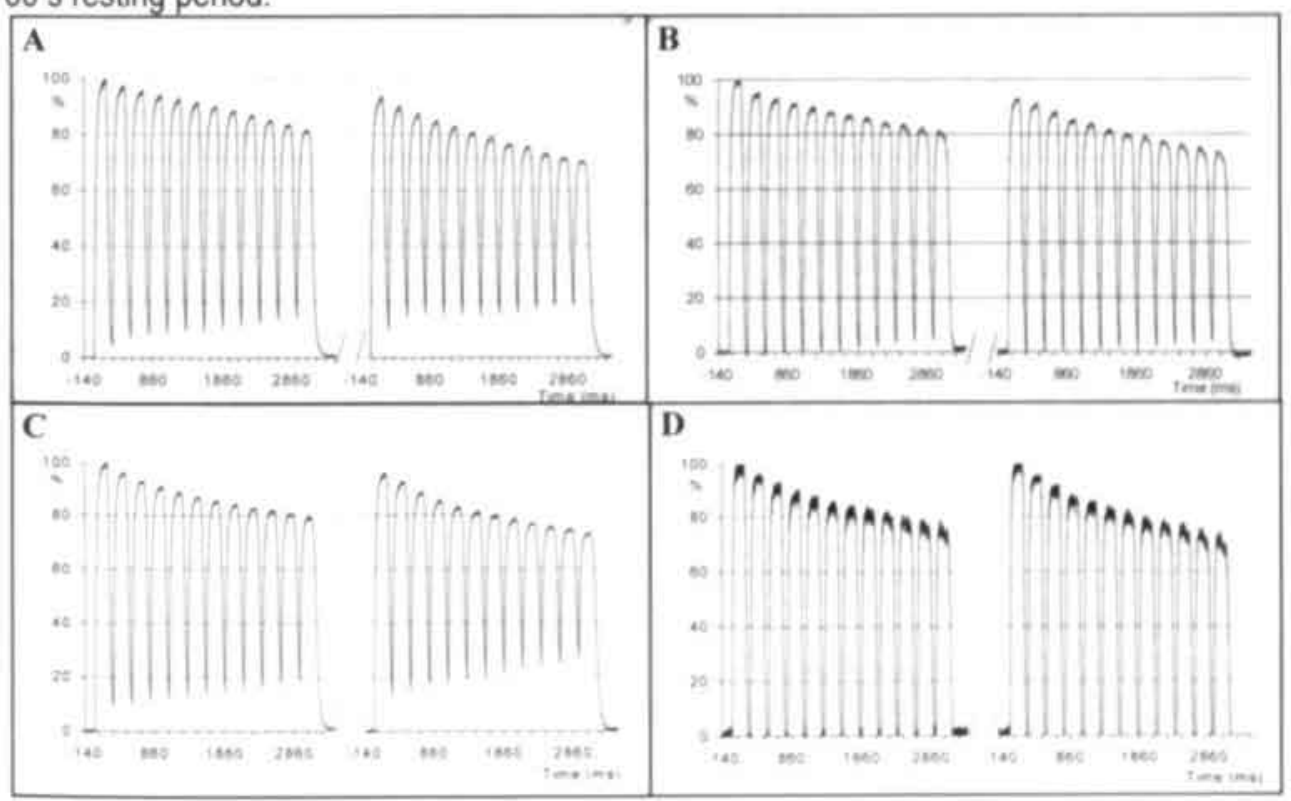




\section{Biochemical parameters}

Glycogen content was significantly increased in AGLU* mice compared to control in both plantar ( $271 \pm 65 \mathrm{vs} .53 \pm 20 \mu \mathrm{mol} \cdot \mathrm{g}^{-1} \mathrm{dw}$ ) and dorsal flexors ( $300 \pm 48 \mathrm{vs} .51 \pm 22$ $\mu \mathrm{mol} \cdot \mathrm{g}^{-1} \mathrm{dw}$ ). The muscular content of alkali soluble protein (all protein minus collagen) was not different between the control group and AGLU* mice (154 \pm 19 vs. $149 \pm 8$ $\mathrm{mg} \cdot \mathrm{g}^{-1} \mathrm{ww}$ ).

When normalised to muscle dry weight, the content of high energy phosphates and related substances showed no significant differences between AGLU - mice and the control group (Table 3.4).

The sum of the adenine nucleotides content (TAN) was similar in both muscle groups of control and AGLU mice. Inosine 5' monophosphate (IMP) contents were low. The total creatine content did not differ between control and AGLU $*$ mice.

Table 3.4: Content of high-energy phosphates and related substances $\left(\mu \mathrm{mol} \cdot \mathrm{g}^{-1} \mathrm{dry}\right.$ weight) in plantar and dorsal flexors of control and AGLU mice.

\begin{tabular}{l|c|c|c|c}
\hline & \multicolumn{2}{|c|}{ Plantar flexors } & \multicolumn{2}{c}{ Dorsal flexors } \\
\hline Substance & Control $(n=4)$ & AGLU $(n=4)$ & Control $(n=4)$ & AGLU $(n=4)$ \\
\hline ATP & $22.3 \pm 4.5$ & $27.5 \pm 8.7$ & $24.8 \pm 3.1$ & $22.2 \pm 7.2$ \\
\hline ADP & $5.2 \pm 0.9$ & $4.0 \pm 0.6$ & $5.4 \pm 1.2$ & $6.1 \pm 1.3$ \\
\hline AMP & $0.2 \pm 0.1$ & $0.4 \pm 0.2$ & $0.4 \pm 0.2$ & $0.9 \pm 0.5$ \\
\hline TAN & $27.7 \pm 5.2$ & $31.9 \pm 9.0$ & $30.5 \pm 1.2$ & $29.2 \pm 6.8$ \\
\hline IMP & $0.1 \pm 0.1$ & $0.2 \pm 0.1$ & $0.1 \pm 0.01$ & $0.1 \pm 0.1$ \\
\hline Cr & $58.3 \pm 11.7$ & $48.9 \pm 8.8$ & $49.2 \pm 9.7$ & $36.5 \pm 13.5$ \\
\hline PCr & $51.1 \pm 8.4$ & $58.3 \pm 8.5$ & $67.2 \pm 5.2$ & $76.4 \pm 10.6$ \\
\hline PCr+Cr & $109.4 \pm 19.7$ & $107.2 \pm 13.9$ & $116.4 \pm 6.1$ & $113.0 \pm 16.5$ \\
\hline NAD & $2.6 \pm 0.4$ & $2.5 \pm 1.0$ & $2.6 \pm 0.4$ & $2.4 \pm 0.7$ \\
\hline
\end{tabular}

Mean \pm SD.

$\mathrm{PCr}$ and $\mathrm{Cr}$ refer to phosphocreatine and creatine respectively, TAN is sum of ATP, ADP and AMP, IMP is inosine monophosphate.

None of the enzymatic activities measured were different between AGLU and control mice except for creatine kinase, which showed a 2-fold decline in AGLU mice (Table 3.5). 
Table 3.5: Activity of the enzymes creatine kinase, citrate synthase, phosphofructokinase and $\beta$-hydroxy acylCoA dehydrogenase in the quadriceps femoris muscle of control and AGLU+ mice, expressed in $\mu \mathrm{mol} \cdot \mathrm{g}^{-1}$ wet weight-min ${ }^{-1}$.

\begin{tabular}{l|c|c}
\hline Enzyme & Control ( $n=4)$ & AGLU $^{*}(n=4)$ \\
\hline creatine kinase & $881 \pm 171$ & $480 \pm 44^{\circ}$ \\
\hline citrate synthase & $32 \pm 11$ & $28 \pm 15$ \\
\hline phosphofructokinase & $124 \pm 42$ & $144 \pm 39$ \\
\hline$\beta$-hydroxy acylCOA dehydrogenase & $19 \pm 7$ & $27 \pm 12$ \\
\hline
\end{tabular}

Mean $\pm S D,{ }^{*}=p<0.05$, control vs. AGLU

Morphological and ultrastructural features

After PAS staining, gastrocnemius muscle of control mice showed a normal appearance (Figure $3.3 \mathrm{~A}$ and $\mathrm{C}$ ), whereas in AGLU mice glycogen accumulation was prominent (Figure $3.3 \mathrm{~B}$ and D). A very few muscle fibres (less than $5 \%$ ) of AGLU mice resembled the normal morphology of control mice. Accumulated material was observed both as large longitudinal arrays and as scattered small spots. Hematoxilin-positive material, most likely nuclei, was observed within the longitudinal arrays (Figure $3.3 \mathrm{~B}$ ). These accumulations were mainly located in the central region of the muscle fibres (Figure 3.3 D). Fibre type distribution was not different between AGLU and control animals, and no differences in pathological features were observed between fibre types as identified by ATPase staining (data not shown). Also Sirius red staining (data not shown) did not show differences in amount or localisation of connective tissue between AGLU and control animals.

\section{For figure 3.3 see page 144}

Ultrastructural analysis (electron microscopy) revealed a disturbed cell structure in the vast majority of muscle fibres of AGLU mice. Affected fibres showed an abundance of glycogen-filled vesicles, which were most likely lysosomes. Moreover, clustering of noncontractile material, i.e., vesicles in various sizes and shapes, myelin figures and nuclei, was often observed in the large longitudinal arrays in the centre of those fibres. Figure 3.4B represents an electron micrograph of an affected fibre. In this picture, approximately $30 \%$ of the myofibrils was interrupted by at least one cluster of noncontractile material over its length of approximately $60 \mu \mathrm{m}$. 
Chapter 3

Muscle performance in aged $\alpha$-glucosidase knockout mice

Figure 3.4: Electronmicrograph of a fibre from the mid-belly region of the tibialis anterior muscle of a control (panel A) and an AGLU mouse (panel B). In panel B, some myofibrils in the centre of the muscle cell are displaced around glycogen-filled vesicles, others are interrupted.

GV, glycogen-filled vesicle; MF, myelin figures; DM, examples of displaced myofibrils; *, last Z- disk of an interrupted myofibril.
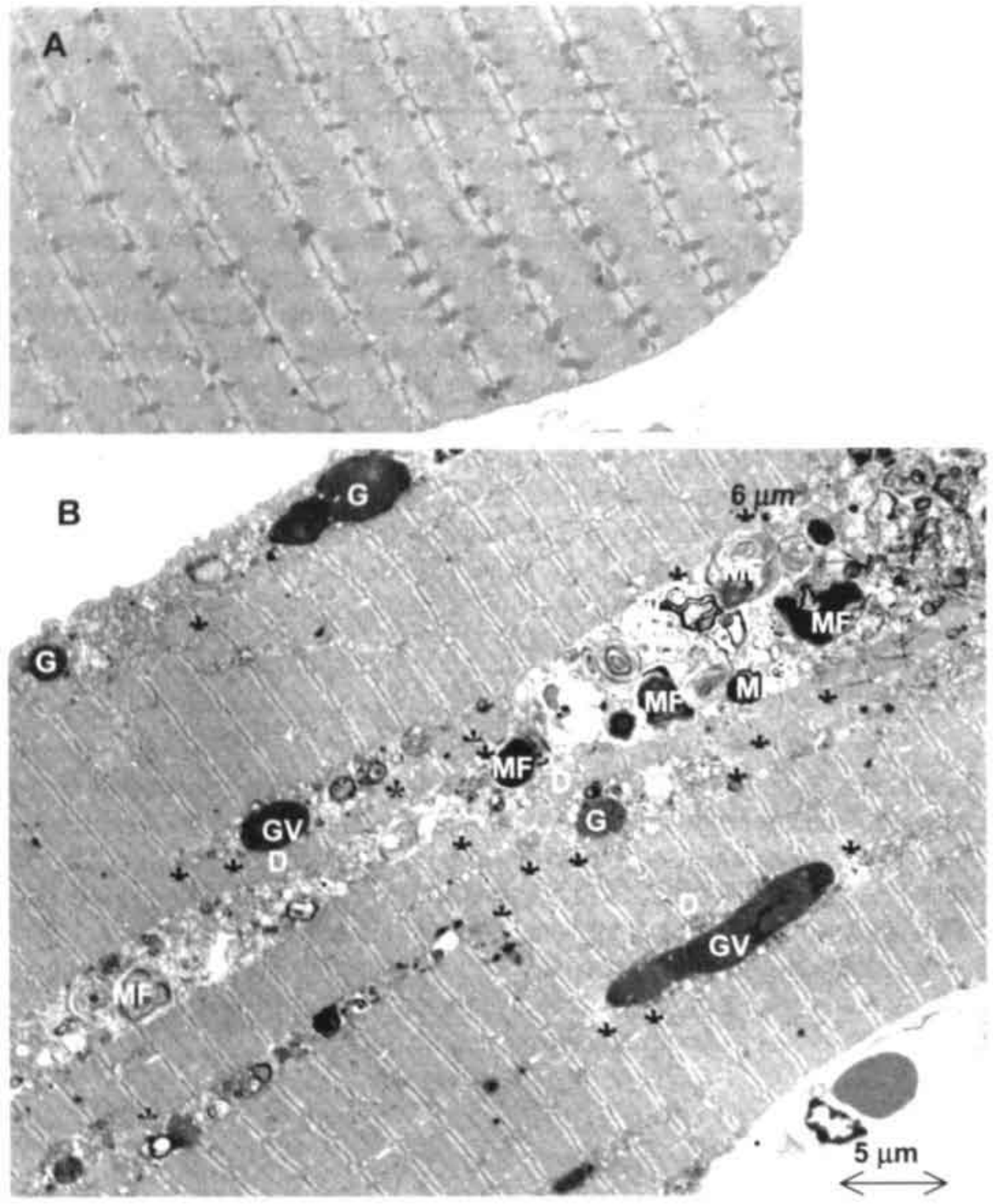
Western blot analysis of the contents of the cytoskeletal proteins desmin and $\alpha$-actinin revealed selective changes in cytoskeleton composition in plantar and dorsal flexors of AGLU- mice compared to control. The desmin content was increased by a factor of 4 in the AGLU+ mice whereas the content of $\alpha$-actinin did not differ from controls (Figure 3.5).

Figure 3.5: Immuno-blotting of $\alpha$-actinin (top panels) and desmin (lower panels) in plantar (left panels) and dorsal (right panels) flexors of four control and four AGLU mice.

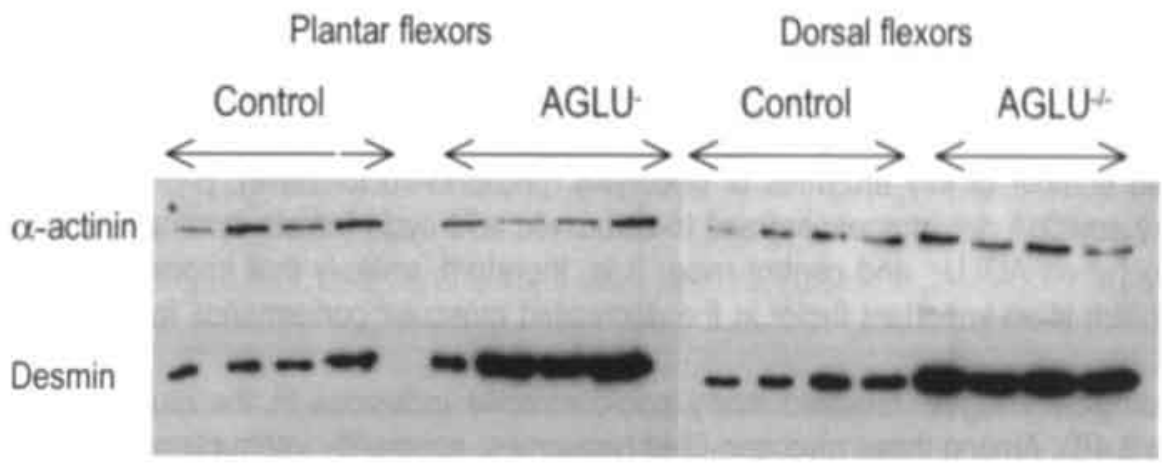

\section{Discussion}

In this study, we quantified the loss of muscle force generating capacity in mice lacking acid $\alpha$-glucosidase, and explored the potential contribution to the decline in contractile performance of a decrease in contractile mass, a decrease in muscular metabolic capacity, and micro-morphological changes of the myofibrillar structure in the affected muscle cells.

The absolute maximal torque was on the average 2 -fold reduced in both plantar and dorsal flexors of AGLU mice. The reduction in maximal torque was associated with a 1.3-fold decrease in muscle mass. Thus, torque production per unit muscle mass was decreased 1.6-fold in AGLU mice. This might be caused by a relative increase in noncontractile material within the muscle. However, the 5 -fold increased glycogen content in the muscle of AGLU mice contributes only $2 \%$ to the total muscle wet weight (including glycogen-associated water). This change in glycogen mass is therefore inconsequential for the value of maximal torque normalised to total muscle mass. As the normalised muscular alkali soluble protein content, mainly consisting of contractile proteins, showed no differences, it is less likely that muscular collagen content is increased. This notion is supported by Sirius red staining (data not shown), which did not show overt differences 
in collagen content and spatial distribution between AGLU and control mice. Therefore, atrophy or selective breakdown of contractile proteins are most likely not the cause of the decreased torque production per unit muscle mass.

As the resting muscle content of high-energy phosphates was comparable in both control and AGLU animals, potential differences in ATP availability at the onset of mechanical activity cannot be the cause of the observed decrease in mechanical performance during a single contraction. It is of interest to note that AGLU muscles and control responded similarly to a short duration ( $3 \mathrm{~s}$ ) fatigue contraction protocol. In both cases, the decline in torque was found to be in the order of $18-27 \%$ (Table 3.3). This observation strongly suggests that mechanisms involved in muscle fatigue during highintensity contractions of relatively short duration did not differ between AGLU* and wild type animals. The observed 2-fold reduction in creatine kinase activity in the AGLU animals, which is potentially rate-limiting in energy transfer during short periods of high ATP demand, does not seem to have functional consequences in the fatigue protocol used. The ATP generating capacity was most likely not decreased, as the activities of a selected number of key enzymes of glycolysis (phospho-fructokinase), $\beta$-oxidation ( $\beta$ hydroxy acylCoA dehydrogenase) and tri-carboxylic acid cycle (citrate synthase) did not differ between $\mathrm{AGLU}^{*}$ and control mice. It is, therefore, unlikely that impaired energy metabolism is an important factor in the decreased muscular performance found in this study.

Morphological analysis revealed many non-contractile inclusions in the muscle fibres (Figure 3.4B). Among these glycogen-filled lysosomes, apparently interrupting myofibrils, were prominent. In a two dimensional plane, the apparent interruption of myofibrils could also result from myofibrils coursing in and out of the sectioning plane of the EM. However, preliminary data using three-dimensional confocal microscopy reveals that these structures indeed did interrupt myofibrils. In Figure 3.6, a free body diagram is shown to illustrate the hypothesised forces occurring in interrupted and adjacent myofibrils during a contraction.

Figure 3.6: Free body diagram of a segment of 6 (bundles of) myofibrils of a muscle cell with a non-contractile inclusion. The hypothesised forces during supramaximal contraction are given only on the left upper quadrant $(F=$ maximal active force of myofibril). In the left border forces are assumed to be equal in all fibres, in the right border forces are increased in myofibrils 2 and 3 . Force is transmitted between adjacent myofibrils through shear forces. Due to the local high forces in myofibrils 2 and 3 , the sarcomere length is assumed to increase locally (L), until total force (passive + active) equals (right) fibre force. Consequently, in other parts of the myofibrils 2 and 3 , sarcomere shortening occurs (S). The decrease in force generating capacity due to sarcomere heterogeneity is not included in this diagram. The radial extension of the altered force (here 2 myofibrils) is basically unknown. 

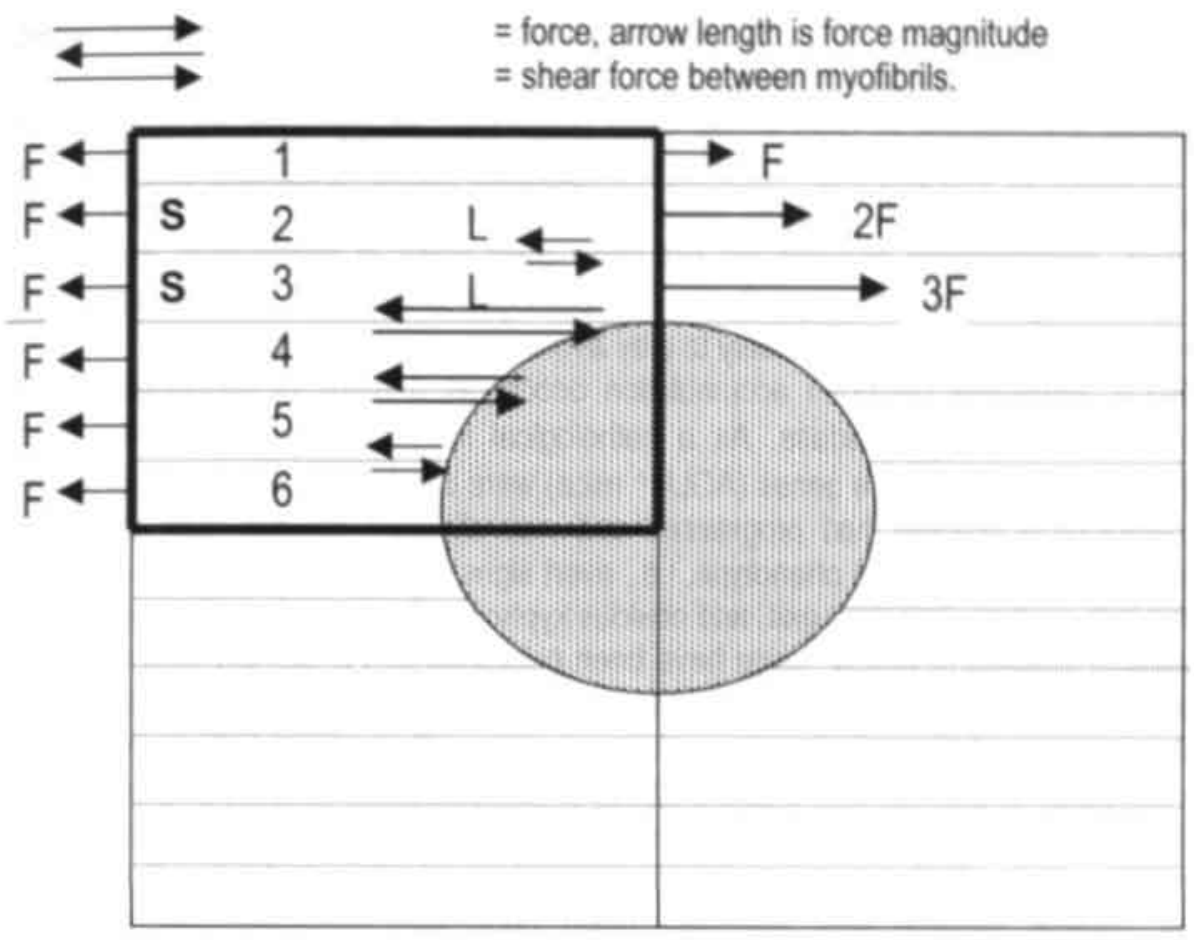

The inclusions are unlikely to be functionally attached to the myofibrils, and their forcetransmitting capabilities are bound to be low. Therefore, the force generated by these interrupted myofibrils is likely to be transversely transmitted to adjacent myofibrils. As a consequence, the longitudinal force in myofibrils adjacent to an inclusion is increased. We speculate that this increase causes local stretching of sarcomeres, indicated by $L$ in Figure 3.6. Consequently sarcomere shortening will occur in other parts of these myofibrils, indicated by $S$ in Figure 3.6, to maintain total myofibril length. These heterogeneities in sarcomere length will reduce the total force-generating capacity of the affected muscle cells. As a consequence, torque production by the whole muscle will be reduced.

It can be envisaged that the local changes in mechanical load may trigger local adaptations in cytoskeletal protein composition [31-33]. Although muscle $\alpha$-actinin content did not differ between control and AGLU mice, desmin expression was approximately 4 -fold increased in mice lacking $\alpha$-glucosidase. Since desmin facilitates transverse force transmission [20], this increase is most likely the consequence of a specific functional adaptation to the interruption of myofibrils. Though no decisive conclusions can be drawn, preliminary localisation studies performed in our laboratory show that there are no vesiculated structures containing desmin, as is the case in a variety of other myopathies [29]. This suggests that the increased desmin observed in 
the Western blots is most likely specifically located at Z-disks and not a non-specific expression of the cytoskeletal protein.

Neurogenic involvement in GSD II has been postulated, as glycogen accumulates in nervous tissue as well $[34,35]$. However, it should be emphasised that in our study no differences in supramaximal current were present between AGLU* mice and control. Moreover, morphological analysis did not show overt signs of denervation dystrophy. Although neurogenic factors may influence the pathogenesis of GSD II, acute effects on electro-stimulated muscles are unlikely to play a role in the present study.

In GSD II, lysosomal glycogen accumulation occurs as a result of mutation-induced deficiency of acid $\alpha$-glucosidase. As a pathological model, 18-month-old mice with disrupted acid $\alpha$-glucosidase genes (AGLU $*$ mice) were used in this experimental study. The pathological process had progressed and was clinically obvious, with the mice showing the typical knockout phenotype, i.e., overt signs of muscle weakness such as a splayed limb posture, impaired gait, and obvious kyphosis. So far, at least four reports of pathological features of AGLU mice have been published $[8,22,36,37]$. In a study by Raben and colleagues, [38] different strains of AGLU mice were compared. They found that the progress of the pathology was slower in mice with a partial FVB background. when compared to animals with a partial $\mathrm{C} 57 \mathrm{BI}$ or 129 background. In the present study, no differences in muscle performance upon electrical stimulation between strains were

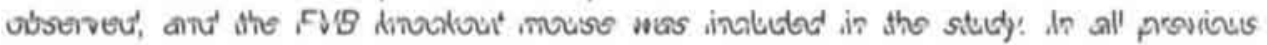
studies, muscle function was assessed using open field measurements such as voluntary exercise, wire hanging, and gait analysis, and found to be impaired. Muscle function impairment appears more pronounced in tasks that require high forcegenerating capacities, such as wire hanging, than in voluntary horizontal exercise [22, 36]. It is likely that the 2-fold reduction of maximal torque in AGLU - mice, as observed in the present study, makes strenuous activities such as climbing cumbersome. An accurate quantitative evaluation of muscle function was performed in the present study. In conclusion, for the first time to the best of our knowledge, accurate measurements were made of the loss in force-generating capacity in muscle of AGLU mice upon electrical stimulation. We also investigated potential mechanisms behind this decline in mechanical performance concluded that in addition to a loss of muscle mass, other factors must contribute to the impairment of muscle performance. The findings of the present study point towards the large clusters of non-contractile material as a potential cause of the decline in muscle function. The observed disruptions in the highly organised muscle cell ultrastructure are likely to hamper intracellular force transmission. The increased desmin content of the affected muscle may be an adaptive response to compensate for the disturbed longitudinal transmission of force. However, the increase in desmin expression is most likely not sufficient to fully compensate the decline in intracellular force transmission due to the accumulation of non-contractile substances as maximal torque in single isometric tetanic contractions significantly declined in mice lacking acid $\alpha$-glucosidase. 


\section{Acknowledgements}

This study has been supported by the Prinses Beatrix Fonds and the Foundation "De Drie Lichten" in the Netherlands. Prof. dr. D.O. Fürst is gratefully acknowledged for providing us with the $\alpha$-actinin antibody. 
Chapter 4

\section{Progression of muscle dysfunction in acid 1-4 $\alpha$-glucosidase knockout mice during isometric and shortening contractions}

Reinout P. Hesselink, Gerrit van Kranenburg, Anton J.M. Wagenmakers, Ger J. van der Vusse, Maarten R. Drost 


\begin{abstract}
In glycogen storage disease type II (GSD II) progressive muscle dysfunction occurs as a result of deficient activity of the lysosomal enzyme acid 1-4 $\alpha$-glucosidase. The prime consequence of this deficient activity is accumulation of glycogen in the lysosomal compartment, eventually leading to impaired muscle contractile performance. We here report on in situ assessment of isometric and isokinetic muscle function upon electrostimulation in acid 1-4 $\alpha$-glucosidase deficient (AGLU) mice, a model for GSD II. Measurements were performed in three groups of mice (6-10, 12-16 and 18-24 months of age), representing different stages of progression of the pathology. Data on muscle mechanical performance were related to loss of muscle mass, muscle protein content, and muscle glycogen content.

In AGLU* mice, isometric maximal torque and peak power progressively declined when related to age matched controls. Moreover, the present data indicate that power production during shortening contraction is affected earlier than isometric strength. Progressive loss of muscle mass was observed starting from age 12-16 months. The reduction of mass normalised power output was progressive with age, loss of mass normalised torque did not further increase after 12-16 months. Optimal shortening angular velocity was about $25 \%$ lower in AGLU than in control mice, and did not change with age. Reduced optimal shortening angular velocity of affected muscles was considered to be a substantial cause of the decline in peak power. Accumulation of glycogen was already prominent in muscles of 6-10 month old AGLU* mice but did not increase significantly thereafter. In the 6-10 months old group, glycogen accumulation might be an important factor in loss of mechanical performance. In later stages of the disease, however, accumulated glycogen can no longer be a crucial factor for the decrease in muscle mechanical function.
\end{abstract}




\section{Introduction}

The decreased activity of the lysosomal enzyme acid 1-4 $\alpha$-glucosidase is the molecular base of glycogen storage disease type II [1], also designated Pompe disease [2] or acid maltase deficiency. In this disease, progressive accumulation of glycogen in the lysosomes occurs, eventually leading to dysfunction of both skeletal and heart muscle. The severest form of this disease commonly has a fatal outcome, and patients die from progressive cardio-respiratory insufficiency. GSD II is inherited in a recessive autosomal way and the incidence is estimated to be $1: 40,000$ births [3], but not all these patients are equally severely affected. The pace of progression depends on the residual activity of the enzyme, and people with more than $25 \%$ residual enzyme activity appear free of clinical symptoms [4]. Patients lacking enzyme activity usually die before the age of 2 years.

Muscle mechanical function is determined by its capacity to generate force in isometric contractions and power during shortening contractions. In everyday life, these distinct types of muscle contractions determine our capacity to maintain posture (force) as well as our locomotive capacity, breathing and cardiac function (power). At present, the exact mechanism of the decrease in muscle function, as readily observed in patients suffering from GSD II, is incompletely understood. To enlarge research possibilities, an acid 1-4 $\alpha$-glucosidase knockout mouse (AGLU) was generated as a model for GSD $॥[5,6]$. Up till now, most measurements of muscle function in studies of GSD II have mainly be qualitative, judging muscle function by tests such as wing flapping in affected Japanese quail [7], or a rotarod, a wire hanging task or daily activity measurement in mouse models [8-10]. In close co-operation with the department of Biomedical Engineering of the Technical University Eindhoven we recently developed two devices that enable accurate assessment of isometric (maximal force) and isokinetic (peak power) muscle functions of ankle dorsal and plantar flexor muscles in an in situ set-up in mice [11, 12]. In an earlier paper we reported on the marked loss of isometric muscle function in AGLU mice 18 months of age [13]. This loss was disproportionate to the loss in muscle mass, suggesting a reduced quality of the remaining muscle tissue. The disturbed microstructure of the affected myocyte, as a result of the glycogen filled lysosomes, has been put forward as a potential cause of the reduced quality of the remaining muscle tissue.

The present paper aims to illuminate both the pace of progression and potential causes of muscle dysfunction in AGLU mice. To this end, maximal torque and peak power generating capacities of dorsal flexor muscles of AGLU-mice and unaffected littermates were determined in different stages of the disease. The groups of mice under investigation ranged in age from 6-10 months, 12-16 months and 18-24 months. In the same mice, muscle mass and amount of muscle protein per unit muscle mass were determined to disclose whether decline in contractile performance was caused by loss of contractile material. To evaluate the possible influence of lysosomal glycogen accumulation in the reduced quality of the muscle, biochemical measurement of the time course of glycogen accumulation was performed in the muscle groups of which the contractile properties were assessed. 


\section{Materials and Methods}

\section{Mouse characteristics}

Measurements were performed on mice almost completely lacking acid 1-4 $\alpha$ glucosidase activity in all tissues (AGLU mice) and on their unaffected littermates. The AGLU mice investigated were the offspring of the mice generated and described by Bijvoet and colleagues [5, 6], backcrossed 10 times to the original C57BI strain. Genetic properties of the animals were tested using PCR with the primer combination described by Bijvoet and co-workers [5].

Groups of mice were studied at the ages of 6-10 months, 12-16 months and 18-24 months. In each age group at least 4 knockout animals and 4 unaffected littermates were included. All experimental procedures were approved by the Institutional Animal Care and Use Committee of Maastricht University and complied with the principles of proper laboratory animal care.

\section{Preparation procedures}

After weighing, mice were anaesthetised with 1.5 to $2.0 \%$ halothane (Fluothane, Zeneca, Ridderkerk, The Netherlands) which was mixed with $\mathrm{O}_{2}$ and $\mathrm{N}_{2} \mathrm{O}\left(2: 1,3.0 \mathrm{~L} \cdot \mathrm{min}^{-1}\right)$, and delivered via a facemask through a flow-meter system (Medec, Montvalle, NJ). The meuse was attached via the hip to a thermostatic platform. The foot was cast in dental cement and rigidly connected to the specifically designed murine torque transducer [11]. After shaving the skin locally, a small incision was made in the lateral part of the knee to expose the peroneal nerve for stimulation of the dorsal flexor complex (tibialis anterior and extensor digitorum longus muscles). A platinum bipolar hook electrode, with an interpole distance of $0.8 \mathrm{~mm}$, was carefully placed around the nerve. The muscle complex was stimulated via a pulse generator (HSE 215/IZ, HSE, Freiburg, Germany). To prevent electrode displacement due to contraction, the electrode was attached to the skin by cyanoacrylate glue. The torque around the ankle was measured with a sample frequency of $1000 \mathrm{~Hz}$.

\section{Stimulation protocol}

In general, the procedure for muscle stimulation during the isometric contraction protocol was similar to that described in detail by Gorselink and co-workers [12]. To achieve maximal isometric muscle performance, supramaximal current was determined in steps of $0.1 \mathrm{~mA}$ and subsequently ankle angle was optimised for torque in steps of $5^{\circ}$ using approximately 7 twitches interspersed by $60 \mathrm{~s}$ rest. Isometric maximal torque was measured at optimal ankle angle, supramaximal current, and a stimulation frequency of $125 \mathrm{~Hz}$. After optimisation of the stimulation conditions, two isometric tetanic contractions were performed interspersed by two minutes rest.

Then ankle angle was maintained while the isometric dynamometer was replaced by a specifically designed isokinetic dynamometer [11]. The protocol used to assess peak power was identical to that described in detail by Gorselink and co-workers [11]. In short, the foot of the mouse was forced into a plantar/dorsal flexion movement of $20^{\circ}$ around 
the optimal ankle angle by a servomotor. In the dorsal flexion phase, the peroneal nerve was stimulated. To ensure that a plateau phase was reached during each contraction, even at high joint angular velocities, the angle at which electrical stimulation started was decreased, while the stimulation frequency was increased and stimulation time was shortened. Torque was measured at joint angular velocities of 80, 160, 240, 320 and 640 degrees per second $\left({ }^{\circ} \mathrm{s}^{-1}\right)$. Measures were performed twice and the calculated average was used, using the isometrically produced maximal torque as the zero angular velocity value, to be fitted to a Hill curve [14]. From the fitted Hill curve, peak power and optimal shortening angular velocity (Vopt.) were calculated.

\section{Sampling and processing of the tissue}

After the stimulation protocol, muscles were dissected in the following order. First the dorsal flexor complex of the exercised leg was dissected, followed by the contralateral dorsal flexor complex. Muscles were dissected from the bone or the visible start of the tendon. Muscle complexes were weighed and frozen in liquid nitrogen within $10 \mathrm{~s}$ after onset of dissection. Mice were subsequently sacrificed by cervical dislocation. The muscle samples were stored at $-80^{\circ} \mathrm{C}$ for biochemical analysis.

Contralateral dorsal flexor complexes were used for biochemical analysis. Frozen muscle tissue was split parallel to the fibre direction. After thawing, half of the tissue was

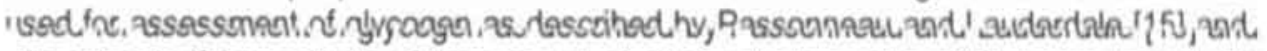
the other half for analysis of the amount of alkali soluble protein [16]. Approximately 25 $\mathrm{mg}$ wet weight of muscle tissue was incubated in $1 \mathrm{ml} 1.0 \mathrm{M} \mathrm{NaOH}$ at $37^{\circ} \mathrm{C}$ for $3 \mathrm{~h}$, neutralised in $1.0 \mathrm{M} \mathrm{HCl}$, and centrifuged at $800 \mathrm{~g}$ for $5 \mathrm{~min}$. Protein content of the supernatant was measured using the Pierce BCA protein assay (Pierce, Rockford, IL) and expressed as $\mathrm{mg} \cdot \mathrm{g}^{-1}$ wet weight of tissue [17]. Biochemical analyses were modified for automated analysis using an automated centrifugal spectrophotometer (COBAS FARA: Roche, Basel, Switzerland).

\section{Data analysis and statistics}

Data are represented as mean and standard deviation. The muscle performance data were processed as follows. Data were filtered using a second order Butterworth filter. Then the average of the signal in the $100 \mathrm{~ms}$ before stimulation was used as zero torque value. Torque produced at the plateau phase of a contraction was calculated as the average of the data points that were within $90 \%$ of the highest value. Also the contractile temporal parameters rise time and half relaxation time were determined. Rise time was defined as the time interval required for the muscle torque to increase from 10 to $50 \%$ of maximal torque. Half relaxation time was defined as the time interval required to decrease the torque from 50 to $25 \%$ of maximal torque [18]. Calculations were performed using the Matlab 6.0 software package (The Math Works Inc., Natick, MA).

For analysis of statistical differences between control and AGLU mice, a Mann Whitney-U test was used. The level of significance was set at $p<0.05$. Statistical analysis was performed using the SPSS 8.0 software package (SPSS Inc.. Chicago, IL). 


\section{Results}

\section{Mouse characteristics}

Table 4.1 shows body mass and dorsal flexor muscle mass of both control and AGLU* mice of the various age groups. Both in control and AGLU mice, body mass did not differ between age groups. Moreover no differences were found between control and AGLU * mice. It is of interest to note that especially in the AGLU $*$ groups both obese and lean mice were present.

In control mice, dorsal flexor muscle mass did not differ between the various age groups. In AGLU mice, however, dorsal flexor muscle mass decreased with age by $11 \%$ (n.s.) and $24 \% \quad(p<0.05)$ in the $12-16$ month and the 18-24 month old groups, respectively, compared to the age matched controls.

Table 4.1: Body mass and mass of the dorsal flexor muscle complex of control and AGLU mice in the various age groups.

\begin{tabular}{c|l|l|l|l}
\hline Age (months) & \multicolumn{2}{|c|}{ Body mass (g) } & \multicolumn{2}{c}{ Muscle mass (mg) } \\
\hline & Control & AGLU & Control & AGLU- \\
\hline $6-10$ & $31.3(5.6) n=5$ & $30.6(3.7) n=4$ & $68.9(3.6)$ & $69.4(4.7)$ \\
\hline $12-16$ & $32.7(8.6) n=9$ & $38.1(19.2) n=4$ & $66.7(9.5)$ & $59.4(13.0)$ \\
\hline $18-24$ & $41.2(3.0) n=5$ & $32.8(4.8) n=4$ & $66.2(6.3)$ & $50.2(8.1)^{*}$ \\
\hline
\end{tabular}

Data are represented as mean (SD). The number of animals included in the various groups is stated with the body mass.

- Significant difference between control and AGLU.

" Significantly different from the 6-10 month old group.

Isometric muscle function

In Figure 4.1, representative tracings of isometric torque produced by the dorsal flexor muscle complex of individual mice from the various age groups are shown. In Table 4.2, the mean and SD of the parameters determined from all tracings are given. Maximal torque did not show any age-related changes in control mice. This was also the case when the isometric torque value was normalised to the mass of the stimulated muscle complex. 
Figure 4.1: Representative tracings of produced isometric torque of control (1A) and AGLU - mice (1B) of the various age groups.
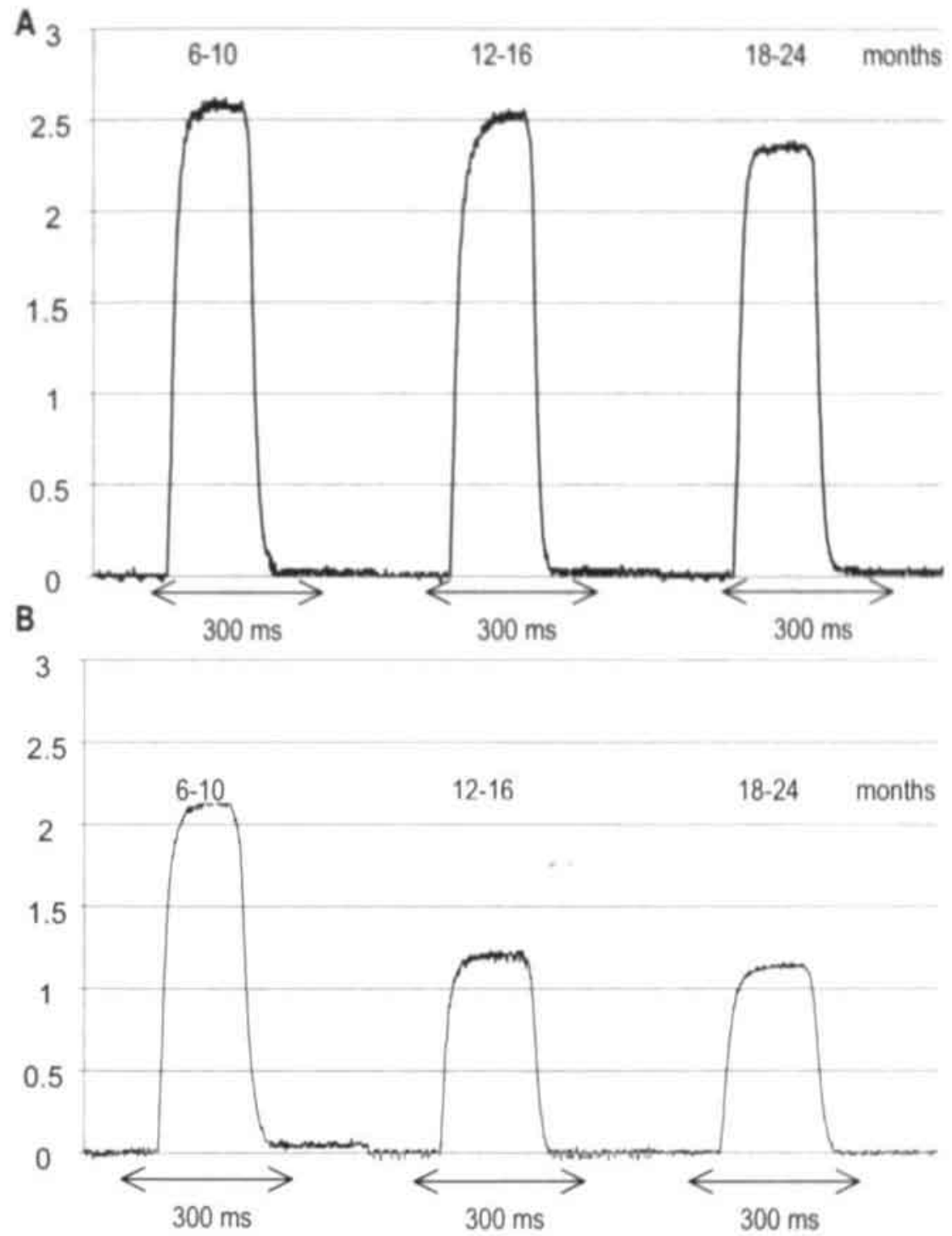

When comparing AGLU mice of different ages, muscle function substantially decreased with advancing age. Maximal torque was reduced significantly by $50 \%$ between $6-10$ and 12-16 months of age, but does not further decrease thereafter. When corrected for muscle mass, the decline in normalised maximal torque amounted to $40 \%$ in the $12-16$ month old animals as compared to the $6-10$ month old mice $(p<0.05)$. The same held for the 18-24 months old group. A comparison of AGLU mice at an age of 6-10 months 
with age matched controls showed that normalised maximal torque tended to be $12 \%$ lower in the diseased muscles. In the 12-16 and 18-24 month old group is the difference between AGLU and unaffected animals was in the order of $40 \%(p<0.05)$.

Rise time and half relaxation times of the contractions showed neither age effects nor differences between $\mathrm{AGLU}$ and control mice of the various age groups. Rise time equalled approximately $11 \mathrm{~ms}$, half relaxation time $10 \mathrm{~ms}$.

Table 4.2: Isometric maximal torque, isometric maximal torque normalised to stimulated muscle mass, rise time and half relaxation time of dorsal flexor muscle complex of control and $\mathrm{AGLU}+$ mice as a function of age.

\begin{tabular}{c|l|l|l|l|l|l|l|l}
\hline $\begin{array}{c}\text { Age } \\
\text { (months) }\end{array}$ & \multicolumn{2}{|c|}{$\begin{array}{c}\text { Isometric torque } \\
\text { (N mm) }\end{array}$} & \multicolumn{2}{|c|}{$\begin{array}{c}\text { Normalised } \\
\text { Isometric torque } \\
\text { (N mm }{ }^{-1} \text { w.W.) }\end{array}$} & \multicolumn{2}{c|}{$\begin{array}{c}\text { Rise time } \\
\text { (ms) }\end{array}$} & \multicolumn{2}{|c}{$\begin{array}{c}\text { Half relaxation time } \\
\text { (ms) }\end{array}$} \\
\hline & Control & AGLU & Control & AGLU & Control & AGLU & Control & AGLU \\
\hline $6-10$ & 2.5 & 2.2 & 36.0 & 32.1 & 11.1 & 11.0 & 10.4 & 10.2 \\
& $(0.6)$ & $(0.4)$ & $(9.3)$ & $(5.8)$ & $(0.3)$ & $(1.9)$ & $(0.6)$ & $(1.6)$ \\
\hline $12-16$ & 2.5 & 1.1 & 37.4 & 19.9 & 10.3 & 12.0 & 9.2 & 11.1 \\
& $(0.4)$ & $(0.3)^{* *}$ & $(6.8)$ & $(8.2)^{* *}$ & $(1.1)$ & $(1.5)$ & $(1.3)$ & $(2.5)$ \\
\hline $18-24$ & 2.4 & 1.1 & 36.5 & 20.8 & 10.6 & 10.3 & 9.7 & 9.3 \\
& $(0.3)$ & $(0.4)^{* *}$ & $(5.2)$ & $(6.7)^{* *}$ & $(1.5)$ & $(1.0)$ & $(1.2)$ & $(0.7)$ \\
\hline
\end{tabular}

Data are represented as mean (SD).

- significant difference between control and AGLU

" significantly different from the 6-10 month old group.

Isokinetic muscle function

The power-angular velocity curves, determined from the torque-angular velocity curve as described in the materials and methods section, of an individual AGLU mouse and one age matched control are shown in Figure 4.2. This figure clearly shows that the torque data were nicely fitted with a Hill curve. It can be appreciated from this figure that values for both peak power and optimal shortening angular velocity are lower in the AGLU animal than in control mouse. The averages for peak power, mass normalised peak power and optimal shortening angular velocity of the dorsal flexor muscle complex of the various age groups of both AGLU and unaffected animals are enumerated in Table 4.3. In control animals, peak power did not differ between the different age groups. The same holds for mass normalised peak power.

In AGLU mice, however, peak power significantly diminished with increasing age. The decline in peak power in $12-16$ month old animals was about $35 \%$ when compared to the 6-10 month group. In the 18-24 month old mice, the reduction amounted to $60 \%$ when compared to the youngest AGLU- animals. The mass normalised peak power in the 12 16 and $18-24$ month groups declined by $24 \%$ and $44 \%$, respectively, when compared to the 6-10 month group. 
Compared to their unaffected littermates, peak power of AGLU - animals was already significantly reduced (by about $30 \%$ ), in the 6-10 month group, and by about $50 \%$ and $70 \%$ in the 12-16 and 18-24 month old mice, respectively. Mass normalised peak power was also lower in all age groups of AGLU mice compared to controls. For example, in AGLU- mice 18-24 months of age, mass normalised peak power was about $60 \%$ lower than in age matched controls.

Figure 4.2: Representative tracings of power output as a function of shortening angular velocity of dorsal flexor muscles of a control and AGLU mouse 12-16 months of age.

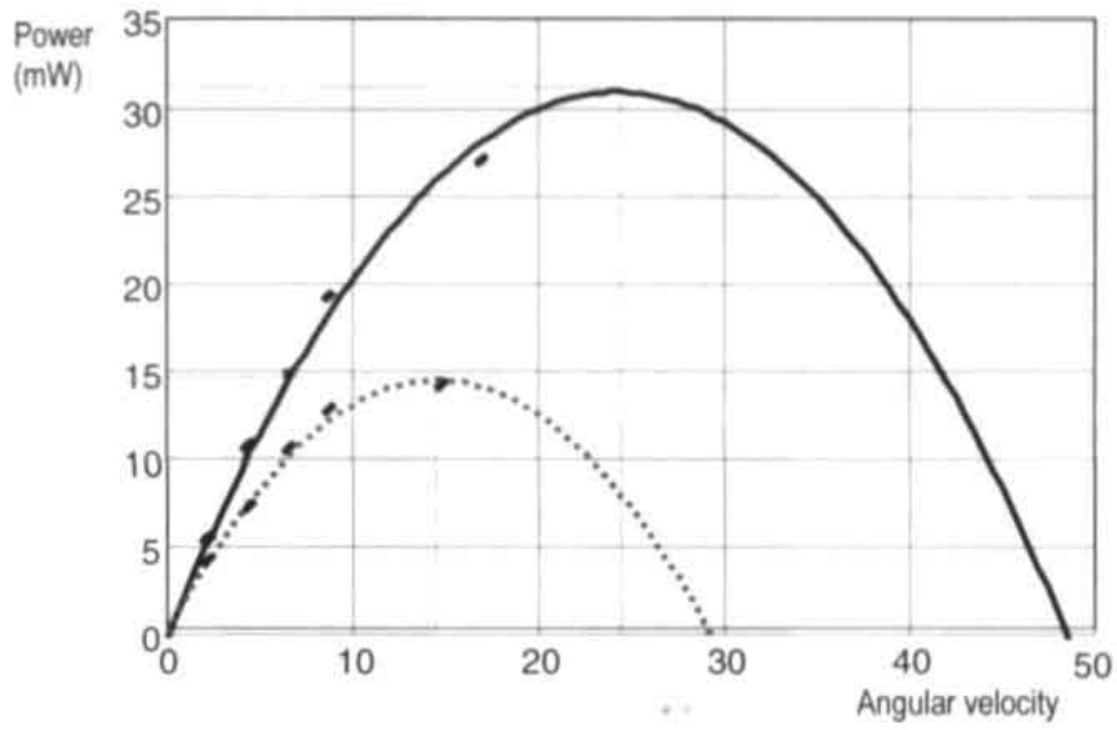

The optimal shortening angular velocity of the dorsal flexor complex amounted to $1420 \pm$ $200{ }^{\circ} \mathrm{S}^{-1}$ in control mice of 6-10 month of age. This value did not change with advancing age. In $\mathrm{AGLU}^{-}$mice, the optimal shortening angular velocity equalled approximately $1050^{\circ} \mathrm{S}^{-1}$ and did not differ between the various age groups. The optimal shortening angular velocity was about $25 \%$ lower in all age groups of AGLU mice, when compared to age matched controls $(p<0.05)$. 
Table 4.3: Peak power, muscle mass normalised peak power and optimal shortening angular velocity of the dorsal flexor muscle complex of control and AGLU - mice in the various age groups.

\begin{tabular}{c|l|l|l|l|l|l}
\hline $\begin{array}{c}\text { Age } \\
\text { (months) }\end{array}$ & \multicolumn{2}{c|}{$\begin{array}{c}\text { Peak power } \\
\text { (mW) }\end{array}$} & \multicolumn{2}{c|}{$\begin{array}{c}\text { Mass normalised } \\
\text { peak power (W.kg-1) }\end{array}$} & \multicolumn{2}{c}{$\begin{array}{c}\text { Optimal shortening } \\
\left.\text { angular velocity ( }{ }^{\circ} \mathbf{S}^{-1}\right)\end{array}$} \\
\hline & Control & AGLU & Control & AGLU & Control & AGLU \\
\hline $6-10$ & 24.2 & 17.2 & 350 & 250 & 1420 & 1050 \\
& $(3.5)$ & $(3.2)^{*}$ & $(60)$ & $(60)^{*}$ & $(200)$ & $(70)^{*}$ \\
\hline $12-16$ & 23.9 & 11.1 & 360 & 190 & 1370 & 1070 \\
& $(4.3)$ & $(2.5)^{* *}$ & $(60)$ & $(40)^{* *}$ & $(100)$ & $(170)^{*}$ \\
\hline $18-24$ & 23.1 & 7.2 & 350 & 140 & 1304 & 1002 \\
& $(2.8)$ & $(3.8)^{* *}$ & $(40)$ & $(50)^{* *}$ & $(120)$ & $(160)^{*}$ \\
\hline
\end{tabular}

Data are represented as mean (SD). The number of experiments are shown in Table 1.

- difference between control and AGLU.

" different from the 6-10 month old group.

\section{Muscle protein content}

When expressed per unit muscle mass, the alkali soluble protein content in the dorsal flexor muscle complex, mainly representing contractile proteins [16], did not show differences between the various age groups of control mice. The same holds for AGLU mice. Furthermore, the values in AGLU did not differ from age matched controls (Table 4.4 and Figure 4.3B).

Table 4.4: Alkali soluble protein content of the dorsal flexor muscle complex of control and AGLU animals of the various age groups.

\begin{tabular}{c|l|l}
\hline $\begin{array}{c}\text { Age } \\
\text { (months) }\end{array}$ & \multicolumn{2}{|c}{$\begin{array}{c}\text { Protein content } \\
\text { (mg. } \mathbf{g}^{-1}\end{array}$} \\
& Ww of tissue) \\
\hline & Control & AGLU \\
\hline $6-10$ & $156(18.4)$ & $162(8.6)$ \\
\hline $12-16$ & $156(18.5)$ & $159(14.9)$ \\
\hline $18-24$ & $141(18.9)$ & $151(14.8)$ \\
\hline
\end{tabular}

Data are represented as mean (SD). Protein content was normalised to muscle wet mass ( $\mathrm{WW}$ ). No significant differences were observed either between various age groups or between AGLU. and age matched control.

\section{Muscle glycogen content}

The content of glycogen in the dorsal flexor complex was dramatically increased (up to 12 fold) in the AGLU mice (Figure 4.3A). The major part of glycogen accumulation had occurred when the mice reached the age of 6-10 months. Thereafter, further increase in the muscle glycogen content did not reach the level of significance. 
Figure 4.3: Glycogen content (A) and protein content (B) of the dorsal flexor muscle complex of control and AGLU' animals of the various age groups.
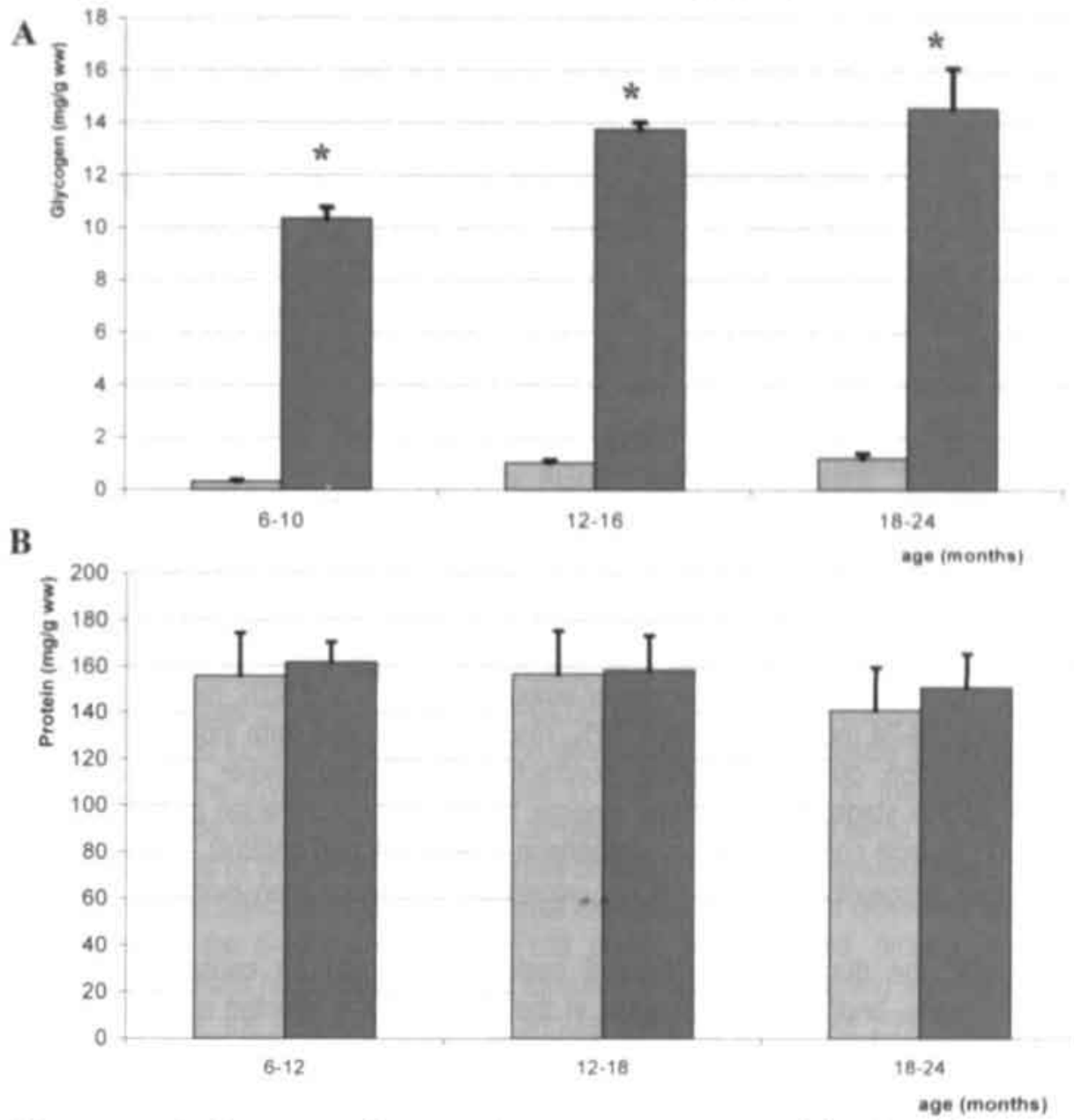

Glycogen content is expressed as $\mathrm{mg}$ glucose per $\mathrm{g}$ wet mass of the dorsal flexor muscle complex. Protein content is expressed as $\mathrm{mg}$ per $\mathrm{g}$ wet mass of dorsal flexor muscle complex. Presented data are the average of $4 \mathrm{AGLU}^{-}$and 5 control mice in each age group. Error bars indicate the SD in each group.

- Denotes significant difference between control and AGLU 


\section{Discussion}

Deficient enzymatic acid 1-4 $\alpha$-glucosidase activity, resulting in progressive lysosomal glycogen accumulation was to found to be associated with a loss of muscle function in AGLU mice $[6,8]$. Until now loss of muscle function has been determined in qualitative terms $[6,8]$, rather than by detailed analysis of relevant parameters such as isometric strength and peak power during shortening contractions of the affected muscles. Therefore, the first aim of the present study was to provide quantitative information about the time course of changes in i) maximal torque production and related temporal parameters, such as rise time and half relaxation time, during isometric contractions and ii) peak power and the optimal shortening angular velocity during shortening contractions. To this end, AGLU mice and age-matched control were studied at various ages. The second aim of the study was to relate changes in mechanical performance, if any, with i) the loss of muscle mass, ii) the loss of muscle protein content and iii) the degree of accumulation of glycogen.

Here, we provide quantitative information that muscle mechanical performance in the AGLU mouse model is compromised and declines with advancing age. This notion is based on the following observations. At 6-10 months of age, the generated maximal torque tended to be reduced by approximately $12 \%$, while peak power was significantly ieuticos' by' $30 \%$ somnaces it agre matched control. In age group 12-16 months, the decline in maximal torque and peak power amounted to $55 \%$ and $50 \%$, respectively, and in age group 18-24 months to 55 and $70 \%$, respectively. These data indicate that peak power production during shortening contraction is affected earlier than isometric strength. At this stage, two questions emerge: i) why is the contractile performance of the AGLU muscle compromised in comparison to age matched controls, ii) why is peak power more susceptible to acid $1-4 \alpha$-glucosidase deficiency than isometric maximal torque.

Theoretically, the decline in mechanical performance could be caused by loss of contractile mass, and/ or by a decrease in the quality of the affected muscle. Indeed, dorsal flexor muscle mass gradually declined with age in the AGLU mice. To explore the effect of this gradual decline in muscle mass we have normalised the maximal torque and peak power to muscle mass. Decline in muscle mass was negligible at 6-10 months and amounted to $24 \%$ at $18-24$ months. The fact that muscle protein content expressed per unit muscle mass never differed between AGLU and control mice, indicates that the loss of muscle mass is proportional to the loss of contractile material. These findings indicate that at 6-10 months of age the decline in muscle performance can not be explained by a loss of contractile material, but fully represent a decrease in quality of muscle tissue. At later stages of the disease, the 12-16 and 18-24 months old groups, the decline in mechanical performance is a combination of decline in mass and muscle quality, because both mass and mass normalised peak power as well as maximal torque were found to be lower in AGLU than in age matched controls. For example, in the 1824 month group it can be calculated from data presented in Table 2, that one third of the 
decline in isometric torque can be attributed to a decrease in muscle mass, leaving $2 / 3$ to a decline in muscle quality.

As hypothesised in Chapter 2, lysosomal glycogen accumulation might negatively affect muscle quality and, hence, contractile performance. The present findings clearly indicate that glycogen accumulation occurred mainly before 6-10 month of age, while the decline in mass normalised maximal torque and peak power was most prominent in animals in a later stage of the disease. Although glycogen accumulation can not be the most important factor in the loss of muscle quality in older animals, the impact of glycogen accumulation in muscle of young AGLU mice might be substantial. In the present experimental set-up, the precise quantitative significance of glycogen accumulation to the loss of muscle mechanical performance could not be determined. The reader is referred to Chapter 6 , where the effect of glycogen filled lysosomes on maximal torque was estimated making use of a numerical model.

It is of interest to note that in each group studied both the rise time and the half relaxation time did not differ between AGLU and control mice. These temporal parameters are, among others, dependent on calcium release and re-uptake by the sarcoplasmatic reticulum. Therefore the cautious conclusion can be drawn that caicium handling is not impaired in muscle cells of AGLU- mice. The corollary of this notion is that loss of muscle quality is not related to changes in calcium homeostasis.

The above considerations lead us to conclude that other factors, as yet unknown, are involved in the loss of muscle quality in AGLU - mice. Micro-morphological factors have been put forward to be of importance in the decreased quality of muscle tissue in GSD ॥ $[13,19,20]$. The involvement of changes in micro-morphology in the quality of the remaining muscle tissue in AGLU mice has been explored in more detail in Chapter 5.

Detailed analysis of the contractile properties of AGLU muscles revealed that generally peak power was affected more than maximal isometric torque. This difference was most pronounced in the 6-10 month group. Peak power is determined, among others, by muscle mass, mass normalised isometric torque and optimal shortening angular velocity. In AGLU mice, the optimal shortening angular velocity was about $25 \%$ lower than in control mice in all age groups. The mass normalised isometric torque, however, progressively declined from $12 \%$ (6-10 month) to $43 \%$ (18-24 month) in AGLU mice compared to their unaffected littermates. The collective findings strongly suggest that in the youngest group, the decline in muscular peak power is mainly caused by a decline in optimal shortening angular velocity. In the older animals, the decline in mass normalised torque appears to be the most prominent factor.

We can only speculate about the causes of the early decline in optimal shortening angular velocity. In general, differences in shortening velocity are caused by differences in muscle fibre type composition. In AGLU mice, however, the fibre type composition was not different from age matched controls [13]. Therefore, we concluded that in the AGLU mouse model the potential effect of changes in fibre type composition on optimal shortening angular velocity can be neglected. Although in human GSD II conflicting findings with respect to the severity of the pathological changes between muscle fibre 
types were published [21-24], no indications were obtained that the severity of the pathological changes in AGLU mice varied between muscle fibre types [13]. It is conceivable that in AGLU* mice, the presence of glycogen filled lysosomes causes a decrease in optimal shortening velocity. In the affected muscle fibre, parts of myofibrils are replaced by swollen lysosomes, representing non-contractile material [13]. Therefore, during shortening contractions at a given velocity of the muscle fibre, sarcomeres inside affected muscle fibres have to shorten faster to compensate for the presence of non-contractile inclusions, such as the glycogen filled lysosomes. This phenomenon results in a declined fibre shortening velocity, if sarcomere shortening velocity does not change. This implicates that optimal shortening angular velocity of a muscle, as determined in this study, can be decreased without a decline in sarcomeric optimal shortening velocity. However, the quantitative contribution of this phenomenon to the observed $25 \%$ decline in muscle optimal shortening angular velocity, remains to be elucidated.

In infantile Pompe patients impaired function of the respiratory muscles is prominent. The main function of these muscles is to generate power, rather than isometric force. The present study shows a progressive decline in power generating capacity, resulting in a peak power that is only $30 \%$ of the power output of unaffected animals in progressed stages of the pathology. If extrapolation of findings in AGLU * mice to Pompe patients is allowed, the present findings might have important cinical ramificauons. Tie jiuyrossiver reduction of power generating capacity observed here might well explain why in patients suffering from GSDII the respiratory system is severely affected.

\section{Acknowledgments}

This study was financed by the Prinses Beatrix Fonds and by the foundation 'De drie Lichten' in The Netherlands. The authors are indebted to Paul Willems for his experience assistance with the calculations in the Matlab program. Dr. A.J.J. Reuser is gratefully acknowledged for providing us with the both the AGLU mice and the primers. 


\section{References}

1 Hers, H.G. (1963) Biochem J 86, 11-16.

2 Pompe, J.C. (1932) Ned Tijdsch Geneesk 76, 304-311.

3 Ausems, M.G., Verbiest, J., Hermans, M.P., Kroos, M.A., Beemer, F.A., Wokke, J.H., Sandkuij, L.A., Reuser, A.J.J. and Van der Ploeg, A.T. (1999) Eur J Hum Genet 7, 713-716.

4 Reuser, A.J.J., Kroos, M.A., Hermans, M.M.P. Bijvoet, A.G.A., Verbeet, M.P. Van Diggelen, O.P., Kleijer, W.J., and Van der Ploeg. A.T. (1995) Muscle \& Nerve Suppl 3, S61-S69.

5 Bijvoet, A.G.A., Van der Kamp, E.H.M., Kroos, M.A., Ding, J.H., Yang, B.Z. Visser, P., Bakker, C.E., Verbeet, M.P., Oostra, B.A., Reuser, A.J.J. and Van der Ploeg, A.T. (1998) Hum Mol Gen 7, 53-62.

6 Bijvoet, A.G,A., Van Hirtum, H., Vermey, M., Van Leenen, D., Van der Ploeg, A.T., Mooi, W.J. and Reuser, A.J.J (1999) J Pathol 189, 416-424.

7 Kikuchi, T., H. Wen Yang, M. Pennybacker, N. Ichihara, M. Mizutani, J.L.K. Van Hove, Y-T Chen. (1998) J Clin Invest 101/4, 827-833.

8 Raben, N., K. Nagaraju, E. Lee, P. Kessler, B. Byrne, L. Lee, M. LaMarca, C. King, J. Ward, B. Sauer, P. Plotz. (1998) J Biological Chem 273/30, 1908619092.

9 Fraites, T.J., Jr., Schleissing, M.R., Shanely, R.A., Walter, G.A., Cloutier, D.A., Zolotukhin, I., Pauly, D.F., Raben, N., Plotz, P.H., Powers, S.K., Kessler, P.D. and Byrne, B.J. (2002) Mol Ther 5, 571-578.

10 Raben, N., Nagaraju, K., Lee, E. and Plotz, P. (2000) Neuromusc Disord 10, 283 291.

11 Gorselink, M., Drost, M.R., de Louw, J., Willems, P.J., Hesselink, M.K.C., Dekkers, E.C., Rosielle, N. and Van der Vusse, G.J. (2001) Pflugers Arch 442, 304-311.

12 Gorselink, M., Drost, M.R., de Louw, J., Willems, P.J., Rosielle, N., Janssen, J.D. and Van der Vusse, G.J. (2000) Pflugers Arch 439, 665-670.

13 Hesselink, R.P., Gorselink, M., Schaart, G., Wagenmakers, A.J.M., Kamphoven, J., Reuser, A.J.J., Van der Vusse, G.J. and Drost, M.R. (2002) Muscle Nerve 25. 873-883.

Hill, A.V. (1938) Proc Royal Soc London B 126, 136-195.

Passonneau, J.V. and Lauderdale, V.R. (1974) Anal Biochem 60, 405-412.

Lowry, O.H., Rosebrough, N.J., Farr, A.L. Randall, R.J. (1951) J Biol Chem 193, 165-275.

17 Smith, P.K., Krohn, R.I., Hermanson, G.T., Mallia, A.K., Gartner, F.H., Provenzano, M.D., Fujimoto, E.K., Goeke, N.M., Olson, B.J. and Klenk, D.C. (1985) Anal Biochem 150, 76-85.

18 Edwards, R.H.T., Hill, D.K. and Jones, D.A. (1975) J Physiol251, 287-301.

19 Griffin, J.L. (1984) Virchows Arch B Cell Pathol Ind Mol Pathol 45, 51-61.

20 Griffin, J.L. (1984) Virchows Arch B Cell Pathol Ind Mol Pathol 45, 37-50. 
Chapter 4

Progression of muscle dysfunction in acid $1-4 \alpha$-glucosidase deficient mice

21 Papapetropoulos, T., Paschalis, C. and Manda. P. (1984) J Neurol Neurosurg Psych 47, 213-215.

22 Schlenska, G.K., Heene, R., Spalke, G. and Seiler, D. (1976) J Neurol 212, 237 252.

23 Matsuishi, T., Yoshino, M., Terawasa, K. and Nonaka, I. (1984) Arch Neurol 41, 47-52.

24 Barohn, R.J., McVey, A.L. and DiMauro, S. (1993) Muscle \& Nerve 16, 672-676. 
Chapter 5

\section{Morphological and structural changes in skeletal muscle of mice lacking acid $\alpha$-glucosidase}

Reinout P. Hesselink, Gert Schaart, Anton J. M. Wagenmakers, Maarten R. Drost

Ger J. Van der Vusse 


\section{Abstract}

In glycogen storage disease type II (GSD II), a lack of functional acid 1-4 $\alpha$-glucosidase (AGLU) leads to accumulation of glycogen within the lysosomes. This leads to a decline in muscle function, with an eventually fatal outcome due to cardio-respiratory insufficiency. Here, we report upon changes in the intracellular structural organisation as a result of a null mutation in the GAA gene encoding for AGLU in a mouse model (AGLU- mice). Morphological and structural features of muscle cells were analysed in AGLU* mice of various ages and compared to findings in non affected littermates. Initially, the glycogen filled lysosomes became visible as focal spots upon per-iodic acid Schiff (PAS) staining in AGLU animals. In later stages, large intracellular inclusions of a mixed cellular debris disturb the sarcoplasmic organisation. These large inclusions also contain lipofuscin, pointing to an overall dysfunction of the lysosomes to digest macromolecules. Concomitant with the appearance of the large inclusions, alterations in the cytoskeletal structure of the affected muscle cells were observed. Initially, the increased deposition of titin bordering the large inclusions inside the affected muscle fibres, most likely occur as an adaptation to changes in intracellular forces. Titin deposition in this case might be a compensatory mechanism to facilitate transmission of forces around the inclusion, thus mitigating the decline in force. Total desmin content gradually increased with advancing age while desmin staining was not confined to areas in close vicinity of the intracellular inclusions. The functional significance of the alterations in desmin expression is incompletely understood. In later stages of the disease, when the structural disarrangement of the muscle cells becomes more severe, in some muscle cells the loss of titin and non-functional deposition of desmin were prominent. 


\section{Introduction}

In a substantial number of acquired or genetically transmitted diseases, skeletal muscles are affected and their mechanical function is impaired. In the early thirties of the last century, the Dutch physician Jan. C. Pompe described a syndrome characterised by skeletal muscle weakness and cardiac hypertrophy [1]. Pathological studies revealed excessive storage of glycogen inside the lysosomes of these patients and, hence, the syndrome was named lysosomal glycogen storage disease type II (GSD II). In 1963 Hers convincingly showed that GSD II was caused by deficiency of the lysosomal enzyme acid 1-4 $\alpha$-glucosidase (EC 3.2.1.20) [2]. This genetic disease is inherited in an autosomal recessive mode [3]. The severity and pace of progression of the disease is primarily depended on the residual activity of acid 1-4 $\alpha$-glucosidase [4-8]. A residual enzyme activity of $25 \%$ or higher usually does not cause clinical symptoms $[9,10]$, while complete lack of enzyme activity leads to death by cardio-respiratory insufficiency before the age of 2 years [11]. In the Dutch population the number of genetically affected births is estimated as 1 out of 40,000 [12].

The clinically most prominent feature of GSD $\|$ is the progressive decline in muscular performance $[3,13,14]$. In a previous study on aged mice lacking acid $1.4 \alpha$ glucosidase (AGLU mice), we showed that the reduction of muscle function is disproportionate to the loss of muscle mass [15]. Therefore we hypothesised that alterations in the intracellular structure of the muscle fibre contribute to the loss of contractile function. This hypothesis is partially based on earlier observations by Griffin in muscles of patients suffering from Pompe disease [16]. Recently we proposed that, among others, the lysosomal accumulation of glycogen, as readily seen in patients and experimental $\mathrm{AGLU}^{*}$ mice, interferes with the highly organised architecture of the striated muscle cells and, hence, negatively affects contractile function [15].

In the present study, the main aim was to delineate the major alterations in the intracellular structure of muscle cells lacking acid $1-4 \alpha$-glucosidase activity. The AGLU mouse was chosen as an experimental model [17]. In order to explore the temporal progression of the structural alterations in muscle fibres, animals of three different age groups were included in this study, i.e. 6-10 months, 12-16 months and 18-24 months. The application of per-iodic acid Schiff (PAS) with hematoxilin counterstaining enabled us to identify focal accumulation of glycogen, localisation of nuclei and gross changes in cytoplasmic appearance. Lipofuscin auto-fluorescence was used to monitor the appearance and intracellular distribution of lipofuscin during the course of the disease [18]. For proper mechanical function of muscle cells, alignment of contractile proteins, (i.e., regular cross striation), is of importance [19]. The cytoskeleton plays a pivotal role in the alignment $[20,21]$. Therefore alterations in the cytoskeletal structure were investigated by immuno-histochemical staining of two prominent cytoskeletal proteins, i.e., titin and desmin. These two proteins were selected since they are known to be involved in intracellular force transmission $[22,23]$. Finally, the changes, if any, in tissue contents of these two cytoskeletal proteins were monitored in muscle specimen of AGLU mice by means of Western blotting. 


\section{Materials and Methods}

\section{Mouse characteristics}

Measurements were performed on mice lacking acid 1-4 $\alpha$-glucosidase (AGLU-) mice [17] and their unaffected littermates. Genetic properties of the animals were tested using PCR with the primer combination described by Bijvoet and co-workers [17]. Also a post hoc analysis of the enzymatic activity of acid 1-4 $\alpha$-glucosidase [24] was performed in the quadriceps muscle tissue to check for residual enzyme activity.

Three different age groups of mice were included in the study, i.e., at the age of 6-10 months, 12-16 months and 18-24 months. Each age group consisted of at least 4 knockouts and 4 unaffected littermates. The AGLU mice were the offspring of the mice generated and described by Bijvoet and colleagues [17], backcrossed 10 times to the original $\mathrm{C} 57 \mathrm{BI}$ strain. All experimental procedures were approved by the Institutional Animal Care and Use Committee of Maastricht University and complied with the principles of proper laboratory animal care.

\section{Sampling of muscle tissue}

Mice were weighed and subsequently anaesthetised using 2.5\% halothane (Fluothane; Zeneca, Ridderkerk, The Netherlands) mixed with $\mathrm{O}_{2}$ and $\mathrm{N}_{2} \mathrm{O}(2: 1,3.0 \mathrm{l} / \mathrm{min})$ delivered shough a flaw-meter (Medec. Montvalle, NJ) to a facemask covering the nose and mouth of the animal. Then muscle tissue was harvested from both the right and the left hind limbs. First the dorsal flexor complex of the left leg was dissected, followed by the right leg's dorsal flexor complex. Muscles were dissected from the bone or the visible start of the tendon. For morphological analysis, muscles from the left leg were used after mounting on ThermoShandon (Cryomatrix, Pittsburg, PA, USA) and subsequent freezing in melting isopentane. The right leg's dorsal flexor complex was weighed and frozen in liquid nitrogen within $10 \mathrm{~s}$ after dissection for protein isolation and Western blotting. Finally, quadriceps muscle of the stimulated leg was harvested for assessment of acid 1 . $4 \alpha$-glucosidase activity. Mice were subsequently sacrificed by cervical dislocation. Samples were stored at $-80^{\circ} \mathrm{C}$ until analysis.

\section{Tissue staining}

To assess muscle morphology, localisation of glycogen and cytoskeletal structure, 4- $\mu \mathrm{m}$ thick longitudinal muscle tissue specimen from the left leg's tibialis anterior were stained. In all cases, tissue sections were obtained from the ventral side and sections were made from the origo to the insertion of the muscle to ensure the largest overview possible. Sections were stained with per-iodic acid Schiff (PAS) for glycogen and hematoxilin for nuclei after formalin/ethanol fixation (9:1). For immuno-fluorescence, the mouse monoclonal antibodies DER-11 (Dako, Glostrup. Denmark) and 9D10 [25] directed against desmin and titin, respectively, were applied after 5 min permeabilisation in $0.5 \%$ Triton X-100 in PBS. To enable proper comparison between different muscle sections, all samples were stained in the same run. Picture grabbing in each section was 
performed using a NIKON E800 fluorescence microscope (UVIKON, Bunnik, The Netherlands) coupled to a Basler A101C progressive scan colour CCD camera, with a Bayer colour filter, with an output picture resolution of $1300^{\circ} 1030$ pixels $(\mathrm{H} \times \mathrm{V})$ and a pixel size of $6.7^{*} 6.7 \mu \mathrm{m}$. Digitally captured images were processed and analysed using LUCIA G/F v4.61 build 0.64 image analysis software (Nikon $\mathrm{GmbH}$, Düsseldorf, Germany). Lipofuscin distribution in the muscle cells was studied by using its autofluorescent properties by means of a Texas red excitation filter $(540-580 \mathrm{~nm})$.

\section{Tissue analysis}

To obtain a representative overview of a muscle section, 5 pictures were taken at separate locations of each longitudinal section, using a 20x magnification. This enabled semi-automated analysis of at least 25 fibres per picture using various photo-processing programmes. The degree of focal glycogen accumulation was measured as the percentage surface area of the glycogen filled lysosomes in the PAS stained sections, which was calculated using a planimetric method. As in PAS staining the cytoplasm of normal muscle cells usually shows a very homogeneous, uninterrupted staining, these sections were also used to study changes in gross cytoplasmic appearance. In this way. irregularities in the cytoplasm other than focal glycogen accumulation could be monitored. The number of muscle fibres with cytoplasmic irregularities was counted and expressed as a percentage of the total number of muscle cells visible in the area analysed. The hematoxilin counter staining allowed for studying the number and localisation of nuclei.

The titin and/or desmin immuno-fluorescence staining tissue sections of AGLU mice were compared with those of age matched control mice to analyse the changes in cytoskeletal structure. In all age groups, the control animals showed a pattern of regular cross striation. Therefore in AGLU animals, the lack of a regular cross striation and/or an inhomogeneous staining intensity within fibres were defined as loss of regular cytoskeletal structure. The area showing disarray of cytoskeletal structure was planimetrically quantified and expressed as percentage of total muscle surface area. Furthermore, the number of muscle fibres in which cytoskeletal structure was in disarray were counted and expressed as a percentage of the total number of muscle cells in the area analysed.

\section{Quantification of desmin and titin}

Muscle tissue was homogenised in a sucrose-EDTA-Tris (SET) buffer using an ultraturrax and centrifuged at $600 \mathrm{~g}$ for $10 \mathrm{~min}$. To separate the cytoskeletal proteins, the pellet was re-suspended in $0.6 \mathrm{M} \mathrm{KCl}$ and incubated on ice for $30 \mathrm{~min}$ and centrifuged at $30,000 \mathrm{~g}$ for $10 \mathrm{~min}$. That pellet was re-suspended in $2 \mathrm{ml} 15$ Triton X-100 and incubated on ice for $30 \mathrm{~min}$. The supernatant of the latter homogenate contained the cytoskeletal proteins. Proteins were separated by means of a $12 \%$ sodium dodecylsulphatepolyacrylamide gel electrophoresis (SDS-PAGE) gel according to Laemmli [26], and transferred to nitrocellulose paper using Western blotting. Equal amounts of total protein 
were loaded onto the gel as was confirmed by digital image processing and analysis after staining of the gels with Coomassie brilliant blue. Desmin and titin were then identified using chemiluminescence immuno-detection after incubation with the same antibodies as used in the immuno-fluorescence staining. Of each age group, samples of three AGLU and three control animals were loaded on separate lanes of the same gel. Muscle desmin and titin content of AGLU* mice were determined relative to control mice by digital image processing and analysis.

Activity of acid 1-4 $\alpha$-glucosidase was assessed in aliquots of approximately $50 \mathrm{mg}$ thawed, homogenated quadriceps femoris muscle, as previously described by De Jonge and co-workers [24].

\section{Data analysis and statistics}

Data are represented as mean and standard deviation. For analysis of statistical differences in the data obtained between groups, signed rank test was used. The level of significance was set at $P<0.05$. Statistical analysis was performed using the SPSS 8.0 software package (SPSS Inc., Chicago, IL).

\section{Results}

\section{Mouse characteristics}

Of the groups of mice under investigation the average body mass, muscle mass and acid 1-4 $\alpha$-glucosidase activity are summarised in Table 5.1. Body mass did not differ between $A G L U$ and control mice at each age group. Mass of dorsal flexor muscles was significantly lower in AGLU mice at both 12-16 and 18-24 months of age. Residual activity of acid $1-4 \alpha$-glucosidase in all age groups of AGLU mice was approximately $5 \%$ of control values.

Table 5.1: Body mass, dorsal flexor muscle mass and activity of acid $1-4 \alpha$-glucosidase in control and AGLU mice of the various age groups studied.

\begin{tabular}{l|c|c|c|c|c|c}
\hline & \multicolumn{2}{c}{$6-10$ months } & \multicolumn{2}{c|}{$12-16$ months } & \multicolumn{2}{c}{$18-24$ months } \\
\cline { 2 - 7 } & $\begin{array}{c}\text { Control } \\
(n=5)\end{array}$ & $\begin{array}{c}\text { AGLU } \\
(n=4)\end{array}$ & $\begin{array}{c}\text { Control } \\
(n=9)\end{array}$ & $\begin{array}{c}\text { AGLU } \\
(n=4)\end{array}$ & $\begin{array}{c}\text { Control } \\
(n=5)\end{array}$ & $\begin{array}{c}\text { AGLU } \\
(n=4)\end{array}$ \\
\hline $\begin{array}{l}\text { Body mass } \\
(\mathrm{g})\end{array}$ & $31.3 \pm 5.6$ & $30.6 \pm 3.7$ & $32.7 \pm 8.6$ & $38.1 \pm 19.2$ & $41.2 \pm 3.0$ & $32.5 \pm 4.8$ \\
\hline $\begin{array}{l}\text { Muscle mass } \\
(\mathrm{mg})\end{array}$ & $68.9 \pm 3.6$ & $69.4 \pm 4.7$ & $66.7 \pm 9.5$ & $59.4 \pm 13.0^{*}$ & $66.2 \pm 6.3$ & $50.2 \pm 8.2^{*}$ \\
\hline $\begin{array}{l}\alpha-\text {-glucosidase } \\
\text { activity }\end{array}$ & $13.2 \pm 1.0$ & $0.8 \pm 0.2^{*}$ & $15.2 \pm 1.3$ & $0.5 \pm 0.3^{*}$ & $14.7 \pm 1.1$ & $0.6 \pm 0.3^{*}$ \\
\hline
\end{tabular}

Data are presented as mean \pm S.D.

${ }^{\circ}=p<0.05$ control vs. AGLU + animals 
Activity of the acid $1-4 \alpha$-glucosidase is expressed as release of $\mu$ mol 4 - methylumbelliferyi- $\alpha-D$ glucopyranoside ${ }^{-1}$ tissue wet weightmin

\section{Morphological features upon PAS staining}

\section{Glycogen}

In Figure 5.1, a tableau of representative samples of PAS staining of AGLU and age matched control muscle specimen is shown. In control mice, 6-10 months of age, all muscle samples showed an appearance after PAS staining not different from previously described in normal mouse skeletal muscle [27]. Slight differences in staining intensity between fibres could be observed, most likely indicating differences in cytoplasmic glycogen content between various muscle fibre types. Individual cells could be distinguished as the membrane was clearly visible (Figure 5.1A). This feature was also present in control mice of more advanced age (Figure 5.1B and 5.1C).

The morphology of the AGLU muscle cell largely differed from control. Focal PAS positive spots were observed in virtually all skeletal muscle fibres of 6-10 month old AGLU mice (Figure 5.1D). The PAS positive spots most likely represent lysosomal accumulation of glycogen since Bijvoet and co-workers previously identified these spots as lysosomes by staining with the lysosomal marker acid phosphatase [17]. The surface area occupied by glycogen filled lysosomes averaged $3 \% \pm 1 \%$ of the total cell surface area in 6-10 month old AGLU- animals. This percentage and did not further increase in older animals (Figure 5.1E and 5.1F). No glycogen filled lysosomes were observed in unaffected littermates.

\section{Gross cytoplasmic appearance}

In control mice 6-10 months of age, cytoplasm of the cells showed a homogeneous staining without interruptions (Figure 5.1A). Nuclei were regularly observed near the cell membranes. In control animals of more advanced age, these features remained unchanged (Figure 5.1B and 5.1C).

In 6-10 month old AGLU - mice, disturbance of the cellular structure other than the focal glycogen accumulations described above, was rarely observed (Figure 5.1D). In the more advanced stages of the disease (12 months and more), however, not only glycogen filled lysosomes were observed, but also large areas of cellular debris accumulating centrally in the muscle cell (Figure 5.1E). At 12-16 months, such central cores could be observed in roughly one fifth of the muscle fibres in the plane of section. In these fibres approximately $12 \% \pm 5 \%$ of the visible surface area was occupied by debris accumulating in the central cores. In AGLU mice of 18-24 months, the cytoplasmic irregularities were so prominent that cells could not longer be distinguished individually using PAS staining. In up to $20 \%$ of the muscle fibres complete loss of cellular structure was observed. In muscle fibres with central cores of debris, also centrally located nuclei were frequently observed (in $50 \%$ of the fibres analysed). 


\section{For figure 5.1 see page 144}

\section{Lipofuscin auto-fluorescence}

In muscles of 6-10 and 12-16 month old control mice, lipofuscin signals were absent (findings not shown). In fibres of aged control mice (18-24 months) the lipofuscin signal was observed occasionally (about $1 \%$ of all cells investigated). No lipofuscin signal could be detected in muscle of AGLU $\%$ mice 6-10 months of age. In muscles of 12-16 month old AGLU mice, however, the lipofuscin signal was detected in about $12 \%$ of the fibres. Accumulation of lipofuscin apparently occurred in conjugation with the central cores. The lipofuscin mostly appeared as bright spots and most pronounced accumulation of lipofuscin was observed inside the central cores. In the more advanced stages of the disease (animals of 18-24 months), lipofuscin accumulated in about $75 \%$ of the muscle fibres and the accumulation was not solely restricted to central cores. In some cases, the entire fibre showed a diffuse lipofuscin signal as indicated in Figure 5.2.

\section{For figure 5.2 see page 145}

\section{Immuno-fluorescence staining of titin and desmin}

\section{Titin}

The signals of the cytoskeletal protein titin in 6-10 months old control animals showed a regular striated distribution in the cytoplasm, and a slightly increased signal at close vicinity to the sarcolemma (Figure 5.3A). This pattern was also observed in controls of older ages (Figure 5.3B and 5.3C). In a limited number of muscle fibres of 6-10 month old AGLU mice, irregularities in the cytoplasmic striation pattern, generally small 'holes' in the cytoplasm, were seen (Figure 5.3D). These holes most likely correspond with the glycogen filled lysosomes. At 12-16 months, when large central cores became apparent in the muscle fibres of AGLU mice, the titin signal was more intense in myofibrils immediately bordering these large cytoplasmic inclusions (Figure 5.3E). At 18 months and older, in all muscle fibres of AGLU mice, the pattern of cross striation was disrupted. $\ln 7 \pm 2 \%$ of muscle fibres of $18-24$ month old AGLU $^{-}$mice the titin signal virtually disappeared (Figure 5.3F).

\section{For figure 5.3 see page 145}

\section{Desmin}

Immuno-fluorescence staining of desmin showed a regular pattern of cross striation in muscle cells of 6-10 months old control animals. Staining intensity at close vicinity of the sarcolemma was more intense than in other cytoplasmic regions (Figure 5.4A). This feature was also observed in animals of older age (Figure 5.4B and C).

In AGLU animals, a normal pattern of cross striation was present in muscles of 6-10 months old mice. The pattern was found to be disturbed in the more advanced stages of 
the disease. At 12-16 months of age, disturbances of the cross striation pattern were prominent in muscle fibres displaying large cores with intracellular deposition of cell debris (Figure 5.4E). In general, the staining signal in these fibres appeared stronger than in healthy fibres present in the same tissue section. In fibres of mice in the 18-24 months group, increased desmin staining signals are observed not only in transversal direction (at z-disks), but also in longitudinal direction, apparently in between the z-disks, parallel to the myofibrils (Figure 5.4F). In general, the position of these longitudinal lines of desmin staining was not directly linked to the position of the inclusions. In the most severely affected fibres, cross striation was completely lost and rearrangement of desmin in large clusters without any regular structure was observed (Figure 5.4F). In general, the relative intensity of desmin staining suggested that the total amount of desmin in the affected muscle cells was increased.

\section{For figure 5.4 see page 146}

Tissue content of desmin and titin

Assessment of titin by Western blotting revealed that the relative content of this cytoskeletal protein was comparable between control and AGLU animals at any age (findings not shown). Analysis of desmin content showed a gradual increase of this protein in muscles of AGLU- mice (Figure 5.5). At 6-10 months of age, relative desmin content did not differ between AGLU and control animals. At 12-16 months of age, however, the desmin content in most AGLU mice was doubled. In AGLU animals of 18 months and older, the muscle desmin content of raised significantly to approximately 4 times the amount in dorsal flexor muscle complex of control mice. Interestingly, the Western blotting of muscles of AGLU mice 12 months and older showed immunoreactive bands at a lower molecular mass than native desmin, indicating degradation of this cytoskeletal protein.

Figure 5.5: Western blots of the cytoskeletal protein desmin in dorsal flexor muscle extracts of 3 different AGLU- and age-matched control mice.

\section{AGLU. Control}

Age (months)

6-10 months

$12-16$ months
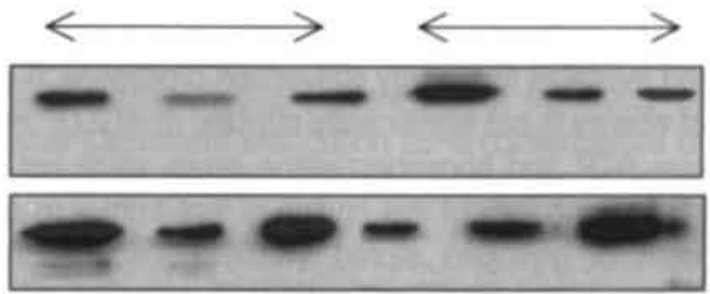

18-24 months

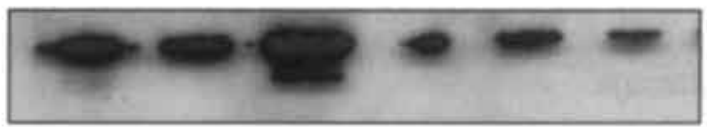




\section{Discussion}

Proper mechanical functioning of skeletal muscles heavily relies on the interplay between electrical, metabolic and contractile processes. Under normal conditions, these processes show a high degree of fine-tuning and are very well adjusted to the tasks to perform. In a variety of pathological states, however, mechanical muscle performance is impaired. This is especially the case in a number of muscle disorders of genetic origin, such as GSD II. The first reports on GSD II emphasised the fact that the muscle structure was severely disrupted in combination with deteriorated muscle function [1, 28]. Up till now it has not been possible to relate the extent of the changes in muscle cell structure to the degree of muscle dysfunction. In an earlier study we accurately assessed the muscle mechanical performance of AGLU mice in different stages of the pathology, exploring both isometric as isokinetic contractions (See Chapter 4).

Here, we describe the morphological and structural changes that take place in muscle cells of mice lacking acid 1-4 $\alpha$-glucosidase. In the present study, tissue of the same three groups of AGLU mice were included as previously used to assess muscle mechanical performance, i.e. at the age of 6-10 months, 12-16 months and 18-24 months. The muscular features were compared with those of age-matched wild type littermates.

\section{Glycogen storage}

Histological analysis revealed that in the skeletal muscles of AGLU mice lysosomal filling with glycogen reached its maximum before the animals reached the age of 6-10 months. This finding corroborates very well with earlier biochemical analysis of the diseased muscles, i.e. the muscle content of glycogen increased approximately 10 fold during the first 6 months of life in AGLU - mice, when compared to control, and levelled off thereafter (See Chapter 4).

Intra-lysosomal accumulation of glycogen is obviously caused by the lack of acid 1-4 $\alpha$ glucosidase activity, rendering the lysosome unable to digest glycogen taken up from the cytoplasmic compartment. One may speculate about the physiological significance of lysosomal uptake and digestion of the glucose polymer. It is can be envisaged that in the overall phagocytic activity of lysosomes, some cytoplasmic macromolecules such as glycogen are inadvertently engulfed and to get rid of this "by-catch" the glucose polymer has to be hydrolysed [29]. The hydrolytic product, glucose, is subsequently transported back into the cytoplasm and available for energy conversion processes. It is of interest to note that the generation of energy is not significantly affected in AGLU muscles, as we recently showed that tissue ATP and phosphocreatine levels were not different from age-matched controls [15]. The corollary of this finding is that from a metabolic point of view the enhanced amount of glycogen stored in the lysosomal compartment is inconsequential. However, this notion does not exclude a potential role of lysosomal glycogen accumulation in the sequel of events leading to impaired muscle contractile function and muscle cell damage. 
Large intracellular inclusions and lipofuscin deposition

Although the physico-chemical consequences of glycogen accumulation in lysosomes are incompletely understood, it is tempting to speculate that the digestive function of the largely swollen sub-cellular particles is severely impaired. This may be due, among others, to the inability to exert phagocytosis at a physiological relevant rate or to maintain the low intra-lysosomal pH required for hydrolysis of the engulfed material [ 30 . 32].

Irrespective of the precise mechanism, the outcome of the debilitated condition is most likely a cytoplasmic accumulation of intracellular debris and waste material in the affected muscle cell. The present findings are in line with this notion. At the age of 12-16 months, large areas, centrally localised in the muscle cell and filled with debris, became apparent in the AGLU mice. These features were even more pronounced at the age of 18-24 months, underlining the progressive nature of this pathological process. Intracellular accumulation of debris was found to be associated with the formation and precipitation of lipofuscin. Lipofuscin is a cell precipitate that may result from the incomplete digestion of macromolecules by lysosomes and, therefore, its intracellular deposition is generally considered as a sign of declining lysosomal activity in senescent cells $[18,33,34]$. The appearance of lipofuscin in muscle cells of AGLU mice at the adult age of $12-16$ months strongly suggests that lysosomal functioning in this mouse strain is already significantly impaired before they reach senescence. At advanced stages of the disease (18-24 months) deposition of lipofuscin and cellular debris was often found to be associated with complete loss of normal intra-cellular structure and disarray of contractile elements within the cytoplasmic compartment.

\section{Alterations in titin and desmin expression}

The cytoskeletal proteins titin and desmin are deemed important in the intracellular transmission of forces $[20-22,35]$. In our mouse model, alterations in the expression and/or spatial distribution of titin and desmin have been observed in progressed stages of the patho-physiology.

In an earlier paper, we hypothesised on possible alterations in the cytoskeleton as a result of the inclusions [15]. As the inclusions interrupt myofibrils and can not develop active force by themselves, they are bound to substantially influence the intracellular transmission of longitudinal forces. Interruptions in contracting myofibrils will lead to an increase in longitudinal force in the myofibrils adjacent to the inclusion [15]. The observed local increases in titin content in the myofibrils bordering inclusions might prevent excessive sarcomere elongation as a consequence of the increased stress. In this way, the localised increases in titin might aid in maintaining longitudinal force transmission capability of a muscle that is structurally disarranged. It should be emphasised that in some muscle cells of the 18-24 month group the titin signal almost completely disappeared. The functional consequence is most likely a completely loss of the contractile function of the affected fibre. Our observation of titin disappearing in 
affected muscle cells of AGLU mice corroborates well with findings in several other studies of damaged or diseased muscle cells [36-38].

Although increased levels of desmin are commonly regarded as pathological [39-41], and longitudinal localisation of desmin has been earlier reported in dystrophic muscles [36], we originally felt that the increases of desmin content as observed in tissue sections of 12-16 month old AGLU animals is most likely an intrinsic measure to preserve muscle function [15]. Desmin is normally expressed in z-disks, leading to the characteristic transversal staining pattern [42]. The physiological function of desmin is aligning adjacent z-disks, enabling lateral force transmission. We hypothesised that the interruptions of myofibrils by the non-contractile inclusions could cause an increased expression of desmin in the z-disks in an area around the tip of an inclusion [15]. As a consequence, forces generated by contracting, interrupted myofibrils will be transmitted in a lateral direction to bypass the interruption [15]. In contrast to our expectations, no specific increase of z-line desmin staining was found at the tip of an inclusion. However, longitudinal patterns of desmin staining were found scattered through the sarcoplasm. The precise impact of the altered expression and deposition of desmin remains to be elucidated

In later stages, cytoskeletal structure is completely lost in the some of the affected fibres, intense staining of disorganised desmin is observed and the titin staining diminishes. The overall content of desmin in muscle of AGLU mice has then increased fourfold. Considering the disorganised distribution in some muscle cells, it is likely that a certain part of the desmin has lost its functional significance. This notion is strengthened by the observations of degradation of desmin in Western blotting.

In summary, we here describe the changes in muscle cell structure during the progressive patho-physiology in the AGLU mouse, serving as a model for of GSD II. Changes in gross sarcoplasmatic features are described, initially as focal spots of glycogen, in later stages as large intracellular inclusions of cellular debris. The fact that these large inclusions contain lipofuscin suggests a decreased function of the lysosomal system. Adaptations of cytoskeletal proteins occur in affected muscle fibres. In case of titin this adaptation most likely aimed to preserve mechanical function of the myocyte. In progressed stages of the disease, a number of muscle cells starts to lose their organised intracellular structure and, hence, were most likely no longer functional.

\section{Acknowledgments}

This study was financed by the Prinses Beatrix Fonds and by the foundation 'De drie Lichten' in The Netherlands. Dr. A.J.J. Reuser is gratefully acknowledged for his useful discussions, as well as for providing us with both the AGLU- mice and the primer combination. 


\section{References}

1 Pompe, J.C. (1932) Ned Tijdsch Geneesk 76, 304-311.

2 Hers, H.G. (1963) Biochem J 86, 11-16.

3 Reuser, A.J.J., M.A. Kroos, M.M.P. Hermans, A.G.A. Bijvoet, M.P. Verbeet, O.P. Van Diggelen, W.J. Kleijer, A.T. Van der Ploeg. (1995) Muscle Nerve, Suppl 3, S61-S69.

4 Ausems, M.G., Kroos, M.A., Van der Kraan, M., Smeitink, J.A., Kleijer, W.J., Ploos van Amstel, H.K. and Reuser, A.J.J. (1996) Clin Genet 49, 325-328.

Huie, M.L., S. Tsujino, S. Sklower Brooks, A. Engel, E. Elias, D.T. Bonthron, C. Bessley, S. Shanske, S. DiMauro, Y.I. Goto, R. Hirschhom. (1998) Biochem Biophys, Res Comm 244, 921-927.

Loonen, M.C.B., Busch, H.F.M., Koster, J.F., Martin, J.J., Niermeijer, M.F., Schram, A.W., Brouer-Kelder, B., Mekes, W., Slee, R.G., and Tager, J.M. (1981) Neurology 31, 1209-1216.

7 Raben, N., Nagaraju, K., Lee, E. and Plotz, P. (2000) Neuromuscul Disord 10, 283-291.

8 Reuser, A.J.J. (2002) GSD II Mutation Database.

9 Wokke, J.H., Ausems, M.G., Van den Boogaard, M.J., Ippel, E.F., Van Diggelene, O., Kroos, M.A., Boer, M., Jennekens, F.G., Reuser, A.J.J. and Ploos-van Amstel, H.K. (1995) Ann Neurol 38, 450-454.

10 Felice, K.J., Alessi, A.G. and Grunnet, M.L. (1995) Medicine 74, 131-135.

11 Matsuishi, T., M. Yoshino, K. Terawasa, I. Nonaka. (1984) Arch. Neurology 41, 47-52.

12 Ausems, M.G., Verbiest, J., Hermans, M.P., Kroos, M.A., Beemer, F.A., Wokke, J.H., Sandkuijl, L.A., Reuser, A.J.J. and Van der Ploeg. A.T. (1999) Eur J Hum Genet 7, 713-716.

Hers, H.G. and De Barsy, T. (1973) in Lysosomes and storage diseases (Hers, H.G. and Van Hoof, F., eds.), pp. 197 -217, Academic Press, New York.

14 Hirschhorn, R. (1995) in The Metabolic and Molecular Basis of Inherited Disease (Scriver, C.R., Beaudet, A.L., Sly, W.S. and Valle, D., eds.), pp. 2443 2464, McGraw-Hill, New York.

Hesselink, R.P., Gorselink, M., Schaart, G., Wagenmakers, A.J.M., Kamphoven, J., Reuser, A.J.J., Van der Vusse, G.J. and Drost, M.R. (2002) Muscle Nerve 25, 873-883. Griffin, J.L. (1984) Virchows Arch B Cell Pathol Incl Mol Pathol 45, 23-36.

17 Bijvoet, A.G.A., E.H.M. Van der Kamp, M.A. Kroos, J-H. Ding, B.Z. Yang, P. Visser, C.E. Bakker, M.P. Verbeet, B.A. Oostra, A.J.J. Reuser, and Van der Ploeg, A.T. (1998) Hum Mol Gen 7, 53-62. Brunk, U. and Terman, A. (2002) Free Radic Biol Med 33, 611.

19 Gordon, A.M., Homsher, E. and Regnier, M. (2000) Physiol Rev 80, 853-924. 
20 Monti, R.J., Roy, R.R., Hodgson, J.A. and Edgerton, V.R. (1999) J Biomech 32 , 371-380.

21 Patel, T.J. and Lieber, R.L. (1997) Exerc Sport Sci Rev 25, 321-363.

22 Labeit, S., Kolmerer, B. and Linke, W.A. (1997) Circ Res 80, 290-294.

23 Li, Z., Mericskay, M., Agbulut, O., Butler-Browne, G., Carlsson, L., Thornell, L.E., Babinet, C. and Paulin, D. (1997) J Cell Biol 139, 129-144.

24 De Jonge, A.J., De Smit, S., Kroos, M.A. and Reuser, A.J.J. (1985) Hum Genet 69, 32-38.

25 Schaart, G., Viebahn, C., Langmann, W. and Ramaekers, F. (1989) Development 107, 585-596.

26 Laemmli, U.K. (1970) Nature 227, 680-685.

27 Junqueira, L.C., Carneiro, J. and Long, J.A. (1986) Basic Histology, Vol. 5, Lange Medical Publications, Los Altos.

28 Putschar, W. (1932) Beitr Pathol Anat 90, 222- 232.

29 Hesselink, R.P., Wagenmakers, A.J.M., Drost, M.R. and Van der Vusse, G.J. (2003) Biochim Biophys Acta 1637, 164-170.

30 Luiken, J.J., Aerts, J.M. and Meijer, A.J. (1996) Eur J Biochem 235, 564-73.

31 Blommaart, E.F., Luiken, J.J. and Meijer, A.J. (1997) Contrib Nephrol 121, 101 108.

32 Van Dyke, R.W. (1996) Subcell Biochem 27, 331-360.

33 Cuervo, A.M. and Dice, J.F. (1998) Front Biosci 3, D25-D43.

34 Zhang, Y. and Herman, B. (2002) Mech Ageing Dev 123, 245-260.

35 Galou, M., Gao, J., Humbert, J., Mericskay, M., Li, Z., Paulin, D. and Vicart, P. (1997) Biol Cell 89, 85-97,

36 Debus, E., Weber, K. and Osborn, M. (1983) EMBO J 2, 2305-2312.

37 Fidzianska, A., Drac, H. and Kaminska, A.M. (1999) Acta Neuropathol (Berl) 97, 509-514.

38 Goebel, H.H. (1995) Muscle Nerve 18, 1306-1320.

39 Helliwell, T.R., Green, A.R., Green, A. and Edwards, R.H. (1994) J Neurol Sci 124, 174-187.

40 Cullen, M.J., Fulthorpe, J.J. and Harris, J.B. (1992) Acta Neuropathol 83, 158169.

41 Durrant, L.A., Archer, C.W., Benjamin, M. and Ralphs, J.R. (1999) J Anat 194, 343-353.

42 Van der Ven, P.F., Jap, P.H., Ter Laak, H.J., Nonaka, I., Barth, P.G., Sengers, R.C., Stadhouders, A.M. and Ramaekers, F.C. (1995) J Neurol Sci 129, 199213.

43 Ausma, J., Wijfels, M., van Eys, G., Koide, M., Ramaekers, F., Allessie, M. and Borgers, M. (1997) Am J Pathol 151, 985-997. 
Chapter 6

\section{Effects of non-contractile inclusions on mechanical performance} of skeletal muscle

Maarten R. Drost, Reinout P. Hesselink, Cees W. Oomens, Ger J. van der Vusse

submitted to:

Journal of Biomechanics 


\section{Abstract}

Glycogen storage disease II is an inherited, progressive muscular disease in which the lack of functional acid 1-4 $\alpha$-glucosidase results in the lysosomal accumulation of glycogen. In the present study, we examine the effect of these non-contractile inclusions on the mechanical performance of skeletal muscle. To this end, force developed in an isometrically contracting slice of a muscle was calculated with a finite element model. Force was calculated at several inclusion densities and distributions and compared to muscle lacking inclusions. Furthermore, ankle dorsal flexor torque was measured in situ of $\alpha$-glucosidase null mice of 6 months of age and unaffected littermates as was inclusion density in the dorsal flexor muscles.

The calculated force loss was shown to be almost exclusively dependent on the inclusion density and less on the type of inclusion distribution. The force loss predicted by the model $(6 \%)$ on the basis of measured inclusion density $(3.3 \%)$ corresponded to the loss in mass-normalised strength in these mice measured in situ (7\%).

Therefore, we conclude that the mechanical interaction between the non-contractile inclusions and the nearby myofibrils is a key factor in the loss of force per unit muscle mass during early stages of GSD II in mice. As glycogen accumulation reaches higher levels in humans, it is highly probable that the impact of this mechanical interaction is even more severe in human skeletal muscle. 


\section{Introduction}

A variety of muscular diseases is characterised by non-contractile inclusions in the affected muscle cells. A typical example is glycogen storage disease II (GSD II), in which the activity of the lysosomal enzyme acid 1-4 $\alpha$-glucosidase (EC 3.2.1.20) is decreased or lacking [1]. This results in a progressive accumulation of glycogen in the lysosomes and a concomitant decline of muscle mechanical performance [2]. In the clinical setting. the progressive muscle insufficiency results in serious cardio-pulmonary complications. These aberrations lead to early death in the infantile and juvenile forms of this disease [3].

Recently, a mouse model has been generated for GSD II in which an exon deletion has been introduced that has similar functional effects as the most frequent mutations causing GSD II in patients of Caucasian origin. This resulted in $\alpha$-glucosidase null mice (AGLU') almost completely lacking the functional enzyme [4]. This mouse model offers the opportunity to correlate biochemical and histological data with muscle performance. A recently developed murine dynamometer allows us to accurately measure produced torque during isometric contractions of ankle dorsal flexors [5]. With this technique we showed that AGLU mice of 18 months of age with overt clinical symptoms developed $50 \%$ lower dorsal flexor muscle strength than age matched controls [6]. Since only approximately one third of this decline could be explained by a decline in muscle mass. a substantial part is most likely caused by intrinsic alterations in the muscle cell. Hesselink and co-workers [6] also found that lower energy status or content of contractile proteins did not cause this force loss per unit mass. They therefore hypothesised, that a decline in the relative strength is caused by a direct mechanical effect of the lysosomal clusters of glycogen on contractile performance. In contrast to sarcomeres, these inclusions are unable to actively generate force. As a consequence, sarcomeres near these inclusions will not uniformly deform during contraction, resulting in in-homogeneities in sarcomere length in the affected muscle and, hence, decreases in muscle mechanical performance. Unfortunately, the model used by Hesselink and colleagues did not allow for estimating of the quantitative importance of the intracellular inclusions in the progressive loss of force in GSD II [6].

The aim of the present study is to quantify the effect of non-contractile inclusions on force generation as it occurs in GSDII. To this end, we used a recently described Finite Element model of contracting skeletal muscle $[7,8]$ to assess the effect of both the density and the spatial distribution of non-contractile inclusions on muscular mechanical performance. Strains were calculated to quantify the in-homogeneities in sarcomere length near the inclusion. Stresses were assessed to quantify force loss. In addition to the model calculations, muscle strength and inclusion density were measured in situ in intact $\mathrm{AGLU}^{-}$and age matched control mice. 


\section{Material and methods}

\section{Theoretical model}

Stresses and strains were calculated with the finite element model recently described in full detail by Oomens and co-workers $[7,8]$. In the present study, we only considered the plateau phase of a fully activated, isometrically contracting muscle section. Local differences in stress and strain are bound to develop due to the presence of noncontractile inclusions in such muscle sections.

The muscle obeys the balance of momentum. Neglecting body forces and inertial forces, this balance can be given as:

$$
\vec{\nabla} \cdot \underline{\sigma}=\overrightarrow{0}
$$

$\underline{\sigma}$ is the Cauchy stress tensor. It is assumed that muscle tissue behaves like an incompressible material, implying the use of the following constraint:

$$
\operatorname{det}(\underline{F})=1
$$

$F$ represents the deformation gradient tensor, a mapping of the un-deformed configuration on the deformed configuration, thereby defining the local strains.

The local stress in the contractile tissue is described as the superposition of the active stress $\sigma_{a}$ in the local averaged fibre direction and the passive stress $\sigma_{p}$ caused by the deformation of the tissue:

$$
\underline{\sigma}=\underline{\sigma}_{p}+\sigma_{a} \vec{e}_{f} \vec{e}_{f}
$$

where $\vec{e}$, denotes the local fibre direction.

The contractile behaviour is described with a two state Huxley equation, introduced by Huxley [9] and modified by Zahalak [10]. Huxley claimed that the probability of the presence of a cross bridge of dimensionless length $\xi$ at a certain moment $t$ equals $n(\xi, t)$. If a large number of cross-bridges is considered, $n(\xi, t)$ can be interpreted as a distribution function representing the fraction of attached cross-bridges with displacement (bond length) $\xi$ at time $t$. The distribution function satisfies the equation:

$$
\frac{\partial n(\xi, t)}{\partial t}-u(t) \frac{\partial n(\xi, t)}{\partial \xi}=r(t) f(\xi)[\alpha-n(\xi, t)]-g(\xi) n(\xi, t)
$$

In this equation $u(t)$ represents the scaled shortening velocity of a half sarcomere, $f(\xi)$ the attachment rate, $g(\xi)$ the detachment rate, $\alpha$ is an overlap factor and $r(t)$ an activation factor, depending on the concentration of free calcium ions in the myofibrillar space. 
The active Cauchy stress $\sigma_{a}$ generated by all cross bridges in a slice of half sarcomeres, i.e. the basic contraction unit, can be shown to equal [11]:

$$
\sigma_{a}(t)=\frac{c_{a} l_{s}}{l_{s, o p t}} Q_{1}(t)
$$

with $Q_{1}$ the first moment of the distribution function of the attached cross bridges, $l_{s}$ is actual length of a sarcomere and $\mathrm{l}_{\text {s.opt }}$ optimal length of a sarcomere.

The overlap factor $\alpha$ (length-force relationship) is described as [12]:

$$
\begin{aligned}
& \alpha(L)=1-6.25(L-1)^{2} \quad L \leq 1 \\
& \alpha(L)=1-1.25(L-1) \quad L>1
\end{aligned}
$$

with $L=l_{y} l_{\text {s.opt. }}$. All sarcomeres were set at optimal length before activation.

The passive tissue stress for both the passive contractile tissue and the non-contractile inclusion is described with an incompressible neo-Hookean model:

$$
\underline{\sigma}_{p}=-p \underline{I}+G(\underline{B}-\underline{I})
$$

with $p$ the pressure, $\underline{l}$ the unit tensor, $\underline{B}$ the Finger tensor $\underline{F} \underline{F}^{\top}$, and $G$ the shear modulus.

The Huxley equation is solved by using the distributed moments approach as described by Zahalak, 1981. By approximating the disfribution function $n(\xi, t)$ by a Gaussian distribution, the partial differential equation can be transformed into a set of three ordinary differential equations for the moments, that can easily be solved numerically. The finite element method was used to solve the field equations by putting them in a weak form, by multiplying the momentum equation and the incompressibility condition with weighting functions and by partial integration. An updated Lagrange procedure is used. A Newton-Raphson procedure was used to linearise the equations. Because of the active stress, the equations are time dependent. In the present implementation each load step represents a time step. By prescribing a stimulation frequency as a function of time, and by solving the equations for the Calcium activation, the activation function $r(t)$ can be derived. Now in each point in time and at each integration point, with known $r(t)$, $\lambda\left(t_{i}\right)$ and $u\left(t_{t}\right)$ and the moments $Q_{\lambda}\left(t_{i}\right)$, the moments $Q_{\lambda}\left(t_{i+1}\right)$ can be calculated by either an Euler explicit scheme or a two or four step Runge Kutta time integration. The active stress is derived from the first moment. All simulations in the sequel were performed by means of a quadrilateral Crouzeix-Raviart element. This type of element has a second order interpolation field for the displacements and a first order discontinuous interpolation for the pressure and satisfies the Babuska-Brezzi condition. 
The parameter values used in the simulations are given in Tables 6.1 and 6.2. The effect of the parameters in table 1 is important in temporal phenomena, but since they also exert an effect on the amplitude of the tetanic plateau, the values are shown in this paper as well. Simulations were performed at $125 \mathrm{~Hz}$ stimulation frequency and a duration of $100 \mathrm{~ms}$, starting at $\mathrm{t}=0$.

Table 6.1: Material parameters used in the simulations: $c_{a}$ active stress modulus; $f_{1}$ Huxley attachment parameter; $g_{1}, g_{2} . g_{3}$ Huxley detachment parameters; (a) [25], (b) [10].

\begin{tabular}{l|l|l|l|l}
\hline $\begin{array}{l}\mathrm{Ca}_{3}[\mathrm{kPa}] \\
\text { (a) }\end{array}$ & $\begin{array}{l}\mathrm{f}_{1}\left[\mathrm{~s}^{-1}\right] \\
(\mathrm{a})\end{array}$ & $\begin{array}{l}\mathrm{g}_{1}\left[\mathrm{~s}^{-1}\right] \\
\text { (b) }\end{array}$ & $\begin{array}{l}\mathrm{g}_{2}\left[\mathrm{~s}^{-1}\right] \\
\text { (b) }\end{array}$ & $\begin{array}{l}\mathrm{g}_{3}\left[\mathrm{~s}^{-1}\right] \\
\text { (b) }\end{array}$ \\
\hline 250 & 163 & 64 & 200 & 30 \\
\hline
\end{tabular}

Table 6.2: Shear modulus $(G)$ used in the simulations. Values in the row "local stresses and strains' were used to calculate local stresses and strains as well as force loss. However one condition (regular, width $=2 \mu \mathrm{m}$ ) could not be simulated successfully. Values in the row 'inclusion stiffness variation' were used to determine the influence of inclusion shear stiffness on the force loss. In these simulations, a higher value of $G$ for the winterestits tissue was used for reasons of numerical stability. (a) based on Myers [26] and Bosboom [27], see also Discussion.

\begin{tabular}{l|l|l}
\hline & $G_{\text {contraction sseut }}[\mathrm{MPa}]$ & $\begin{array}{l}G_{\text {machson }} \\
{[\mathrm{MPa}]}\end{array}$ \\
\hline Local stresses and strains & $0.3(\mathrm{a})$ & 0.1 \\
\hline Inclusion stiffness variation & 1 & $0.01,0.1,1$ \\
\hline
\end{tabular}

The model consisted of 3-D elements, but the geometry was in essence 2-D: a rectangular slice of 1 element thickness ( 3 nodes). No external stress was exerted on the upper surface of the slice, i.e. the height of the muscle slice could vary. The four boundaries were forced to remain straight. By doing so, symmetry axes were provided in such a way, that the calculation area is representative for a muscle fibre (Figure 6.1A and $6.1 \mathrm{~B}$ ). All myofibrils were initially assumed to lie parallel in the $x$-(longitudinal) direction, but their direction could change with deformation. The total longitudinal force in this calculation area was assumed to be proportional to the force at the tendons of the muscle. The reference geometry consisted of a rectangular slice of contractile tissue of 6 * $10 \mu \mathrm{m}^{2}$ without non-contractile inclusions. 
Figure 6.1: Part of a muscle fibre with a regular (A) and a shifted (B) distribution of noncontractile inclusions (black ellipses). The calculation area in each geometry is indicated with a rectangle. Calculation areas with un-deformed finite element mesh of in regular and shifted distribution are shown in (C) and (D) respectively. The boundary of the noncontractile inclusion is denoted with a thick line. Mesh size was roughly adjusted to expected deformation gradients, i.e. smaller element size near the inclusion. Inclusion density was varied by variation of the area of the calculation area by varying length of the calculation area from 8-15 $\mu \mathrm{m}$ (x-direction) and width from 2-6 $\mu \mathrm{m}$ (y-direction), while keeping the area of the inclusion constant $\left(\pi / 2 \mu \mathrm{m}^{2}\right)$. In the figures shown, inclusion density equals $2.6 \%$ in A, C and $5.2 \%$ in B, D. Meaningful comparisons between shifted and regular geometries were made at equal inclusion densities. Muscle fibre direction was horizontal in the un-deformed mesh.
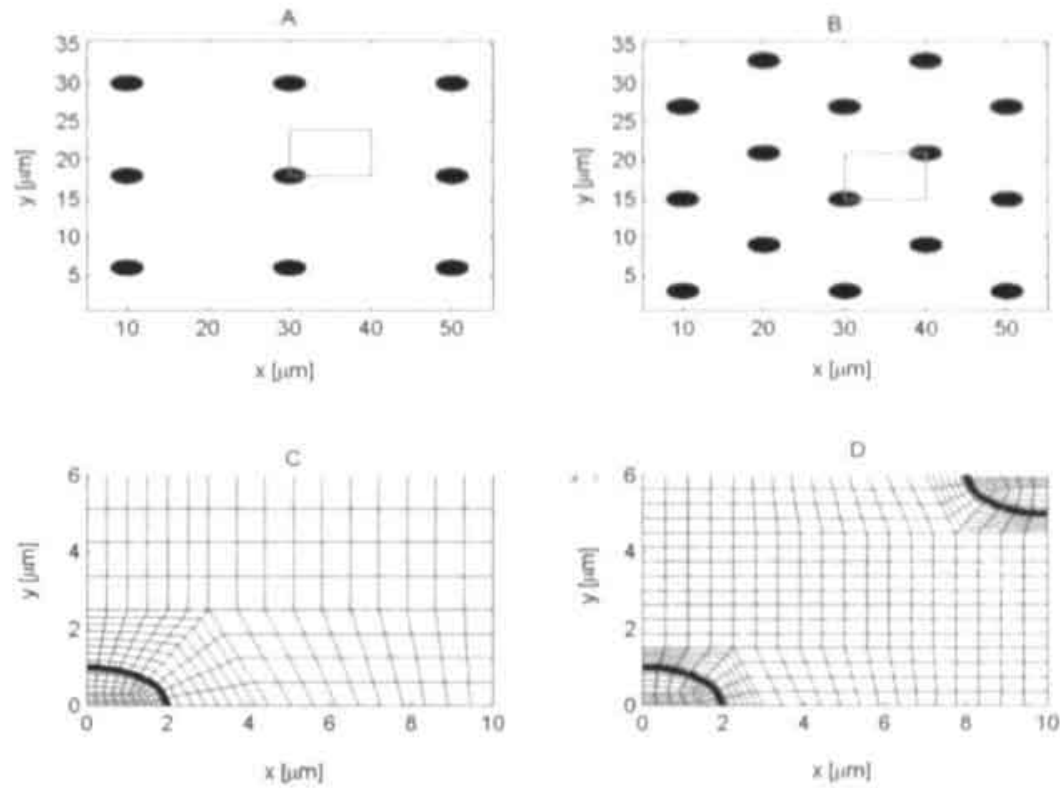

Two geometries with non-contractile inclusions were studied: regular and shifted. A finite element mesh of a regular geometry is shown in Figure 6.1C. The geometry is considered to be part of a muscle fibre with a homogeneous distribution of inclusions as shown in Figure 6.1A. The shape of the non-contractile inclusion was assumed to be an ellipsoid with axes lengths of 4 and $2 \mu \mathrm{m}$, roughly based on the geometry of the glycogen filled lysosomes as assessed in tissue slides of 6 month old AGLU mice with the use of confocal microscopy (data not shown) In a shifted geometry (Figure 6.1D) the 
inclusions alternated (as indicated in Figure 6.1B). The size of the calculation areas was varied (see later).

In total 50 time steps of 2 ms were calculated, corresponding with stimulation of the muscle lasting $100 \mathrm{~ms}$. All findings presented here are the results of calculations at the last time step. These data represent the plateau phase of the tetanus, as $99 \%$ of the maximal force was reached at $55 \mathrm{~ms}$. Inclusion density was expressed as percentage of the calculation area. The effect of inclusion density on the (longitudinal) force was quantified by varying the size of the calculation areas. The length was varied between 4 $\mu \mathrm{m}$ (regular) or $6 \mu \mathrm{m}$ (shifted) and $15 \mu \mathrm{m}$. The width values (y-direction) equalled $2 \mu \mathrm{m}$, $4 \mu \mathrm{m}$ and $6 \mu \mathrm{m}$. This resulted in inclusion densities between $1.7 \%$ and $20 \%$ in a regular geometry; and $3.4 \%$ and $26.2 \%$ in a shifted geometry. In some occasions very large values for length ( 50 and $250 \mu \mathrm{m}$ ) were used to simulate very low inclusion densities.

The longitudinal force was calculated as the integral of the stress in the $\mathrm{x}$-direction over the surface of the right boundary. The force loss (FL) was calculated as:

$$
F L=\frac{\left(F_{n f}-F_{i m i l}\right)}{F_{n f}} * 100 \%
$$

with $F_{\text {ref: }}$ longitudinal force without inclusion (reference value) and $F_{\text {mcc: }}$ longitudinal force with inclusion.

\section{In situ measurements}

Measurements were performed on 4 AGLU mice 6 months of age, lacking acid $\alpha$ glucosidase activity [13]. Four wild type littermates served as age-matched control. All animals were 10 times backcrossed on their original strain C57BI. All experimental procedures were approved by the Institutional Animal Care and Use Committee of Maastricht University and complied with the principles of proper laboratory animal care. In general, the preparation and stimulation procedures were similar to that described earlier by Gorselink and co-workers [5]. Mice were anaesthetised with 1.5 to $2.0 \%$ halothane (Fluothane, Zeneca, Ridderkerk, The Netherlands), mixed with $\mathrm{O}_{2}$ and $\mathrm{N}_{2} \mathrm{O}$ (2:1) and delivered via a facemask. The mouse was attached via the hip to a thermostatic platform to keep the mouse at a constant temperature of $37^{\circ} \mathrm{C}$. The foot was cast and rigidly connected to a torque transducer. A bipolar hook electrode was placed around the peroneal nerve for stimulation of the dorsal flexor complex (tibialis anterior and extensor digitorum longus muscles via a pulse generator (HSE 215/IZ, Freiburg, Germany). The torque around the ankle was measured at $1000 \mathrm{~Hz}$. All experiments were performed at optimal ankle angle, supramaximal current, and a stimulation frequency of $125 \mathrm{~Hz}$.

After the stimulation protocol, the dorsal flexor complexes of both legs were dissected from the bone to the visible start of the distal tendon. Mice were subsequently sacrificed by cervical dislocation. Contralateral dorsal flexor complexes were used for biochemical 
analysis. Muscle tissue was split parallel to the fibre direction. Half of the tissue was used for assessment of glycogen as described by Passonneau and Lauderdale [14]. Other parts of the muscles were stored at $-80^{\circ}$ for future studies. Glycogen analysis was modified for automated analysis using an automated centrifugal spectrophotometer (COBAS FARA; Roche, Basel, Switzerland).

\section{Results}

\section{Finite Element Model}

As expected, the reference geometry, i.e. without inclusion, showed zero strain during the plateau phase of an isometric contraction during supramaximal stimulation (data not shown). Figure $6.2 \mathrm{~A}$ shows the longitudinal strains occurring in a regular geometry at an inclusion density of $2.6 \%$ under the same conditions. The inclusion elongated by $16 \%$. Longitudinal shortening occurred in front of the inclusion (bluish); near the tip of the inclusion the muscle tissue was shortened by $10 \%$. The shortening equalled $2 \%$ at the lower right corner. Muscle tissue was elongated by $2 \%$ at upper right corner. A large elongation occurred to the side of the inclusion, indicated by red and maximally $20 \%$. This elongation rapidly decreased in transverse direction; it equalled maximally $10 \%$ at $y=2 \mu \mathrm{m}$, i.e. $1 \mu \mathrm{m}$ lateral from the inclusion. These findings indicate an inhomogeneous strain distribution during overall isometric contraction in muscle fibres with intracellular non-contractile inclusions.

\section{For figure 6.2 see page 146/ 147}

The reference geometry, i.e. without inclusion, showed a homogeneous stress of 223 $\mathrm{kPa}$. In Figure $6.2 \mathrm{~B}$ the longitudinal stress occurring in a regular geometry at an inclusion density of $2.6 \%$ is depicted. The longitudinal stress was higher than $223 \mathrm{kPa}$ to the side of the inclusion (red and yellow). It was decreased in front of the inclusion (bluish and dark green) with a minimum value at the tip of the inclusion (near $50 \mathrm{kPa}$ ). The stress rapidly increased in front of the tip, e.g., a value of $150 \mathrm{kPa}$ was reached at $x=4 \mu \mathrm{m}$, approximately $2 \mu \mathrm{m}$ from the tip. The longitudinal force was calculated as the integral of the stress in the x-direction over the surface of the right boundary. On basis of these calculations, the force loss (relative to the reference geometry) was found to be $4.9 \%$.

Figure 6.3 shows the relation between inclusion density and force loss. As expected, force loss increased with increasing density. At lower densities the force loss was approximately proportional to the inclusion density. The relationship between force loss and inclusion density appeared to be slightly curvilinear. The figure shows that force loss was mainly dependent on the inclusion density, with only marginal effects of the variation in geometry (shifted and regular distribution) and width of the calculation area $(2,4$ or 6 
$\mu \mathrm{m})$, when compared at equal inclusion density. In the simulations shown in Figure 6.4, it was verified that force loss approximated zero at very low inclusion densities.

Figure 6.3: Force loss as a function of inclusion density. Inclusion density was varied by varying width and length of the calculation area, while inclusion size was maintained constant. Each symbol represents an individual simulation. Lines connect simulations with equal width. Solid lines indicate a regular geometry, broken lines a shifted geometry.

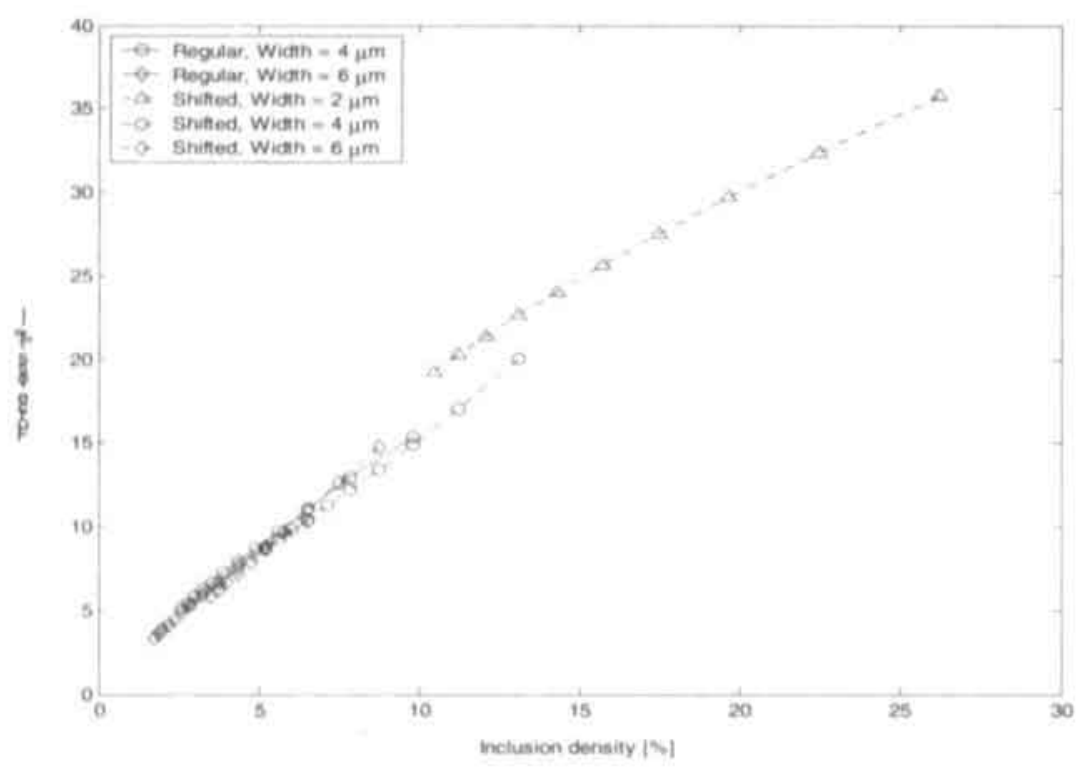

To determine the effect of inclusion stiffness on force loss, simulations were performed with three values of the inclusion shear modulus. A high value of the inclusion shear modulus $\left(G_{\text {nccusion }}=1 \mathrm{MPa}\right)$ resulted a moderate increase in force loss with increasing inclusion density (Figure 3). The relation between force loss and inclusion density at lower values of $\mathrm{G}_{\text {molusion }}(10 \mathrm{kPa}$ and $100 \mathrm{kPa}$ ) showed a much steeper relation. Although the latter two values of $G_{\text {nchusin }}$ differ by a factor of 10 , the force loss at equal inclusion density differed only by $10 \%$. It could therefore be concluded that at values of $G_{\text {motsion }}$ lower than $100 \mathrm{kPa}$ the value of $\mathrm{G}$ has negligible effect on the calculated force loss. 
Figure 6.4: Force loss as a function of inclusion density for different values of inclusion shear stiffness (triangles denotes $G_{\text {nocusion }}=10 \mathrm{kPa}$, circles $\mathrm{G}_{\text {nccusion }}=100 \mathrm{kPa}$ and diamonds $\mathrm{G}_{\text {ncluion }}=1 \mathrm{MPa}$ ). $\mathrm{G}_{\text {mucie }}$ equaled $1 \mathrm{MPa}$ in these simulations. Inclusion density was varied by varying length of the calculation area.

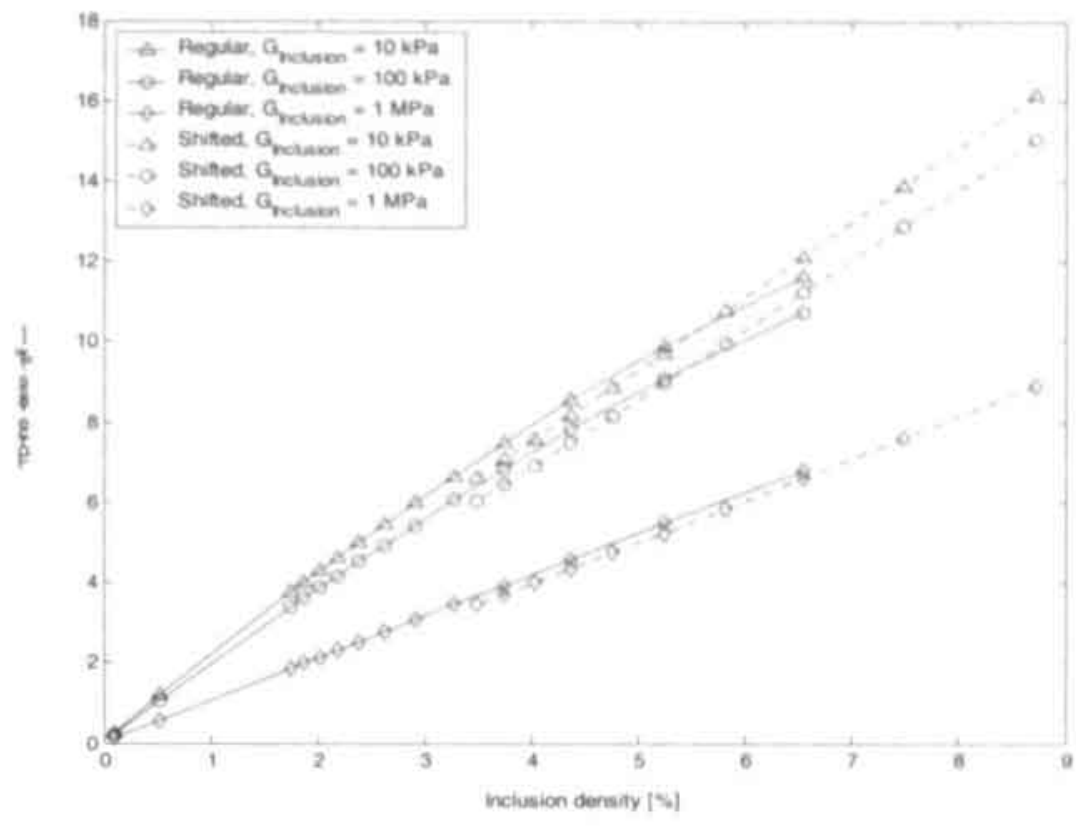

In situ measurements

On the average, isometric torque of the dorsal flexors in intact AGLU mice showed a $7 \%$ decline relative to age-matched controls (Table 6.3). The relative glycogen content amounted to $5.5 \pm 0.3 \%$ (dry glycogen mass per unit dry muscle mass) in AGLU mice. In contrast, in age matched control mice the relative glycogen content was found to be only $0.16 \pm 0.02 \%$.

Table 6.3: Relative isometric tetanic torque and chemically measured glycogen density (dry weight glycogen per unit dry weight muscle) of dorsal flexor complexes of 4 AGLUt. mice. Torque is relative to mean of 4 littermate controls.

\begin{tabular}{l|l}
\hline Normalised torque (\%) & $93 \pm 6$ \\
\hline Glycogen density (\%) & $5.5 \pm 0.3$ \\
\hline
\end{tabular}




\section{Discussion}

Loss of muscle force due to non-contractile inclusions

The main goal of the present study was to estimate the quantitative effect of noncontractile sarcoplasmic inclusions on the loss of muscle force as observed in storage diseases such as GSD II. The present numerical model enabled us to quantify the isometric performance of skeletal muscle as a function of both the density and distribution of sarcoplasmic inclusions. Since the dry/wet ratio of glycogen equals 0.33 [15], and the dry/wet ratio of murine dorsal flexor muscle equals 0.20 (unpublished results), the wet glycogen density (wet mass glycogen per unit wet muscle) as measured in the dorsal flexor muscles of the intact animal equalled $3.3 \%$. The assumption that the wet glycogen density is equivalent to the inclusion density was supported by planimetric assessment of glycogen density in tissue sections of 6-month-old AGLU* mice. In that analysis, the density of lysosomal accumulated glycogen was found to approximate $3 \%$ of the cell surface (Chapter 5). Using the value of wet glycogen density in the simulations, it was found that the force loss due to inclusion density amounted to approximately $6 \%$. The force loss measured in muscles of six month old mice was found to be in the order of $7 \%$ (Chapter 4). This good match between physiological measurements and the present simulations strongly suggests that non-contractile inclusions are the major cause of the loss of force in the affected muscles in the first stage of the disease. In the original model of force loss due to non-contractile inclusions [6], it was hypothesised that the myofibrils just lateral to the inclusion elongate lateral to the inclusion and shorten in front of the inclusion, while myofibrils interrupted by the inclusion do shorten. In the present simulations, interrupted myofibrils showed a large shortening, with a maximum near the tip of the inclusion. The non-interrupted myofibrils just lateral to the inclusion show a large elongation lateral to the inclusion, but only a minor elongation in front of it. With increasing inclusion density the calculation area decreased in size. This resulted in greater in-homogeneities in strain (and stress) at the boundaries. Because the boundaries of the calculation area were symmetry-axes (see Figure 6.1) this was considered to be a valid way to calculate the effect of inclusion density on muscle mechanical performance.

\section{Critiques on the model}

The spatial distribution of the inclusions was varied in two ways. First, two distributions were used: regular and shifted. Additionally, inclusion densities were obtained by several combinations of length and width of the calculation area. Wider areas lead to trains of inclusions at small longitudinal distances with more non-interrupted myofibrils in between. More narrow areas lead to the opposite. Longitudinal trains of inclusions are indeed present in affected muscle cells (e.g., Bijvoet [16] and Hesselink [6]). However, the spatial distribution of the inclusions is much more regular in the model geometry than in the affected muscle cells. As the force loss was shown to be almost exclusively dependent on the inclusion density and less on the type of distribution, it was felt that the degree of over-regularity as used in the present model, exerted only a minor effect on 
the calculated force loss. All modelled cytoplasmic inclusions were of the same size $\left(4^{*} 2\right.$ $\mu \mathrm{m})$. This size is assumed to be a fair approximation of average size of glycogen filled lysosomes, as verified using confocal microscopy and electron microscopic pictures (data not shown). In order to assess the effect of inclusion size on force loss, one simulation with an inclusion with axis lengths of 5 and $50 \mu \mathrm{m}$ was performed. The force loss was shown to be equal to the force loss with a small inclusion when compared at equal inclusion density (data not shown). It was therefore concluded that inclusion density, rather than inclusion size or inclusion distribution, is the most prominent factor in force loss due to non-contractile inclusions.

Parameter variation showed that the shear stiffness of the inclusion ( $\left.G_{\text {motuson }}\right)$ has a substantial influence on the calculated force loss (Figure 6.4). At values of $G_{\text {mctusion }}$ less than $0.1 \mathrm{MPa}$, force loss showed only a minor dependency on shear stiffness. With increasing values of shear stiffness the force loss decreased: a very stiff inclusion (5 $\mathrm{MPa}$ ) lead to minor loss of force (data not shown). Unfortunately, values for the shear stiffness of glycogen inclusions are not available in the literature. Two lines of reasoning however, can be followed to estimate the inclusion shear stiffness. First, electron microscopic pictures of resting muscles of AGLU mice, fixated either at short of at long muscle length, revealed no differences in length between sarcomeres directly lateral to the inclusion and sarcomeres directly in front of the tip between these two length conditions. This indicates that the inclusion is not stiffer than passive contractile tissue. Second, glycogen inside the inclusions was supposed to be hydrated, as opposed to crystalline, and glycogen bound water was assumed to be in equilibrium with the hydrated cytoplasm, indicating a low value for inclusion shear stiffness. Even when assuming an inclusion shear modulus of $1 \mathrm{MPa}$, i.e. more than 3 times the modulus of passive contractile tissue, the calculated force loss at a wet inclusion density of $3.3 \%$ equals $3.5 \%$, which is still half to the measured force loss of $7 \%$. So, the conclusion that non-contractile inclusions are the major cause of the loss of force in the affected muscles seems to hold when the inclusion stiffness is varied within reasonable boundaries.

\section{Patho-physiological implications}

The present findings indicate that at the early stage of GSDII the sarcoplasmic inclusions, i.e., glycogen filled lysosomes, can be held responsible for the experimentally determined degree of skeletal muscle force loss. It has been shown that the accumulation of glycogen levelled of between 7 and 10 months of age (see Chapter 4 and Raben [17]). The maximal relative glycogen content (wet mass glycogen per unit wet mass muscle) was found to be in the order of $5 \%[6,17]$, which corresponds to a calculated force loss of $8 \%$ as based on the relation between inclusion density and loss of force (Figure 6.3). It is of interest to note, that this calculated degree of force loss is substantially lower than the experimentally determined loss of muscle force per unit muscle mass $(36 \%)$ in the latter stages of GSDII [6]. Histological studies revealed that with advancing age, besides glycogen filled lysosomes, also large cytoplasmic clusters 
of non-contractile material are present in the affected muscle cells. It is feasible that these large inclusions cause additional loss of muscle function. Examination of histological sections indicated that the total volume content of these large inclusions did not exceed $5 \%$ of the total cell volume (Hesselink et al., unpublished results). Adding this value to the $5 \%$ of volume occupied by glycogen filled lysosomes, total cytoplasmic inclusion volume will be in the order of $10 \%$, corresponding to $15 \%$ of force loss (see relation in Figure 6.3 ), i.e., about $40 \%$ of the experimentally determined loss of force per unit muscle mass. This implies that in the advanced stages of the disease other factors are of quantitative importance in impaired muscle function. A potential candidate are Dystrophin Associated Proteins, which are known to be important in transmission of force from the interior of the muscle cell to the endomysium [18], as alterations in level and distribution of these proteins were recently demonstrated in patients with advanced GSDII [19].

In humans suffering from the infantile form of GSDII (Pompe disease), intracellular accumulation of glycogen occurred at a higher rate in the affected muscles than in AGLU- mice. Moreover, overt clinical signs of impaired muscle function are present before the age of 3 months $[20,21]$. The muscle glycogen levels can reach values up to $15 \%$ [22]. On basis of the relationship shown in Figure 3, under such conditions a doclino in forco por unit mass of about $20 \%$ can be expected. However, clinical studies [23] indicate a much more pronounced loss in muscle force, strongly suggesting the presence of additional detrimental factors in muscles of young children with Pompe disease.

Bijvoet and colleagues [13] have reported that cardiac mass significantly increased in AGLU mice. Moreover, Kamphoven and co-workers [24] found a positive correlation between left ventricular mass and cardiac glycogen content, while glycogen continued to accumulate up to the age of 24 months. In the heart, maximal glycogen levels of $15 \%$ were found [17], corresponding to a loss of muscle force of about $20 \%$ (Figure 6.3). Cardiac performance of AGLU mice was measured to be decreased significantly, e.g. $30-40 \%$ decrease in $\mathrm{dP} / \mathrm{dtmax}$ depending on measurement condition. It is tempting to speculate that also in the heart, glycogen deposition within the cardio-myocyte hampers contractile function, which may be a key factor in the cardio-respiratory implications in acid $\alpha$-glucosidase deficiency as readily seen in most human patients suffering from GSD II.

\section{Acknowledgements}

This project has been supported by the foundation "De Drie Lichten" in the Netherlands. R.H. has been supported by the Prinses Beatrix Fonds. The authors gratefully acknowledge Martijn van der Linden for performing the simulations. We are indebted to Dr A. Reuser for providing us with the AGLU mice and the primer combination, as well as for useful discussion. 


\section{References}

1 Hoefsloot, L.H., Hoogeveen-Westerveld, M., Reuser, A.J.J. and Oostra, B.A. (1990) Biochem J 272, 493-497.

2 Hers, H.G. (1963) Biochem J 86, 11-16.

3 Hers, H.G. and De Barsy, T. (1973) in Lysosomes and storage diseases (Hers, H.G. and Hoof, F.V., eds.), pp. 197 -217, Academic Press, New York.

4 Bijvoet, A.G.A., Van Hirtum, H., Vermey, M., Van Leenen, D., Van der Ploeg, A.T., Mooi, W.J. and Reuser, A.J.J. (1999) J Pathol189, 416-424.

Gorselink, M., Drost, M.R., de Louw, J., Willems, P.J., Rosielle, N., Janssen, J.D. and Van der Vusse, G.J. (2000) Pflugers Arch 439, 665-670.

Hesselink, R.P., Gorselink, M., Schaart, G., Wagenmakers, A.J.M., Kamphoven, J., Reuser, A.J.J., Van der Vusse, G.J. and Drost, M.R. (2002) Muscle and Nerve 25, 873-883.

Gielen, A.W., Oomens, C.W., Bovendeerd, P.H., Arts, T. and Janssen, J.D. (2000) Comp Meth in Biomech and Biomed Engin 3, 231-244.

Oomens, C.W., Maenhout, M., Ooijen, C.H., Drost, M.R. and Baaijens, F.P. (2003) Proc Royal Soc Series B in press.

Huxley, A.F. (1957) Progress in Biophysics and Biophysical Chem 7, 255-318.

Zahalak, G.I. and Ma, S.P. (1990) J of Biomech Engin 112, 52-62.

13 Bijvoet, A.G.A., Kroos, M.A., Pieper, F.R., Van der Vliet, M., De Boer, H.A., Van der Ploeg, A.T., Verbeet, M.P. and Reuser, A.J.J. (1998) Hum Mol Gen 7, 1815-1824.

14 Passonneau, J.V. and Lauderdale, V.R: (1974) Analytical Biochem 60, 405-412.

15 Newsholme, E.A and Leech, A.R. (1995) Biochemistry for the medical sciences, John Wiley, Chichester.

16 Bijvoet, A.G.A., Van de Kamp, E.H., Kroos, M.A., Ding, J.H., Yang, B.Z., Visser, P., Bakker, C.E., Verbeet, M.P., Oostra, B.A., Reuser, A.J.J. and Van der Ploeg, A.T. (1998) Hum Mol Gen 7, 53-62.

17 Raben, N., Nagaraju, K., Lee, E. and Plotz, P. (2000) Neuromusc Disorders 10, 283-291.

18 Patel, T.J. and Lieber, R.L. (1997) Exerc Sport Sci Rev 25, 321-363.

19 Radojevic, V., Humm, A.M., Rosler, K.M., Lauterburg, T. and Burgunder, J.M. (2003) Acta Neuropathol (Berl) 105, 373-380.

20 Reuser, A.J.J., Van den Hout, H., Bijvoet, A.G.A., Kroos, M.A., Verbeet, M.P. and Van der Ploeg. A.T. (2002) Europ J Pediatr 161 Suppl 1, S106-111.

21 Van den Hout, J.M.P., Hop. W., Van Diggelen, O.P., Smeitink, J.A.M., Smit, G.P.A., Poll-The, B.T., Bakker, H.D., Loonen, M.C.B., DeKlerk, J.B.C., Reuser, A.J.J. and VanderPloeg, A.T. (2003) Pedriatrics 112, 332-340

22 Reuser, A.J.J., Koster, J.F., Hoogeveen, A. and Galjaard, H. (1978) Am J Hum Gen 30, 132-143. 
23 Van den Hout, J.M., Reuser, A.J.J., De Klerk, J.B., Arts, W.F., Smeitink, J.A. and Van der Ploeg, A.T. (2001) J Inherit Metab Dis 24, 266-274.

24 Kamphoven, J.H., Stubenitsky, R., Reuser, A.J.J., Van der Ploeg, A.T., Verdouw, P.D. and Duncker, D.J. (2001) Physiological Genomics 5, 171-179.

25 Maenhout, M. (2000) in Skeletal Muscle Mechanics, from mechanism to function (Herzog, W., ed.), pp. 135-154, John Wiley and Sons.

26 Meyer, R.A. and Prior, B.M. (2000) Exerc Sport Sci Rev 28, 89-92.

27 Bosboom, E.M., Hesselink, M.K.C., Oomens, C.W., Bouten, C.V., Drost, M.R. and Baaijens, F.P. (2001) J Biomech 34, 1365-1368. 


\section{Chapter 7}

\section{Protein metabolism, regeneration and apoptosis: an explorative study in muscle of mice lacking acid $\alpha$ - glucosidase}

Reinout P. Hesselink, Lydie Combaret, Gert Schaart, Didier Attaix, Maarten R. Drost, Ger J. van der Vusse and Anton J.M. Wagenmakers 


\section{Abstract}

In this chapter, a first exploration was performed of the key metabolic processes that may explain the muscle wasting in acid $1-4 \alpha$-glucosidase deficient mice (AGLU $*$ ), a model for glycogen storage disease type II (GSD II). Muscle mass of both AGLU* and unaffected littermates was determined at 6-10,12-16 and 18-24 months of age and was found to be decreased in AGLU* mice at the latter two ages. Protein synthesis rates were measured as the rate of incorporation of $\mathrm{L}-\left[\right.$ ring $\left.-{ }^{13} \mathrm{C}_{6}\right]$-phenylalanine into mixed muscle protein in AGLU mice and unaffected littermates at 12-16 months of age. Also, the proteolytic activity of the ubiquitin proteasome complex was determined in pooled muscles of mice of the various age groups. Furthermore, localisation of the 19S regulatory subunit of the proteasome complex was performed on muscle tissue slides of control and affected mice of the above mentioned age groups, as well as assessment of apoptotic activity by determination of the contents of TUNEL positive nuclei.

It was found that at 12 months, protein synthesis rates were minimally 3 -fold higher in AGLU mice compared to unaffected animals, while the activity of the proteasome and antibody staining of the $19 \mathrm{~S}$ regulatory subunit were increased too. In AGLU mice 6-10 months of age, the indicated markers of proteolysis are increased as well, while muscle mass remains constant. In AGLU animals 18-24 months of age, activity of the proteasome complex is reduced, while wasting of muscle is prominent. Only in these old affected animals a small number of nuclei $(1.5 \%)$ was TUNEL positive.

The data collectively suggest that disruption of the myofibrillar structure in early stages of the disease leads to high activities of the proteasome system and clearance of the disrupted or damaged myofibrils. High rates of regeneration, most likely via activation of satellite cells in the damaged areas, appear to lead to high rates of protein synthesis. This then results in a rapid replacement (turnover) of the damaged myofibrils with newly synthesised myofibrils and minimal visible loss of structure. It is hypothesised that in older animals the regenerative capacity may be lost due to satellite cell depletion and the rates of protein synthesis must fall. In order to prevent a very rapid loss of myofibrils the activity of the proteasome system seems to show an adaptive downregulation. 


\section{Introduction}

Glycogen storage disease type II (GSD II or Pompe disease) is a muscular disease in which accumulation of glycogen in the lysosomes occurs as a result of a genetic defect in the GAA gene [1]. Depending on the locus of the mutation, such a genetic defect may result in an insufficient function of the enzyme acid 1-4 $\alpha$-glucosidase [2-6]. Severity of the disease depends on the residual activity of the enzyme [7]. When enzyme activity is virtually lacking, the patho-physiological process results in death due to cardiorespiratory insufficiency before the age of 2 years $[2,3,8]$.

In several muscular diseases, wasting of muscle protein is prominent. Often this loss of muscle mass, and the concomitant decrease of muscle contractile function, is fatal, as the function of both heart and respiratory muscles can become hampered to such an extent that the patients die. When heart and respiratory muscles are not affected, wasting of skeletal muscle reduces quality of live as patients commonly show exercise intolerance or develop skeletal muscle weakness and become wheelchair bound [9-11]. It was found that in GSD II, wasting of skeletal muscle readily occurs. In the most severe cases of this disease patients show clinical symptoms as early as 3 months after birth. Reduced development of motor skills is usually one of the first signs of GSD II [12]. Patients that have a residual activity of the enzyme develop clinical symptoms only later in life. In these late-onset patients, the reduced function of skeletal muscles is the aspect that most severely affects life in the early stages of the disease and dystrophy of skeletal muscle is prominent $[13,14]$. Estimates of protein synthesis and/or degradation have been made in a number of muscular diseases [9,15], including some studies in the late onset forms of GSD II [16-18]. However, these studies only protein synthesis and degradation at the whole body level were measured. No specific attention was paid to the changes that occurred in the skeletal muscle of the patient. Loss of the myofibrillar integrity due to the lysosomal glycogen accumulations may well lead to a substantial increase of the activity of the proteolytic enzymes in the affected muscles.

Various combinations of quantitative changes in protein synthesis and degradation may lead to a slow progressive loss of the muscle mass. To prevent rapid muscle wasting. increased proteolytic activity must be compensated by an increased protein synthesis rate to enable regeneration of atrophied or lost muscle fibres. On the other hand it is also possible that rates of protein degradation remain stable, while a small decrease occurs in protein synthesis. A slow rate of muscle protein wasting in other words may be attended both by small and large changes in the rate of protein turnover, that is, the rate at which amino acids exchange between the protein and the amino acid pool. As so little is known of the mechanisms leading to muscle protein wasting in GSD II, here we performed an explorative study to investigate whether protein synthesis and breakdown are substantially or only minimally altered. It was hypothesised that a gradual shift in the balance between protein synthesis and degradation eventually leads to the decrease in muscle mass that is observed in prolonged GSD II. To test this hypothesis, we performed studies on genetically engineered mice (the AGLU mouse model) serving as a model for GSD II [19]. We measured the rate of incorporation of L-[ring ${ }^{13} \mathrm{C}_{6}$ ]- 
phenylalanine into muscle protein as a measure of protein synthesis [20-22]. Animals 12-16 months of age were included in these measurements, as at this age muscle function becomes clearly impaired (see Chapter 4) and muscle mass is reduced in comparison to unaffected littermates.

To obtain information on potential increases of muscle protein breakdown, we measured the chymotrypsin-like activity of the cytoplasmic ubiquitin-proteasome system in muscle homogenates of groups of both control and AGLU mice at 6-10, 12-16 and 18-24 months of age. The ubiquitin-proteasome pathway is the major route involved in the degradation of the contractile proteins $[23,24]$. As earlier studies revealed that the intramuscular structural damage shows a large intracellular and between fibre variability, we hypothesised that upregulation of proteasome complex will primarily occur in those areas where loss of myofibrillar structure is most prominent. Therefore, also the distribution of the $19 \mathrm{~S}$ regulatory proteasome subunits in individual fibres was studied in the age groups under investigation, using immuno-fluorescence staining of longitudinal muscle sections with a specific antibody. Another degenerative process that may contribute to muscle wasting and loss of myofibrillar integrity in muscle diseases is programmed cell death (apoptosis) [25]. Apoptosis starts with fragmentation of the DNA in the nuclei and eventually leads to total disruption of the cell and degradation of the cellular proteins by caspases [25]. To look for signs of apoptosis in GSD II, a terminal deoxynucloetidyl transferase mediated dUTP nick end labelling (TUNEL) assay was applied on muscle specimen of AGLU mice and control animals of the various groups. The number of TUNEL positive nuclei in muscle fibres was assessed.

\section{Materials and Methods}

Mouse characteristics

Measurements were performed on mice lacking acid 1-4 $\alpha$-glucosidase activity (AGLU and their unaffected littermates. Genetic properties of the animals were tested using PCR with the primer combination described by Bijvoet and co-workers [26]. The AGLU mice investigated were the offspring of the mice generated and described by Bijvoet and colleagues $[19,26]$, backcrossed 10 times to the original C57BI strain. All experimental procedures were approved by the Institutional Animal Care and Use Committee of Maastricht University and complied with the principles of proper laboratory animal care.

Harvesting of muscle tissue

Of each age group, 6 AGLU and 6 non-affected littermates were included in the studies. Mice were anaesthetised using $2.5 \%$ halothane (Fluothane; Zeneca, Ridderkerk, The Netherlands) dissolved in $\mathrm{O}_{2}$ and $\mathrm{N}_{2} \mathrm{O}$ delivered in a 2:1 ratio via a flowmeter (Medec; Montvalle, $\mathrm{NJ}$ ) to a facemask covering the mouth and nose of the mice. Then muscle tissue was harvested subsequently from right and left hind limbs of the animal. In all cases, dorsal flexor complexes were dissected first, followed by the plantar flexor complexes. Muscle were dissected from the bone or the visible start of the tendon 
and weighed after dissection. Dorsal flexor complexes were washed in an ice-cold $0.9 \%$ $\mathrm{NaCl}$ solution, mounted on ThermoShandon, (Cryomatrix, Pittsburg, PA) and frozen in melting isopentane for cryo-sectioning and immuno-fluorescence staining. Plantar flexor complexes were immediately frozen in liquid nitrogen for analysis of the activity of the ubiquitin proteasome complex.

\section{Muscle protein synthesis}

\section{Measurement of protein synthesis rate}

In the AGLU model, wasting of muscle mass becomes prominent after 12-16 months of age. Therefore, protein synthesis rates were determined at this age. As a measure of protein synthesis, the rate of incorporation of $\mathrm{L}$-[ring ${ }^{13} \mathrm{C}_{6}$ ) phenylalanine $(99 \%$, Cambridge Isotope Laboratories, Andover, MA, USA) was assessed in a separate set of 3 AGLU mice and a mixed population of unaffected littermates (1 wild type and 3 heterozygous animals). To this end, animals received via intra-peritoneal injection a flooding dose $(1 \mathrm{ml} / 100 \mathrm{~g}$ body weight, $150 \mathrm{mM}) \mathrm{L}$-[ring $-{ }^{13} \mathrm{C}_{6}$ ) phenylalanine and were sacrificed by cervical dislocation exactly $10 \mathrm{~min}$ after injection. Hind limbs were immediately surgically removed to stop blood flow, and skin was removed from the dissected leg. The skinned hind limbs were submerged in an ice cold $0.9 \% \mathrm{NaCl}$ solution within $40 \mathrm{~s}$ after the mice were sacrificed to entirely stop protein synthesis in the hind limb muscles. After 3 min of cooling, tibialis anterior muscle was dissected from the chilled leg and muscle tissue was homogenised in $2 \mathrm{ml}$ of a $2 \%$ perchloric acid (PCA) solution and left on ice for $10 \mathrm{~min}$. After centrifugation for $10 \mathrm{~min}$ the protein pellet was washed twice in $2 \%$ PCA to remove free amino acids that were not incorporated in muscle protein. Collagenous proteins were removed by dissolving the washed protein pellet in $1.5 \mathrm{ml}$ of a $0.3 \mathrm{M} \mathrm{NaOH}$ solution at $37^{\circ} \mathrm{C}$ for 60 -min. After 10 -min centrifugation, the alkali soluble, non-collagenous, proteins dissolved in the supernatant were transferred to another tube. Dissolved proteins were precipitated again by addition of 1.5 $\mathrm{ml}$ of an ice-cold $10 \%$ PCA solution and kept on ice for $10 \mathrm{~min}$. After centrifugation, the protein pellet was hydrolysed overnight in $6 \mathrm{M} \mathrm{HCl}$ at $120^{\circ} \mathrm{C}$ in an oven. The hydrolysed protein fraction was dried under a nitrogen stream while heating the tubes to $120^{\circ} \mathrm{C}$ in a heating block (2-3h), dissolved in a 50\% acetic acid solution, and passed over a Dowex exchange resin (AG 50W-X8 Resin, 100-200 mesh hydrogen form, Biorad, Hercules, CA) using $2 \mathrm{M} \mathrm{NH}_{4} \mathrm{OH}$. The eluate was dried.

The purified amino acid fraction was then derivatised into the $\mathrm{N}$-acetyl-methyl-esters. In short, $650 \mu \mathrm{l}$ methanol and $100 \mu \mathrm{l}$ acetyl-chloride were added to $450 \mu \mathrm{l}$ of the purified amino-acid fraction, left to react at room temperature for an hour and subsequently dried under a nitrogen stream at $70^{\circ} \mathrm{C}$ for $15 \mathrm{~min}$. To the dried sample, $400 \mu$ t tetrahydrofuran and $400 \mu \mathrm{l}$ acetic-anhydride were added and after mixing left to react for 30 min at $60^{\circ} \mathrm{C}$. After cooling and centrifugation, samples were dried under a nitrogen stream at room temperature for $2.5 \mathrm{~h}$. To the dried sample, $100 \mathrm{ml}$ of tert-butylmethylether was added, mixed well and left to react at room temperature for 1-h. Then, the L-fring${ }^{13} \mathrm{C}_{6}$ ]phenylalanine enrichment was measured by GC combustion Isotope Ratio Mass 
Spectrometry (GC-IRMS; Finnigan MAT 252, Bremen, Germany). Protein synthesis rates in the knock out animals and wild type littermates are expressed as the increase in $\mathrm{L}-\left[\right.$ ring- $\left.{ }^{13} \mathrm{C}_{6}\right]$ phenylalanine enrichment in the mixed muscle protein compared to the background.

Background values were obtained by taking muscle samples of 4 mice that had not been injected with $\mathrm{L}-\left[\right.$ ring $-{ }^{-13} \mathrm{C}_{6}$ ] phenylalanine and repeating the entire procedure. The increase in ${ }^{13} \mathrm{C}$-enrichment is expressed as the delta per mil difference between the phenylalanine present in the muscle protein of the animals injected with tracer and in the protein of the background samples.

\section{Muscle protein degradation}

\section{Measurement of proteasome activity}

Proteins of pooled gastrocnemius muscle (6 KO mouse in each age group) were extracted in an ice cold 10\% glycerol, $1 \mathrm{mM}$ DTT, $1 \mathrm{mM}$ Tris (pH 7.5), $10 \mathrm{mM}$ ATP, 10 $\mathrm{mM} \mathrm{MgCl} 2$ buffer. This homogenisation buffer contained the protease inhibitors antipaine $(10 \mu \mathrm{g} / \mathrm{ml})$, aprotinine $(10 \mu \mathrm{g} / \mathrm{ml})$, pepstatine A $(10 \mu \mathrm{g} / \mathrm{ml})$ leupeptine $(10 \mu \mathrm{g} / \mathrm{ml})$ and PMSF $(200 \mu \mathrm{M})$. Homogenates were then centrifuged for $1 \mathrm{~h}\left(100,000 \mathrm{~g}, 4^{\circ} \mathrm{C}\right)$. Supernatant was removed and $1.5 \mathrm{ml}$ was loaded on a $10-40 \%$ glycerol gradient of the same composition as the homogenisation buffer. Samples were centrifuged for $22 \mathrm{~h}$ $\left(100,000 \mathrm{~g}, 4^{\circ} \mathrm{C}\right)$ and $0.45 \mathrm{ml}$ fractions were collected from the bottom of the tube. To measure the chymotrypsin-like activity of the proteasome system in each loaded homogenate, of each collected $0.45 \mathrm{ml}$ fraction a $200 \mu \mathrm{l}$ portion was incubated for 45 min with $100 \mu \mathrm{M}$ Suc-Leu-Leu-Val-Tyr-7-amido-4 methylcoumarin (Suc-LLVT-AMC) (Affinity Research Products Ltd., Mamhead, Exeter, UK) at $37^{\circ} \mathrm{C}$. The incubation buffer consisted of $\mathrm{MgCl}_{2}(10 \mathrm{mM})$, ATP $(10 \mathrm{mM})$, DTT $(1 \mathrm{mM})$, dissolved in a $50 \mathrm{mM}$ Tris buffer (pH 8.0). Reaction was stopped by adding ice-cold $100 \mathrm{mM}$ monochloroacetate, $40 \mathrm{mM}$ sodium acetate to the reaction solution and placing it on ice for $10 \mathrm{~min}$. The chymotrypsin-like activity of the proteasome system was measured as the amido-4 methylcoumarin (AMC) release using a Perkin Elmer fluorimeter (excitation $365 \mathrm{~nm}$, emission $430 \mathrm{~nm}$ ).

Localisation of the proteasome complex in individual muscle fibres and sub-cellular areas

To establish the intracellular distribution of the proteasome system, immunohistochemical localisation studies were performed on sections of muscle tissue from two animals of the various age groups. Frozen muscle sections, $4 \mathrm{~m}$ thick, were permeabilised for 5 min using $1 \%$ Triton $\times 100$ dissolved in PBS. The primary antibodies used for identification of the protein of interest were MCP72 (1:1000), raised against the 19S regulatory subunit of the proteasome system (kindly provided by Dr. Klavs Hendil), and 2E8 (1:20) against laminin (Developmental Studies Hybridoma Bank. The University of lowa). After overnight incubation at $4^{\circ} \mathrm{C}$ with the primary antibodies, labelling with an appropriate secondary antibody was applied. The 19S signals shows in red, the laminin 
shows in green fluorescent signal. Of each animal, at least two muscle sections were studied, taking 5 micrographs from the origo to the insertion of the muscle to obtain a representative overview of that section.

Picture grabbing in each section was performed using a NIKON E800 fluorescence microscope (UVIKON, Bunnik, The Netherlands) coupled to a Basler A101C progressive scan colour CCD camera, with a Bayer colour filter, having an output picture resolution of $1300^{*} 1030$ pixels $(\mathrm{HxV})$ and a pixel size of $6.7^{*} 6.7 \mu \mathrm{m}$. To enable comparison between pictures, camera settings were kept constant. Digitally captured images were processed and analysed for differences in staining intensities using LUCIA G/F v4.61 build 0.64 image analysis software (Nikon $\mathrm{GmbH}$, Düsseldorf, Germany).

\section{Presence and localisation of apoptotic nuclei}

To check for the presence of apoptotic nuclei in damaged muscle fibres a terminal deoxynucloetidyl transferase mediated dUTP nick end labelling (TUNEL) assay (Fluorescin-FragEI ${ }^{\mathrm{T}}$, Oncogene Research Products, Boston, MA) was performed on frozen tissue sections of $4 \mu \mathrm{m}$ thickness, according to the suppliers specifications. This assay shows nuclei with fragmented DNA (TUNEL positive nuclei) in green, in contrast to the blue staining of non-apoptotic nuclei. Immuno-fluorescent staining with the laminin antibody 2E8 (Developmental Studies Hybridoma Bank. The University of lowa) was performed in red to allow determination of the cell outtines. Of two animals of the various groups, at least two muscle sections were studied, taking 5 micrographs from the origo to the insertion of the muscle to obtain a representative overview of that section. This approach allowed analysis of at least 500 nuclei per section of muscle tissue. Picture grabbing in each section was performed using the same microscope, camera and picture grabbing software as described above. 


\section{Results}

Wasting of muscle mass

With progression of age, and thus of pathology, dorsal flexor muscle mass of AGLU* animals decreased compared to that of unaffected littermates. Wasting of muscle mass becomes prominent after 12 months of age, and this reduction progressively increases at 18 months of age. In Table 7.1 the muscle masses of the dorsal flexor complexes and the percentage decline in AGLU compared to unaffected littermates are summarised for the 3 different age groups studied.

Table 7.1: Masses of plantar flexor muscle complexes and the percentage differences between AGLU* and control mice in the 3 different age groups studied.

\begin{tabular}{|c|c|c|c|}
\hline \multirow{3}{*}{$\frac{\begin{array}{c}\text { Age group } \\
\text { (months) }\end{array}}{6-10}$} & \multicolumn{2}{|c|}{ Muscle mass (mg) } & \multirow{2}{*}{$\%$ difference } \\
\hline & Control & AGLU - & \\
\hline & $\begin{array}{c}68.9(3.6) \\
(n=5)\end{array}$ & $\begin{array}{c}69.4(4.7) \\
(n=4)\end{array}$ & 0.7 \\
\hline $12-16$ & $\begin{array}{c}66.7(9.5) \\
n=9\end{array}$ & $\begin{array}{c}59.4(13.0) \\
n=4\end{array}$ & -10.9 \\
\hline $18-24$ & $\begin{array}{c}66.2(6.3) \\
n=5\end{array}$ & $\begin{array}{c}59: 2(8.1) \\
n=4\end{array}$ & $-24.1^{*}$ \\
\hline
\end{tabular}

Data are represented as mean (SD). The number of animals $(n)$ included in the various groups is stated

- difference $(p<0.05)$ between control and AGLU animals.

\section{Muscle protein synthesis}

Assessment of the increase in ${ }^{13} \mathrm{C}$-enrichment of the phenylalanine fraction of muscle alkali soluble protein in the first $10 \mathrm{~min}$ after $\mathrm{L}$-[ring $\left.{ }^{13} \mathrm{C}_{6}\right]$-phenylalanine administration revealed that the incorporation of this amino acid was approximately 3 times faster in 12 16 months old AGLU mice compared to their unaffected littermates. This implies that the protein synthesis rates in these animals are higher than in their unaffected littermates.

In Figure 7.1 the increase in ${ }^{13} \mathrm{C}$-enrichment of phenylalanine in the mixed muscle protein of the AGLU and unaffected animals is shown. 
Figure 7.1: ${ }^{13} \mathrm{C}$-enrichment of phenylalanine in the alkali soluble protein of $12-16$ months old $\mathrm{AGLU}$ and control animals $10 \mathrm{~min}$ after $\mathrm{L}-\left[\right.$ ring $-{ }^{13} \mathrm{C}_{6}$ ]phenylalanine administration.

${ }^{13} \mathrm{C}$-enrichment is expressed as the $\delta$ per mil difference between phenylalanine in muscle protein of tracer injected animals and in protein of background samples

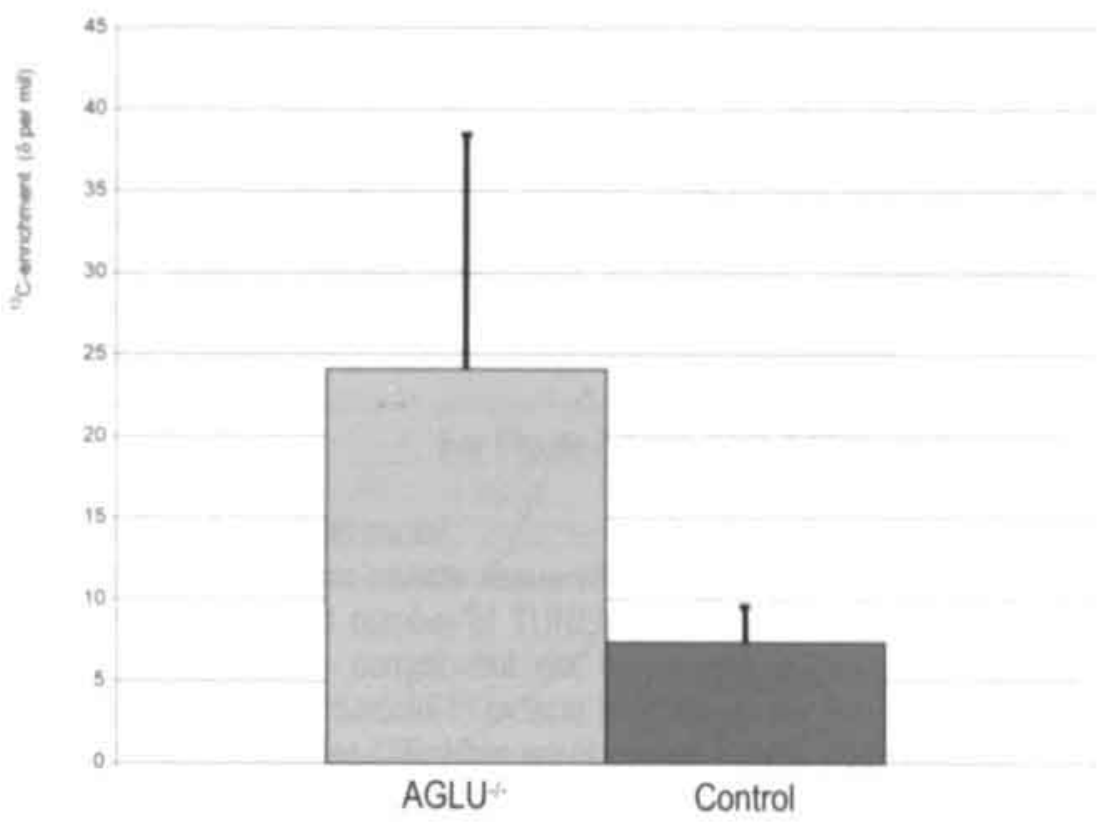

Muscle protein degradation

Proteasome activity

In Figure 7.2 the activity of the proteasome complexes as percentage of the control values are depicted for mice 6-10 months (7.2A), 12-16 months (7.2B) and 18-24 months $(7.2 \mathrm{C})$ of age. Percentage differences in proteasome chymotrypsin-like activity of AGLU mice compared to control is indicated on the $y$-axis, the glycerol gradient fraction number is shown on the $x$-axis. At the age of 6-10 and 12-16 months, chymotrypsin-like activity of the proteasome system was substantially higher in AGLU mice (Figure 7.2A and 7.2B). At ages 18-24 months, however, the proteasome activity in $A G L U$ mice is decreased compared to control animals (Figure 7.2C). 
Chapter 7

Protein metabolism in $\alpha$-glucosidase knockout mice

Figure 7.2: Chymotrypsin-like activity of the proteasome complex in pooled dorsal flexor

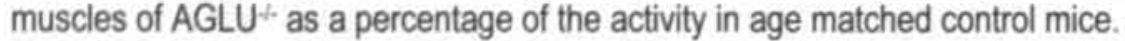

A

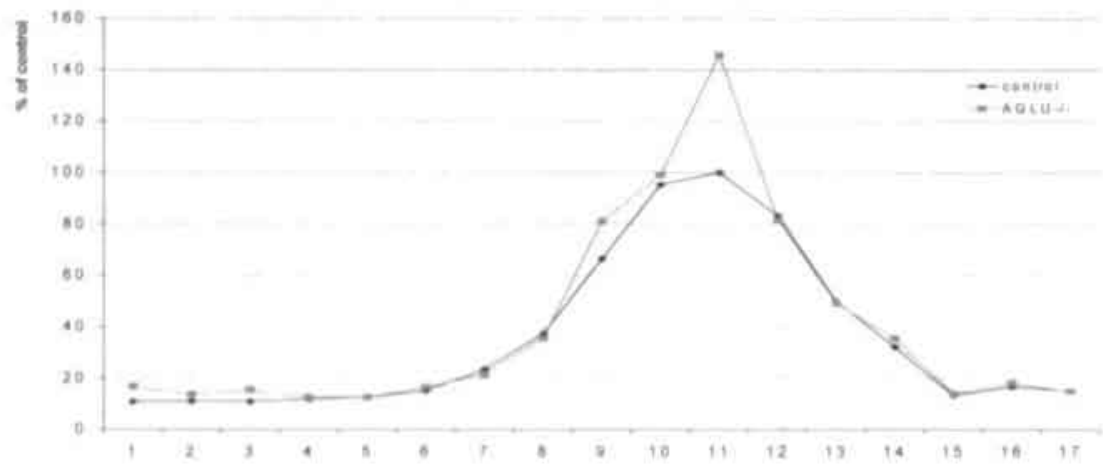

B

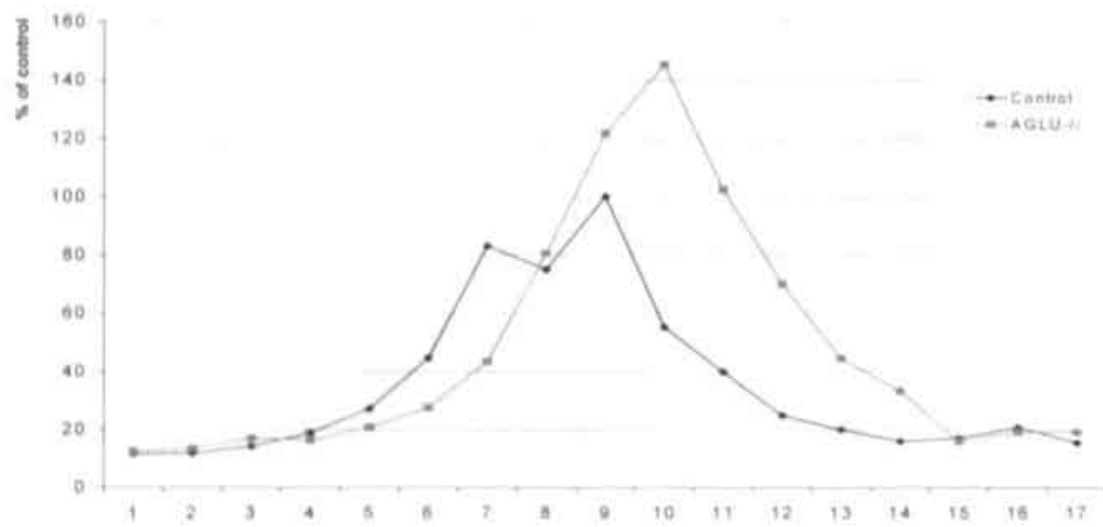

C

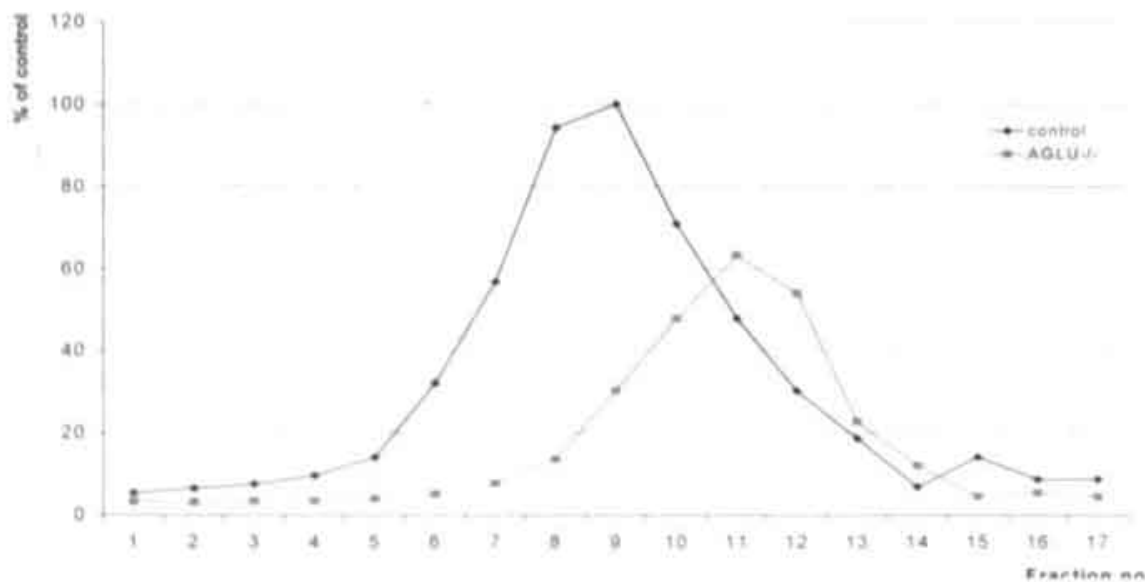

Fraction no. refers to the $0.45 \mathrm{ml}$ fractions collected of each glycerol gradient. Concentration of the proteasome complex was usually highest in the mid-section of the gradient, represented by the highest activity in those fractions. 


\section{Intracellular localisation of the proteasome complex}

Figure 7.3 shows the distribution of proteasome staining in individual muscle fibres of the tibialis anterior muscle of control and AGLU- animals 12-16 months of age. Staining with the mouse monoclonal antibody MCP 72 against the $19 \mathrm{~S}$ regulatory unit of the ubiquitin proteasome complex (staining signal in red) showed little staining signal in control animals. If visible, staining was most intense around nuclei (Figure 7.3A and $7.3 \mathrm{C}$ ). In AGLU animals, however, both large differences in intra- and inter-cellular staining intensity were observed. Proteasome staining was generally intense in sub-cellular areas where muscle cell structure was damaged, as indicated by arrowheads in figure $7.3 \mathrm{~B}$ and $7.3 \mathrm{D}$. Results obtained in other age groups were similar to the depicted examples (data not shown). The staining intensity was higher on the muscle specimens from the affected animals suggesting an increased muscular content of the 19S regulatory unit, but due to the small number of animals studied in each group ( $n=2)$, the difference between the groups could not be statistically verified.

\section{For Figure 7.3 see page 147}

\section{Localisation of apoptotic nuclei}

Staining of dorsal flexor muscle tissue with a TUNEL assay to identify apoptotic nuclei revealed an increased number of TUNEL positive nuclei in aged AGLU mice (18-24 months) compared to control, but not in younger animals. As reported earlier, the percentage of apoptotic nuclei in muscle is relatively low (usually less than $2 \%$ ), even in severely diseased states [27]. Here we observed TUNEL positive nuclei (see Figure 7.4) only in the most progressed stages of the pathology in the AGLU animals (18 months and more). In these animals, about $1.5 \%$ of the nuclei reacted TUNEL positive, whereas in unaffected littermates TUNEL positive nuclei were absent.

\section{For Figure 7.4 see page 148}

\section{Discussion}

Loss of muscle mass and cachexia, are generally considered to be detrimental for muscle contractile function in both acute and chronic pathological situations [9, 28-30]. Especially in muscle diseases, where muscle function is usually already hampered as a result of a muscle specific pathology, wasting of muscle mass will contribute to, and most likely enhance the disabilitating effect of the disease. Often, atrophy caused by disuse explains only part of the massive wasting of muscle mass observed in patients suffering from muscle diseases. To be able to counteract the detrimental effects of muscle wasting in chronic muscle diseases, understanding the pathology specific mechanisms of muscle tissue wasting is essential.

As shown here and reported earlier [31], the loss of muscle mass observed in AGLU:mice is about $25 \%$ at the age of $18-24$ months. Though this reduction in muscle mass in 
not sufficient to fully explain the decline in muscle function in AGLU $^{+}$mice (see Chapter 3 [31] and Chapter 4), it does make a substantial contribution to the reduction of the force generating capacity. Theoretically, reduction of muscle mass is caused by an imbalance between muscle protein synthesis and protein degradation. Here, quantitative and qualitative estimates of synthesis and degradation of proteins in muscle tissue of AGLU mice have been made and will be compared with data obtained in other chronic muscle diseases in earlier publications.

The incorporation of $\mathrm{L}_{-}\left[\right.$ring $\left.^{-13} \mathrm{C}_{6}\right]$ phenylalanine in the muscle tissue of $\mathrm{AGLU}$ animals at 12-16 months of age shows a 3-fold increase in comparison to a mixed population of age matched wild-type and heterozygous control animals. When we assume that the enrichment of the intramuscular free amino acid precursor pool in the affected animals and littermate controls is about equal during the protein synthesis experiment, the observed 3 -fold increase in ${ }^{13} \mathrm{C}$-enrichment reflects a 3 -fold increase in the muscle protein synthesis rate. If differences in the enrichment of the precursor pool would exist, the expectation is that the enrichment will be lower in the affected animals due to the observed increased activity (Figure 7.2) and protein content (Figure 7.3) of the ubiquitinproteasome system. The amino acids liberated by protein degradation will not carry the tracer label and, therefore, will dilute the precursor pool. These considerations imply that the increase in protein synthesis rates in 12 months old AGLU animals is at least 3-fold higher.

In AGLU mice 6-10 months of age, the activity of the proteasome complex, which is a major contributor to the degradation of myofibrillar proteins [29], is increased, while wasting of muscle tissue is absent at this age. This suggests that in early stages of the disease, both protein synthesis and degradation rates are equally increased, leading to high turnover rates of proteins and maintenance of muscle mass. At later ages, it is likely that the observed decrease in muscle mass is caused by an imbalance between protein synthesis and degradation. In the 12 months old animals the increase in protein degradation must exceed the increase in protein synthesis, implying that the overall muscle protein breakdown rate must be increased more than the 3 -fold increase that we observe for protein synthesis (Figure 7.1). As the increase in the activity of the proteasome system in the pooled muscles of 12-16 month old AGLU mice is only about 1.5 -fold, other proteolytic systems (e.g. Iysosomal cathepsins, calcium activated proteases and/ or caspases) must be activated as well. It is also possible that the ubiquitin-proteasome system is primarily responsible for the increase in protein breakdown and that inside the intact muscle cell it is activated by allosteric mechanisms and/ or phosphorylation/ de-phosphorylation of some of its subunits, or via increased protein expression of its regulatory subunits or ubiquitin ligases. The latter mechanisms are not measured in the analytical techniques applied in this study. Most of the regulatory mechanisms of the ubiquitin-proteasome system in health and diseased muscle are yet to be discovered.

An important question is why protein synthesis is increased 3 -fold or more in young affected animals. Structural damage to the myofibrils or individual myofibrillar proteins 
has been suggested to lead to increased rates of myofibrillar protein breakdown by activation of the ubiquitin-proteasome system $[24,32,33$. To compensate for this loss of damaged proteins, the muscle appears to up-regulate its capacity for protein synthesis. A potential mechanism to achieve this is activation of satellite cell [34] to increase regeneration rates of damaged muscle fibres or muscle fibre sections. Then, the high turnover of the myofibrillar proteins is needed to replace structurally damaged myofibrils with newly synthesised, functional myofibrils. A similar adaptive response with high rates of regeneration and satellite activation has previously been observed in young mdx mice [35], a mouse model of Duchenne muscular dystrophy. In aged $m d x$ mice, it was shown that the regenerative capacity of muscle is substantially decreased [36]. Excessive satellite cell activation at a young age appeared to lead to satellite cell depletion in older animals [36] and, as a consequence, to a much more progressive structural muscle damage in the older animals. As the pattern of high regeneration rates, function loss and structural damage in the muscle cells shows many similarities in AGLU and mdx mice, we feel that a reduced capacity to activate satellite cells might well be a major contributor to the increase in muscle damage observed in aged AGLU mice.

The activity of the proteasome system was found to be reduced in the most severely affected animals ( 18 months and older), while the loss of muscle mass is most pronounced in those animals. It can not be excluded that the activity of the proteasome system is down-regulated when the muscle cells have lost most of their ability for regeneration as a consequence of a depletion of satellite cells. Failure to down-regulate muscle protein breakdown at this stage would lead to a very rapid, probably fatal, progression of the disease. Davies and co-workers have provided a potential mechanism for this down-regulation of the proteasome system. They observed that the activity of the proteasome complex diminishes when proteins aggregate to lipofuscin plaques [37-39]. As in aged AGLU animals lipofuscin is prominent (see Chapter 5), it could be speculated that the reduced activity of the proteasome system in older animals is at least partially caused by the intracellular accumulation of this substance.

These findings collectively indicate that during the patho-physiological process, the balance between protein synthesis and degradation shows a gradual shift. In young animals the turnover rate of myofibrillar proteins is high with equal rates of protein synthesis and breakdown. In 12-month-old animals protein synthesis is still high but protein breakdown is higher and there is a gradual loss of muscle mass. In old animals the regenerative capacity is lost and protein synthesis must be falling. Protein breakdown is down regulated, but not enough to prevent a further gradual loss of muscle mass and structural organisation of intact myofibrils.

Based on both the structural damage that occurs to muscle fibres, as earlier described in Chapters $3[40]$ and 5 , and the progressive reduction in muscle mass as shown here and in Chapter 4, the observed increased activity of the proteasome system could be expected. Localisation of the $19 \mathrm{~S}$ regulatory complex of the proteasome complex showed that in AGLU animals this proteolytic system is mainly present in areas where damage to the muscle fibres is most prominent. In control animals, staining intensities 
were low, and signal was most prominent near the sarcolemma and around nuclei. These observations support the notion that proteolysis by the ubiquitin-proteasome complex is specifically aimed to degrade non-functional muscle proteins in damaged parts of muscle cells and suggest that both cellular contents and localisation of this system are well regulated. Further research is needed to quantify the apparent increase in the expression of the 19S regulatory subunit and to investigate whether similar increases in protein expression and localisation also occur for the other proteolytic subunits.

In the present study we observed a number of TUNEL positive nuciei in the older affected animals only. This may indicate that some apoptotic activity may occur. However, a pilot experiment to verify this notion failed to find indications of caspase activity in the muscle fibres of affected animals of any age group. Together, these observations seem to indicate that apoptosis makes only a minimal contribution to the protein breakdown even in severely affected muscle fibres. We also should keep in mind that in muscle cells, apoptosis of a single or a few nuclei will not automatically lead to the death of a muscle fibre $[27,41]$. Muscle cells are poly-nucleated, and degradation of one nucleus often leads to degradation of only a part of the myofibrillar structures in a muscle fibre $[25,27]$, which then will usually be followed by regeneration after activation of one or more satellite cells.

In conclusion, the data collectively suggest that disruption of the myofibrillar structure in early stages of the disease leads to high activities of the ubiquitin proteasome system and clearance of the disrupted or damaged myofibrils. The resulting high rates of protein breakdown appear to be compensated, most likely by a high regenerative activity via activation of satellite cells in the damaged muscle fibres and/or in damaged muscle fibre sections. This then results in a rapid replacement of the damaged myofibrils with newly synthesised myofibrillar proteins and minimal visible loss of structure in the young animals (Chapter 5 ). In older animals the regenerative capacity may be lost due to satellite cell depletion and the rates of protein synthesis must fall. In order to prevent a very rapid loss of myofibrils the activity of the proteasome system seems to show an adaptive downregulation.

\section{Acknowledgments}

This study was supported by the Prinses Beatrix Fonds and Foundation "De Drie Lichten" in the Netherlands. Dr. K. Hendil is gratefully acknowledged for providing us with the antibody against the $19 \mathrm{~S}$ regulatory proteasome subunit. The authors are indebted to A. Claustre for her expert help in assessment of the proteasome activity, and to A. Rousseau and A. Gijsen for their expert support with the assessment of ${ }^{13} \mathrm{C}$-tracer enrichments. We would like to thank Dr A. Reuser for providing us with both the AGLU animals and the primer combination. 


\section{References}

1 Hoefsloot, L.H., Hoogeveen-Westerveld, M., Reuser, A.J.J. and Oostra, B.A. (1990) Biochem J 272, 493-497.

2 Hirschhorn, R. (1995) in The Metabolic and Molecular Basis of Inherited Disease (Scriver, C.R., Beaudet, A.L., Sly, W.S. and Valle, D., eds.), pp. 24432464, McGraw-Hill, New York.

3 Ausems, M.G., Kroos, M.A., Van der Kraan, M., Smeitink, J.A., Kleijer, W.J., Ploos-van Amstel, H.K. and Reuser, A.J.J. (1996) Clin Genet 49, 325-328.

Huie, M.L., S. Tsujino, S. Sklower Brooks, A. Engel, E. Elias, D.T. Bonthron, C. Bessley, S. Shanske, S. DiMauro, Y.I. Goto, R. Hirschhorn. (1998) Biochem Biophys, ResComm244, 921-927.

Kroos, M.A., Van der Kraan, M., Van Diggelen, O.P., Kleijer, W.J., Reuser, A.J.J., Van den Boogaard, M.J., Ausems, M.G., Ploos-van Amstel, H.K., Poenaru, L., Nicolino, M. and et al. (1995) J Med Genet 32, 836-837. Reuser, A.J.J. (2002) GSD II mutation database.

Wokke, J.H., Ausems, M.G., Van den Boogaard, M.J., Ippel, E.F., van Diggelene, O., Kroos, M.A., Boer, M., Jennekens, F.G., Reuser, A.J.J. and Ploos-van Amstel, H.K. (1995) Ann Neurol 38, 450-454. Dower, A $132-143$.

Griggs, R.C., Jozefowicz, R., Kingston, W., Nair, K.S., Herr, B.E. and Halliday, D. (1990) Ann Neurol 27, 505-512.

10 Lewis, S.F. and Haller, R.G. (1989) Exerc Sport Sci Rev 17. 67-113. Merlini, L. and Granata, C. (1990) Curr Opin Neurol Neurosurg 3, 738-741.

12 Reuser, A.J.J., M.A. Kroos, M.M.P. Hermans, A.G.A. Bijvoet, M.P. Verbeet, O.P. Van Diggelen, W.J. Kleijer, and Van der Ploeg, A.T. (1995) Muscle \& Nerve Suppl 3, S61-S69.

13 Barohn, R.J., A.L. McVey, S. DiMauro. (1993) Muscle \& Nerve 16, 672-676.

14 Ausems, M.G., Lochman, P., Van Diggelen, O.P., Ploos van Amstel, H.K., Reuser, A.J.J. and Wokke, J.H. (1999) Neurol 52, 851-853.

Furuno, K., Goodman, M.N. and Goldberg, A.L. (1990) J Biol Chem 265, 85507.

16 Umpleby, A.M., Trend, P.S., Chubb, D., Conaglen, J.V., Williams, C.D., Hesp, R., Scobie, I.N., Wiles, C.M., Spencer, G. and Sonksen, P.H. (1989) J Neurol Neurosurg Psych 52, 954-961.

17 Umpleby, A.M., C.M. Wiles, P.S. Trend, I.N. Scobie, A.F. Macleod, G.T. Spencer, P.H. Sonksen. (1987) J Neurol Neurosurg Psych 50, 587-592.

18 Slonim, A.E., R.E. Coleman, M.A. McElligott, J. Najjar, K. Hirschhorn, G.U. Labadie, R. Mrak, O.B. Evans, E. Shipp, R. Presson. (1983) Neurol 33, 33-38.

19 Bijvoet, A.G.A., Van Hirtum, H., Vermey, M., Van Leenen, D., Van der Ploeg, A.T., Mooi, W.J. and Reuser, A.J.J. (1999) J Pathol 189, 416-424. 
20 Lundholm, K., Ternell, M., Zachrisson, H., Moldawer, L. and Lindstrom, L. (1991) Acta Physiol Scand 141, 207-219.

21 Davis, T.A., Fiorotto, M.L., Nguyen, H.V. and Burrin, D.G. (1999) Am J Physiol 277, E103-E109.

22 Garlick, P.J., McNurlan, M.A. and Predy, V.R. (1980) Biochem J 192, 719-723.

23 Lecker, S.H., Solomon, V., Mitch, W.E. and Goldberg, A.L. (1999) J Nutr 129, 227S-237S.

24 Mitch, W.E. and Goldberg, A.L. (1996) N Engl J Med 335, 1897-1905.

25 Vescovo, G., Volterrani, M., Zennaro, R., Sandri, M., Ceconi, C., Lorusso, R., Ferrari, R., Ambrosio, G.B. and Dalla Libera, L. (2000) Heart 84, $431-437$.

26 Bijvoet, A.G.A., Van der Kamp, E.H.M., Kroos, M.A., Ding, J.H., Yang, B.Z., Visser, P., Bakker, C.E., Verbeet, M.P., Oostra, B.A., Reuser, A.J.J. and Van der Ploeg, A.T. (1998) Hum Mol Gen 7, 53-62.

27 Borisov, A.B. and Carlson, B.M. (2000) Anat Rec 258, 305-318.

28 Tsujinaka, T., Fujita, J., Ebisui, C., Yano, M., Kominami, E., Suzuki, K., Tanaka, K., Katsume, A., Ohsugi, Y., Shiozaki, H. and Monden, M. (1996) J Clin Invest 97, 244-249.

29 Voisin, L., Breuille, D., Combaret, L., Pouyet, C., Taillandier, D., Aurousseau, E Gbled. C. and Attaix. D. (1996) J Clin Invest 97, 1610-1617.

30 Rooyackers, O.E., Hesselink, M.K.C. and Wagenmakers, A.J.M. (1997) Clin Sci (Colch) 92, 189-195.

31 Hesselink, R.P., Gorselink, M., Schaart, G., Wagenmakers, A.J.M., Kamphoven, J., Reuser, A.J.J., Van der Vusse, G.J. and Drost, M.R. (2002) Muscle Nerve 25, 873-883.

32 Feasson, L., Stockholm, D., Freyssenet, D., Richard, I., Duguez, S., Beckmann, J.S. and Denis, C. (2002) J Physiol 543, 297-306.

33 Taillandier, D., Aurousseau, E., Meynial-Denis, D., Bechet, D., Ferrara, M., Cottin, P., Ducastaing, A., Bigard, X., Guezennec, C.Y., Schmid, H.P. and et al. (1996) Biochem J 316, 65-72.

34 Partridge, T.A. (2002) Gene Ther 9, 752-753.

35 Nakae, Y., Stoward, P.J., Shono, M. and Matsuzaki, T. (2001) Histochem Cell Biol 115, 205-214.

36 Luz, M.A., Marques, M.J. and Santo Neto, H. (2002) Braz J Med Biol Res 35 , 691-695.

37 Davies, K.J. (2001) Biochimie 83, 301-310.

38 Sitte, N., Merker, K., Von Zglinicki, T., Davies, K.J. and Grune, T. (2000) Faseb J 14, 2503-2510.

39 Sitte, N., Merker, K., Von Zglinicki, T., Grune, T. and Davies, K.J. (2000) Faseb J 14, 2495-2502.

40 Hesselink, R.P., Wagenmakers, A.J.M., Drost, M.R. and Van der Vusse, G.J. (2003) Biochim Biophys Acta 1637, 164-170. 
Chapter 8

General Discussion 


\section{Introduction}

Glycogen storage disease type II (GSD II) has been first described in the 1930's by the Dutch physician Jan C. Pompe [1]. Since then, numerous case reports have been published, describing the pathological features of this disease (for reviews, see Reuser [2] and Hirschhorn [3]). Despite the fact that the clinical features are known in detail, until now the mechanisms that cause the eventually fatal muscle dysfunction, are incompletely understood. The lack of insight in the patho-physiological sequel of events and the underlying mechanisms hampered development of effective therapies. As the severely affected patients are usually very young (under 1 year of age) and are in general diagnosed only in an advanced state of the disease, systematic examination of the time course of the patho-physiology of GSD II is cumbersome. To facilitate systematic and reproducible research, a mouse model was generated by Bijvoet and coworkers [4]. The mouse model has been instrumental in the development of enzyme replacement therapy for GSD II [5]. At present, the experimental therapeutic approach has been tested in phase II clinical trials [6] and is currently subject for further development.

In the experiments described in this thesis, the mouse model of Bijvoet and colleagues [4] has been used to gain insight in both the sequel of events and the mechanisms that underlie progressive muscle dysfunction in GSD II. At the start of the study, three potential causes for mechanical dysfunction in muscle diseases were put forward: (1) decline in contractile mass, i.e., muscle mass and contractile protein content; (2) decrease in capacity for oxidative energy conversion, resulting in insufficient amounts of ATP available for muscle contraction; and (3) impaired innervation of the muscle resulting in submaximal activation. During the course of the investigations, it became clear that additional factors were implicated in muscle dysfunction in AGLU- mice. In this General Discussion, the outcome of the studies conducted in the present thesis will be summarised and discussed in relation to findings reported by other investigators. Furthermore, the differences between pathological features of human GSD II and the AGLU mouse will be discussed. Finally directions for future research are indicated.

\section{Experimental approach}

In order to investigate the sequel and nature of patho-physiological changes in muscles lacking acid 1-4 $\alpha$-glucosidase activity, experiments were performed on AGLU- mice. Mice of three age groups were included in the study, i.e., 6-10 months, 12-16 months and 18-24 months of age.

Central in the present studies was the assessment of decline in mechanical performance of the affected muscles. To this end, contractile properties of the dorsal flexor muscle complex of mouse hind limbs were monitored in situ. Anaesthetised mice were mounted on a device that has recently been developed in a research collaboration between the University of Maastricht and the faculty of Biomedical Engineering of the Technical 
University Eindhoven. This device is uniquely suited to measure torque production around the ankle during isometric contractions and power generation during shortening contractions in mice $[7,8]$. These in situ measurements allow us to closely investigate how enzyme deficiencies or over-expression in knockout or transgenic mice affect skeletal muscle contractility.

To elucidate potential causes of impaired muscle mechanical performance, skeletal muscle content of high-energy phosphate compounds and related substances was analysed by means of high-pressure liquid chromatography (HPLC). Theoretically, decreased concentration of high-energy phosphates in the rested state in affected muscles could be a cause of impaired contractile function. The activity of a selection of glycolytic and mitochondrial enzymes that play a key role in muscle energy conversion was monitored as well. This was done to obtain indications of a potential downregulation of the capacity to generate sufficient amounts of ATP to maintain forces during repeated contractions.

To explore the relationship between the decline in muscle mechanical performance and muscle cell structure, morphological studies were performed on tissue samples of the tibialis anterior muscle of mice of the various age categories indicated above. To visualise the localisation and to estimate the size of intracellular glycogen depositions. per-iodic acid Schiff (PAS) staining was employed. In combination with a hematoxilin staining for localisation of nuclei, the overall morphological features of the cell could be studied to explore whether the lysosomal glycogen depositions disturb the spatial organisation of the myofibrils.

In later stages of the disease, also other substances accumulated in the cell, one of which being lipofuscin, a marker for cell senescence. Deposition of lipofuscin in the muscle cells was made visible by means of its auto-fluorescent properties.

It can be envisaged that the disturbed myofibrillar organisation as a result of the accumulation of un-metabolised material in the myocyte changes the direction and magnitude of intracellular stresses and strains. Since cytoskeletal proteins such as titin and desmin play an important role in the intracellular transmission of forces $[9,10]$, changes in localisation and contents of these two proteins were investigated. Intracellular localisation was made visible by means of immuno-fluorescence staining of tissue slides using antibodies specifically raised against desmin and titin. Moreover, the tissue content of these two cytoskeletal proteins was assessed by Western blotting.

In order to estimate the quantitative contribution of glycogen filled lysosomes to the decline in torque output by dorsal flexor muscles of AGLU mice, intracellular heterogeneity in stresses and strains during isometric contraction was estimated with the use of the finite element computational model as described earlier by Gielen and coworkers [11].

Muscle wasting is a general feature in patients suffering from Pompe disease. In the AGLU mouse model, skeletal muscle mass and content of contractile proteins were assessed with standard techniques. A first exploration of the potential causes of the decline in muscle mass in AGLU- mice was performed by measuring the activity of the 
ubiquitin-proteasome complex [12] as a potential indicator of changes in protein degradation rates. Skeletal muscle protein synthesis rate was calculated from the incorporation rate of an amino acid labelled with a stable isotope, which was administered in vivo by intraperitoneal injection [13]. Programmed cell death (apoptosis) is a common mechanism to diminish the negative effect of a diseased cell on its environment. The possible contribution of apoptosis in skeletal muscle wasting was, therefore, assessed as well. To this end, the number of TUNEL positive nuclei (as indicator of increased apoptosis rate) was monitored in the affected muscle cells.

Where possible, the observed changes in morphological and biochemical characteristics in muscle of $A G L U$ mice were related to the decline in mechanical performance of the muscle complex under investigation.

\section{Experimental findings}

Muscle mechanical performance

The experiments performed in the present thesis underscore the progressive nature of the loss of skeletal muscle performance when the lysosomal enzyme acid 1-4 $\alpha$ glucosidase is lacking. In AGLU mice, the decline in mechanical performance of the dorsal flexor muscle complex is relatively mild at 6-10 months of age. At this age, decline in maximal torque production during isometric contractions is in the order of $12 \%$ and the decrease in peak power amounts to $30 \%$. A more pronounced decline in muscle mechanical function, over $50 \%$ loss of isometric torque and power output, was observed in animals of 12 months and older. The observed changes in muscle mechanical behaviour could partially be explained by loss of muscle mass, indicating that additional factors, obviously affecting the quality of the muscle fibres, are important in the decline of contractile function.

\section{Quality of the remaining muscle tissue}

\section{Quantitative considerations}

At 6-10 months of age, the decline in muscle performance can not be explained by a loss of contractile material, but fully represents a decrease in quality of the remaining muscle tissue. At later stages of the disease, the 12-16 and 18-24 months old groups, the decline in mechanical performance was found to be a combination of decline in contractile mass and muscle quality, because both mass and mass normalized peak power as well as maximal torque were found to be lower in AGLU than in age matched controls. For example, in the 18-24 months group it can be calculated from data presented in Table 4.2 that one third of the decline in isometric torque can be attributed to decline in muscle mass, leaving $2 / 3$ to a decline in muscle quality. 


\section{Changes in the first 6-10 months of age}

Both biochemical and morphometrical analyses revealed that accumulation of glycogen within the lysosomes already approximated its maximum level when the AGLU animals reached the age of 6-10 months. Computational analysis (Chapter 6) showed that the glycogen filled lysosomes might be a major cause of the $12 \%$ decline in isometric maximal torque. In Chapter 4 it was hypothesised that these lysosomes might also cause a decline in optimal shortening angular velocity, although the magnitude of the effect of glycogen filled lysosomes on this contractile parameter is unknown. One might conclude that at $6-10$ months the decrease in muscle quality is caused by the presence of swollen lysosomes.

\section{Changes in older animals}

Despite the fact that accumulation of glycogen in lysosomes lacking acid 1-4 $\alpha$ glucosidase is by itself not a likely cause of the severe loss of mechanical function in aged AGLU* animals, impaired lysosomal function may set the stage for a whole array of alterations in skeletal myocyte (ultra)structural features, ultimately impairing mechanical performance.

Since glycogen accumulation in lysosomes is followed by the appearance of large intracellular cores of cell debris. it is temoting to speculate that the swollen lysosomes have lost their capacity to remove damaged macromolecules and cellular debris from the sarcoplasm. The fact that the central cores with precipitated cellular debris often contain lipofuscin, a substance normally observed in muscle cells of advanced age, strongly suggests that the process of senescence is accelerated in muscle cells of AGLU- mice. It should be emphasised that computer calculations predicted that the mechanical impact of these central cores on muscle mechanical behaviour is way too small to explain the decrease in mechanical function (Chapter 6).

Furthermore, changes in distribution of the cytoskeletal proteins desmin and titin were observed in older AGLU mice. Initially, the increased deposition of titin bordering the central inclusions containing non-contractile material inside the affected muscle fibers most likely occurs as an adaptation to changes in intracellular forces. Titin deposition in close vicinity of the central core seems to facilitate transmission of forces around the inclusion, thus mitigating the decline in force due to the presence of the cores. The functional significance of the alterations observed in desmin expression, however, is incompletely understood and might be unfavorable. In later stages of the disease, when the structural disarrangement of the muscle cells becomes more severe, in a number of muscle cells loss of titin and obviously non-functional deposition of increased amounts of desmin were prominent. It is highly unlikely that these severely affected muscle cells will be able to generate force.

Normalised isometric maximal torque declined between 6-10 and 12-16 months, but showed no further decrease after 12-16 months of age. Peak power showed a more gradual decline. The micro-morphological analysis showed a large decrease in quality of the myofibrillar organization in AGLU- mice between 12-16 and 18-24 months. At 18-24 
months, in $20 \%$ of the fibers a complete loss of cellular structure was observed, without an obvious decrease in diameter. At present it is incompletely understood why mass normalized maximal torque did not further decline after 12-16 months of age, while muscle cell morphological appearance appreciably deteriorated. Moreover, from a quantitative point of view, the substantial loss in peak power (up to $70 \%$ ) as compared to the age-matched controls is only partially explained. Obviously, more detailed studies are required to elucidate all factors involved in the loss of peak power generation in muscles lacking 1 -4 $\alpha$-glucosidase.

\section{Muscular energy conversion}

As has been put forward in chapter 2, loss of muscle mechanical function may be caused by unfavourable changes in muscle energy metabolism. However, biochemical analysis of muscle tissue indicated that in resting muscles the contents of ATP and phospho-creatine did not differ between control and AGLU mice (Chapter 3). Moreover, the activity of a number of key enzymes involved in muscle energy conversion did not differ either. These findings collectively make a causative role of alteration in muscle energy metabolism in the decline in muscle mechanical performance as assessed in the present studies less likely. It does, however, not exclude that energy metabolism during prolonged repetitive contractions is disturbed.

\section{Mechanisms of muscle wasting}

A first exploration of the factors that lead to the increased rate of muscle mass loss and muscle fibre atrophy in AGLU mice has been performed in Chapter 7. The rate of protein synthesis in skeletal muscle of AGLU ${ }^{+}$mice 12 months of age was found to be 3 fold increased. However, also the activity of the proteasome system, the main contributor to the degradation of muscle contractile proteins in healthy muscies in catabolic situations [17], was increased, while muscle mass showed only a minor decline. These findings indicate that in AGLU mice myofibrils are subject to increased protein turnover rates. In these animals, damaged myofibrils are rapidly broken down and replaced with newly synthesised myofibrils. Under normal conditions, local injury to muscle cells, eventually leading to myocyte loss, will activate satellite cells present in close vicinity of the muscle fibres [18]. Activation of satellite cells repairs the damage inflicted upon the muscle. The regenerative capacity of muscle tissue depends among others on the number of satellite cells $[18,19]$. Earlier studies have shown that the number of satellite cells in the muscle can be significantly reduced under myopathological conditions [20-22]. As a consequence, the regenerative capacity is severely depressed, resulting in loss of muscle mass when the diseased state is prolonged. It remains to be established, whether this is also the case in muscles of AGLU mice. Interestingly, in the eldest group of AGLU mice (18-24 months), in which the reduction of muscle mass is the greatest (about $25 \%$ ), the activity of the proteasome system was found to be lower than in age matched control. This may indicate that a downregulation of the normal protein breakdown process occurs in the final stages of the disease in an 
attempt to rescue some of the remaining muscle fibres. Earlier studies have shown that reduced activity of the proteasome system will readily occur in cells with a prominent accumulation of lipofuscin $[23,24]$. If the ubiquitin-proteasome system is no longer the key factor in the control of protein mass, activation of caspases and calcium-activated proteolytic enzymes as a result programmed cell death of (parts of) the affected muscle fibres might contribute to wasting of muscle mass in aged AGLU mice. The decline in activity of the proteasome system in the eldest, most severely affected, animals might therefore be a prelude to loss of cellular integrity and apoptosis. Moreover, it has been shown that impaired cytoskeletal organisation will hamper the adaptation of the cell to unfavourable conditions. As cytoskeletal proteins are essential to maintain cellular integrity and, hence, cell survival, the changes in cytoskeletal proteins in the advanced stages of the disease might contribute to the increased atrophy and apoptosis of skeletal muscle cells in AGLU mice. Due to the complexity of the pathological process in muscle cells lacking acid 1-4 $\alpha$-glucosidase activity, the precise mechanism underlying loss of muscle mass and decline in muscular mechanical performance remains, however, enigmatic.

\section{Comparison between experimental animal model and patients}

An important issue to consider is to what extent the patho-physiological features of AGLU mice are comparable with those of GSD II patients. In some regards, the mouse model was found to be similar to the human patient. For instance, the effect of the deletion in the GAA gene that causes the deficiency in the AGLU mice [4] is identical to the most frequent deletions in Caucasian patients [25]. Also the fact that early in life lysosomal accumulation of glycogen occurs in virtually all tissues investigated, corroborates with findings in patients $[4,26]$. In both humans and mice, supplementation of acid 1-4 $\alpha$-glucosidase was found to be most effective when started in early stages of the disease $[6,27]$.

Comparison of data obtained in the present study with findings in patients at the Sophia Children Hospital in Rotterdam revealed that, in general, patients show a much more severe patho-physiology and loss of muscle function than the mouse model. It is of interest to note that the rate of glycogen accumulation and absolute amount of glycogen stored per unit muscle mass is substantially lower in mice than in humans. Mice lacking acid 1-4 $\alpha$-glucosidase start showing overt clinical symptoms in between 10 and 12 months of age, which is approximately at $40 \%$ of the expected lifespan of unaffected animals. In contrast, severe pathology is already present in children suffering from Pompe disease before they reach the age of $4-5$ months. If the hypothesis of glycogen accumulating in the lysosomes after being inadvertently engulfed as 'by-catch' in the process of phagocytosis is correct [28-30], the fact that the sarcoplasmic glycogen content of mice is approximately 20 fold lower than that of humans $[5,31]$ may cause this inter-species difference in pace of pathology. 
Extrapolation of findings in experimental studies to patients should be done with care, since the chain of events might be much more condensed in patients. However, qualitatively and mechanistically the alterations in muscles of AGLU* mice may represent the sequel of changes taking place in muscles of patients lacking acid 1-4 $\alpha$ glucosidase activity.

\section{Directions for future research}

As the knockout mouse model for GSD II has been generated only 6 years ago, and despite recent detailed studies on patients performed by several research groups, a lot of questions remain to be answered. The picture that emerges from the studies described in this thesis is that the patho-physiology that occurs due to deletion of the GAA gene is highly complex. The results of the studies described here, indicate that reduced contractile mass, disturbed cell morphology and altered organisation of the cytoskeleton all contribute to the deterioration of muscle function. The quantitative contribution of the individual factors remains to be elucidated. Moreover, the ways in which those factors are connected to the lack of acid 1-4 $\alpha$-glucosidase should be looked into in more detail.

\section{Muscle contractile performance}

The data on peak power indicated a reduction in contractile velocity of the affected muscles. The cause of this decline is incompletely understood. No gross differences in muscle fibre type distribution were observed between AGLU and control mice. However, as data on young mice are lacking, quantification of fibre type distribution as a function of age should be performed. Furthermore, other factors remain to be identified that might cause a decrease in muscle shortening velocity. In Chapter 7 it was shown that at 12 months and older, degradation of muscle proteins is prominent. The progressive degradation of desmin as shown on Western blotting (see Chapter 5) might well indicate that a substantial amount of the proteins present in the skeletal myocyte is no longer (fully) functional. Therefore, Western blotting should be applied to identify if and to what extent proteins involved in contraction (actin, myosin, troponin) and cellular integrity (desmin, titin, $\alpha$-actinin, laminin, fibronectin) are being degraded.

\section{Energy metabolism in prolonged contractions}

No indications were obtained that in single contractions muscle energy metabolism is impaired. The present set-up, however, can not exclude that energy metabolism fails during prolonged contractions. Development of an appropriate technique to study prolonged muscular activity should allow for the assessment of the role of blood-borne and intracellular substrates in muscular energy conversion. Special attention should be paid to the transport of glucose and fatty acids across the sarcolemma, the metabolic conversion of intracellularly stored carbohydrates (glycogen) and lipids (triacylglycerol), 
the flux through glycolytic and $\beta$-oxidative pathways and mitochondrial citric-acid cycle and respiratory chain activity.

\section{Mechanisms of muscle wasting}

Presently, the mechanism by which a decreased activity of acid $1-4 \alpha$-glucosidase causes breakdown of muscle tissue remains elusive. The data presented in Chapter 7 suggest high protein turnover at the earlier stages of the disease. This might explain the minor damage to muscle tissue observed in 6-10 months old AGLU mice. To gain insight in the protein balance at the various age groups, further measurements of the protein synthesis rates as a function of age should be performed. In addition to this, degradation of muscle protein should be assessed by measuring the tyrosine release in the presence of cycloheximide, an inhibitor of protein synthesis, in isolated muscle preparations. Apart from the ubiquitin-proteasome pathway, also the activity of calcium activated enzymes (caspases) and lysosomal enzymes involved in breakdown of muscle protein should be studied in the various patho-physiological stages of the disease. Assessment of the regenerative capacity of the diseased muscle at various stages, i.e. the presence of satellite cells, is then vital to estimate the possibility of re-growth of muscle tissue. Where possible, these data should be related to systematic observations in patients.

\section{Therapeutic interventions supporting enzyme supplementation}

Besides more extensive analysis of the factors causing muscle function decline, the causes of the substantial inter-individual differences in clinical symptoms need to be elucidated. Apart from the residual activity of the enzyme as a consequence of differences in locus of the mutation, other factors appear to play a role. Even in our inbred mouse strain, we regularly observed substantial inter-individual differences in both decline in muscle mechanical performance as well as in the degree of morphological changes in individual muscle fibres of AGLU mice.

As contractile activity of the muscle causes release of the endogenous, anabolic, IGF-1 related, muscular growth factor (MGF) [32], differences in physical activity might be the cause of the differences in severity of clinical symptoms. Looking into the effects of habitual physical activity as a potential modulator of severity of clinical symptoms, and assessing the residual acid 1-4 $\alpha$-glucosidase activity required to be safeguarded against clinical complaints, might be helpful in the development of effective therapy for GSD II. Subjecting AGLU mice to a physical exercise intervention will show the influence of increased muscular activity on the degree of the patho-physiology. In addition to the study on physical activity as a supportive therapy, also therapies using compounds that stimulate muscle growth, such as IGF-1 [32], should be considered.

\section{Improvements in the enzyme supplementation therapy}

Although results obtained so far indicate that enzyme replacement therapy is potentially effective $[5,6]$, additional research is needed to establish both the full potency and 
potential setbacks of this therapy. It has also become clear that the efficacy of enzyme replacement therapy depends on the stage of the pathological process at the onset of the therapy $[6,27,33]$. Therapy is most effective when started in early stages of the disease. As the progression of the pathology in the mouse model is slower than in humans, the AGLU mouse in combination with our present set-up is a very good tool to evaluate which stage in the patho-physiology can be considered the 'point of no return'. In this way, one is able to evaluate the reversibility of the pathology, and to study the regression of the pathology after termination of the therapy. The information made available will enable the physician to estimate the likeliness of success when GSD II is diagnosed.

Both in patients and AGLU mice, IgG mediated reactions upon supplementation of the endogenous protein via the blood have been reported $[5,6]$. It is therefore of utmost importance to investigate which procedure to supplement the enzyme is safe and effective in order to combat the deleterious side-effects of the supplementation.

The fact that the present form of the enzyme is not able to cross the blood/ brain barrier, leaving a vital system in the body untreated, is a potential drawback of the present therapy. It can be envisaged that during the therapy, accumulation of glycogen continues in cells of the central nervous system. At present, the consequences of lysosomal glycogen accumulation in the latter tissue are incompletely understood, since untreated patients die from cardio-respiratory insufficiency before neurological symptoms could develop. It is therefore advisable to monitor neurological function in patients receiving enzyme therapy.

There are a number of indications that heart muscle reacts differently to lysosomal glycogen storage than skeletal muscle. It has been shown that, despite massive glycogen storage, cardiac function remains preserved for an extended period during the progression of the disease [34], and that this organ seems more responsive towards supplementation of the deficient enzyme [27]. As cardiac muscle has no satellite cells and, hence, little regenerative capacity, it is of interest to explore the mechanisms by which the cardiac muscle maintains its function at a sufficient high level to withstand the patho-physiological changes.

In the future, gene transfer therapy might be the solution for patients suffering from GSD II. However, extensive research is required before the promises of the strong potentials of such therapy can be safely made true in patients. Animal models and sophisticated measuring devices to monitor muscle function are of great importance to reach this goal. 


\section{References}

1 Pompe, J.C. (1932) Ned Tijdsch Geneesk 76, 304-311.

2 Reuser, A.J.J., Kroos, M.A., Hermans, M.M.P., Bijvoet, A.G.A., Verbeet, M.P., Van Diggelen, O.P., Klejer, W.J. and Van der Ploeg. A.T. (1995) Muscle \& Nerve Suppl 3, S61-S69.

3 Hirschhorn, R. (1995) in The Metabolic and Molecular Basis of Inherited Disease (Scriver, C.R., Beaudet, A.L., Sly, W.S. and Valle, D., eds.), pp. $2443-$ 2464, McGraw-Hill, New York.

Bijvoet, A.G.A., Van der Kamp, E.H.M., Kroos, M.A., Ding, J.H., Yang, B.Z. Visser, P., Bakker, C.E., Verbeet, M.P., Oostra, B.A., Reuser, A.J.J. and Van der Ploeg, A. T. (1998) Hum Mol Gen 7, 53-62. Bijvoet, A.G.A. (1999) Thesis, Dep Clin Gen, Erasmus Universiteit, Rotterdam. Van den Hout, J.M., Reuser, A.J.J., de Klerk, J.B., Arts, W.F., Smeitink, J.A. and Van der Ploeg, A.T. (2001) J Inherit Metab Dis 24, 266-274. Gorselink, M., Drost, M.R., de Louw, J., Willems, P.J., Rosielle, N., Janssen, J.D. and Van der Vusse, G.J. (2000) Pflugers Arch 439, 665-670.

8 Gorselink, M., Drost, M.R., de Louw, J., Willems, P.J., Hesselink, M.K.C., Dekkers, E.C., Rosielle, N. and Van der Vusse, G.J. (2001) Pflugers Arch 442. 304-311.

Monti, R.J., Roy, R.R., Hodgson, J.A. and Edgerton, V.R. (1999) J Biomech 32. 371-380.

10 Patel, T.J. and Lieber, R.L. (1997) Exerc Sport Sci Rev 25, 321-363.

11 Gielen, A.W., Oomens, C.W., Bovendeerd, P.H., Arts, T. and Janssen, J.D. (2000) Comput Methods Biomech Biomed Engin 3, 231-244.

12 Voisin, L., Breuille, D., Combaret, L., Pouyet, C., Taillandier, D., Aurousseau, E., Obled, C. and Attaix, D. (1996) J Clin Invest 97, 1610-1617.

Garlick, P.J., McNurlan, M.A. and Predy, V.R. (1980) Biochem J 192, 719-723. Lewis, S.F. and Haller, R.G. (1989) Exerc Sport Sci Rev 17, 67-113. Hesselink, R.P., Gorselink, M., Schaart, G., Wagenmakers, A.J.M., Kamphoven, J., Reuser, A.J.J., Van der Vusse, G.J. and Drost, M.R. (2002) Muscle Nerve 25, 873-883.

6 Galou, M., Gao, J., Humbert, J., Mericskay, M., Li, Z., Paulin, D. and Vicart, P. (1997) Biol Cell 89, 85-97.

17 Lecker, S.H., Solomon, V., Mitch, W.E. and Goldberg, A.L. (1999) J Nutr 129 , 227S-237S.

18 Partridge, T.A. (2002) Gene Ther 9, $752-753$.

19 Roth, S.M., Martel, G.F., Ivey, F.M., Lemmer, J.T., Metter, E.J., Hurley, B.F. and Rogers, M.A. (2000) Anat Rec 260, 351-358.

20 Carpenter, S. and Karpati, G. (1986) Hum Pathol 17, 683-703.

21 Luz, M.A., Marques, M.J. and Santo Neto, H. (2002) Braz J Med Biol Res 35. 691-695. 
22 Nakae, Y., Stoward, P.J., Shono, M. and Matsuzaki, T. (2001) Histochem Cell Biol 115, 205-214.

23 Sitte, N., Merker, K., Von Zglinicki, T., Grune, T. and Davies, K.J. (2000) Faseb J 14, 2495-2502.

24 Sitte, N., Merker, K., Von Zglinicki, T., Davies, K.J. and Grune, T. (2000) Faseb J 14, 2503-2510.

25 Ausems, M.G., Kroos, M.A., Van der Kraan, M., Smeitink, J.A., Kleijer, W.J., Ploos-van Amstel, H.K. and Reuser, A.J.J. (1996) Clin Genet 49, 325-328.

26 Bijvoet, A.G.A., Van Hirtum, H., Vermey, M., Van Leenen, D., Van Der Ploeg, A.T., Mooi, W.J. and Reuser, A.J.J. (1999) J Pathol 189, 416-424.

27 Raben, N., Jatkar, T., Lee, A., Lu, N., Dwivedi, S., Nagaraju, K. and Plotz, P.H. (2002) Mol Ther 6, 601-608.

28 Van der Ploeg, A.T., Kroos, M., Van Dongen, J.M., Visser, W.J., Bolhuis, P.A. and Loonen, M.C.B. (1987) J Neurol Sci 79, 327-336

29 Van der Ploeg, A.T., Bolhuis, P.A., Wolterman, R.A., Visser, J.W., Loonen, M.C.B. an Reuser, A.J.J. (1988) J Neurol 235, 392-396

30 Hesselink, R.P., Wagenmakers, A.J.M., Drost, M.R. and Van der Vusse, G.J. (2003) Biochim Biophys Acta 1637, 164-170.

31 Van der Vusse, G.J., Coumans, W.A., Van der Veen, E., Drake, A.J., Flameng, W., Suy, R. (1984) Vasc. Surg. 18, 127-134.

32 Goldspink, G. (1999) J Anat 194, 323-334.

33 Amalfitano, A., Bengur, A.R., Morse, R.P., Majure, J.M., Case, L.E., Veerling, D.L., Mackey, J., Kishnani, P., Smith, W., McVie-Wylie, A., Sullivan, J.A., Hoganson, G.E., Phillips, J.A., 3rd, Schaefer, G.B., Charrow, J., Ware, R.E., Bossen, E.H. and Chen, Y.T. (2001) Genet Med 3, 132-138.

34 Kamphoven, J.H., Stubenitsky, R., Reuser, A.J.J., Van der Ploeg, A.T., Verdouw, P.D. and Duncker, D.J. (2001) Physiol Genom 5, 171-179. 
Summary 


\section{Summary}

Inherited enzyme deficiencies in muscle commonly lead to decreased contractile function, severely hampering patients locomotive capacities and/or leading to their death due to cardio-respiratory insufficiency. Glycogen storage disease type II (GSD II or Pompe's disease) is an inherited autosomal recessive disorder, in which the patient has insufficient activity of the lysosomal enzyme acid 1-4 $\alpha$-glucosidase. As a consequence, glycogen accumulates in the lysosomes of all tissue, most severely depressing muscle contractile function. In the most severe cases of this muscular disorder, patients die before they reach the age of 2 years. In this thesis, studies are described which aimed to unravel the patho-physiological process that takes place in skeletal muscle tissue lacking acid 1-4 $\alpha$-glucosidase. Using the acid 1-4 $\alpha$-glucosidase deficient mouse (AGLU mouse) as a model for human GSD II, we aimed to improve the insight in the processes underlying the disease, and to provide information that might facilitate the research regarding the therapeutic treatment of this disease.

After a general introduction on GSD II, the objectives of the studies described in the thesis are formulated in the first chapter. The main objective of this thesis was to gain insight in the time course of the decline in muscle mechanical performance in AGLU \% mice in both isometric and isokinetic contractions. The second aim was to obtain information on possible mechanisms that lead to the decline in muscle performance. This includes alterations in muscle mass and quality of the remaining muscle tissue. As a number of factors can influence both muscle mass and quality of remaining muscle tissue, the third aim of this thesis was to identify mechanisms underlying muscle wasting that occurs in GSD II. To this end, changes in protein turnover, the activity of the ubiquitin proteasome complex and apoptotic activity were subject of study.

The thesis continues with an overview of the literature on lysosomal storage diseases in Chapter 2, paying special attention to the cellular pathology as it occurs in GSD II. In this chapter, a number of potential causes for the tissue damage that takes place in lysosomal storage diseases are identified. In the fast majority of lysosomal storage diseases accumulation of lipofuscin is prominent. Normally, lipofuscin only occurs in aged cells, and is connected to a diminished lysosomal activity. Moreover, lipofuscin accumulation in cells is connected to programmed cell death. As a result of this, two hypotheses are formulated about the possible ways of muscle wasting in GSD II. First, it is hypothesised that the gradual loss of muscle mass is caused by a combination of disuse atrophy and lipofuscin mediated apoptosis of myocytes. Second, we hypothesised that in the remaining skeletal muscle cells longitudinal transmission of force is hampered by swollen lysosomes, clustering of non-contractile material and focal regions with degraded contractile proteins, which results in muscle weakness.

Chapter 3 of this thesis describes a study on aged AGLU mice. In this study a number of parameters, i.e. the force production capabilities, contractile mass, oxidative capacity, energy status, gross morphology, and desmin content of skeletal muscle were measured in the severely diseased state and compared to age matched control animals. Assessment of muscle contractile performance was performed is a specifically designed 
in situ set-up. It was found that at 18 months of age, with obvious clinical symptoms, AGLU mice produced a maximal torque during single tetanic contraction that was $50 \%$ reduced compared to unaffected animals. This decline in contractile performance was accompanied by a reduction of $20 \%$ in muscle mass, implying that loss of developed torque was disproportionate to the loss in muscle mass. During a series of supramaximal contractions, fatigue (when expressed as percentile decline of developed torque) did not differ between AGLU mice and age-matched controls. Muscle oxidative capacity, energy status, and protein content (normalised to either dry or wet weight) were not changed in knockout mice compared to control. At 18 moths of age, the gross morphology of muscle cells of AGLU was clearly disturbed by the glycogen filled lysosomes and by large areas of cell debris that accumulated in the central region of the myocyte. Desmin content was found to be increased, whereas $\alpha$-actinin was not, suggesting a specific adaptation of the cytoskeleton in affected muscle cells. It was felt that the large clusters of non-contractile material present in the cytoplasm hamper longitudinal force transmission, and, hence, muscle contractile function. The increase in muscular desmin content is most likely reflecting adaptations to altered intracellular force transmission.

In Chapter 4, a study is described in which measurements were performed in three groups of mice (6-10, 12-16 and 18-24 months of age), representing different stages of progression of the pathology. Data on muscle mechanical performance were related to loss of muscle mass, muscle protein content, and muscle glycogen content, to analyse the contribution of each of these individual pathological features.

The progressive nature of the pathological process was underlined by the fact that in AGLU mice, isometric maximal torque and peak power progressively declined when related to age matched controls. Moreover, the data presented indicate that power production during shortening contraction is affected earlier than isometric strength. Progressive loss of muscle mass was observed starting from age 12-16 months. The reduction of mass normalised power output was progressive with age, loss of mass normalised torque did not further increase after 12-16 months. Optimal shortening angular velocity was about $25 \%$ lower in AGLU than in control mice, and did not change with age. As power-output is also determined by the shortening velocity of the muscle, reduced optimal shortening angular velocity of affected muscles was considered to be a substantial cause of the decline in peak power. Accumulation of glycogen was already prominent in muscles of 6-10 month old AGLU mice but did not further increase thereafter. Therefore, it was concluded that in the 6-10 months old group. glycogen accumulation might be an important factor in loss of mechanical performance. In later stages of the disease, however, it is unlikely that accumulated glycogen is a crucial factor for the decrease in muscle mechanical function.

Chapter 5 elaborates on the effects of the lysosomal glycogen accumulation on the structure of the muscle cell. Morphological and structural features of muscle cells were analysed in AGLU mice of the same ages as in the study described in the previous chapter, and compared to findings in non-affected littermates. Initially, the glycogen filled 
lysosomes became visible as focal spots upon per-iodic acid Schiff (PAS) staining in AGLU animals. In later stages, large intracellular inclusions of mixed cellular debris disturb the sarcoplasmic organisation. These large inclusions also contain lipofuscin, pointing to an overall dysfunction of the lysosomes to digest macromolecules. Concomitant with the appearance of the large inclusions, alterations in the cytoskeletal structure of the affected muscle cells were observed. Initially, increased deposition of titin bordering the large inclusions inside the affected muscle fibres occurs. It was hypothesised that these titin depositions might be a compensatory mechanism to facilitate transmission of forces around the inclusion, thus mitigating the decline in force. Total desmin content gradually increased with advancing age while desmin staining was not confined to areas in close vicinity of the intracellular inclusions. The functional significance of the alterations in desmin expression is incompletely understood. In later stages of the disease, when the structural disarrangement of the muscle cells becomes more severe, in some muscle cells the loss of titin and non-functional deposition of desmin were prominent.

Analysis of loss of contractile function in Chapter 4, and analysis of morphological features in Chapter 5 revealed that in the youngest AGLU mice the disturbance of cellular organisation by the glycogen filled lysosomes might be the most prominent factor in the loss of muscle function. Therefore, in Chapter 6 the contribution of this phenomenon to the decrease in muscle contractile function in an isometrically contracting slice of a muscle was calculated with a finite element model. Force was calculated at several inclusion densities and distributions and compared to normal muscle. Results from the calculations were compared to in situ measures of dorsal flexor torque of $\alpha$-glucosidase null mice of 6 months of age and unaffected littermates and assessments of inclusion density in the dorsal flexor muscles. The calculated force loss was shown to be almost exclusively dependent on the inclusion density and less on the type of inclusion distribution. The force loss predicted by the model $(6 \%)$ on the basis of measured inclusion density $(3.3 \%)$ corresponded to the loss in mass-normalised strength in situ measurements $(7 \%)$. It was concluded that the mechanical interaction between the non-contractile inclusions and the adjacent myofibrils is a key factor in the loss of force per unit muscle mass during early stages of GSD II in mice. As glycogen accumulation reaches higher levels in humans than in mice, it is highly probable that the impact of this mechanical interaction is even more severe in patients suffering from Pompe disease.

In Chapter 7, the mechanisms of muscle wasting in AGLU mice are studied in more detail, using a series of techniques to study both the synthesis and the degradation of muscle protein. Muscle mass of both AGLU and unaffected littermates was determined at the same ages as in Chapters 4 and 5 , and was found to be decreased in AGLU mice of the eldest 2 age groups. Protein synthesis rates were measured as the rate of incorporation of $\mathrm{L}$-[ring $\left.-{ }^{13} \mathrm{C}_{6}\right]$-phenylalanine into mixed muscle protein in $\mathrm{AGLU}$ mice and unaffected littermates at 12-16 months of age. Proteolytic activity of the ubiquitin proteasome complex was determined in pooled muscles of mice of the various age 
groups all 3 age groups. Furthermore, localisation of the 19S regulatory subunit of the proteasome complex was performed on muscle tissue slides of control and affected mice of all age groups, as well as assessment of apoptotic activity by determination of the contents of TUNEL positive nuclei.

The results show that at 12 months, protein synthesis rates were at least 3 -fold higher in AGLU mice compared to unaffected animals, while the activity of the proteasome and antibody staining of the $19 \mathrm{~S}$ regulatory subunit were increased too. In AGLU mice 6-10 months of age, the indicated markers of proteolysis are increased as well, while muscle mass remains constant. In AGLU animals 18-24 months of age, activity of the proteasome complex is reduced. while wasting of muscle is prominent. Only in these old affected animals a small number of nuclei $(1.5 \%)$ was TUNEL positive.

The data collectively suggest that disruption of the myofibrillar structure in early stages of the disease leads to high activities of the proteasome system and clearance of the disrupted or damaged myofibrils. High rates of regeneration, most likely via activation of satellite cells in the damaged areas, appear to lead to high rates of protein synthesis. This then results in a rapid replacement (turnover) of the damaged myofibrils with newly synthetised myofibrils and minimal visible loss of structure. The chapter ends with the hypothesis that in older animals, the regenerative capacity may be lost due to satellite coll depletion and the rates of prutein synthesis must fall. in uruer fo prevent a very rapid loss of myofibrils the activity of the proteasome system seems to show an adaptive downregulation.

Finally in Chapter 8, the results of the previous chapters are discussed and directions for future areas of research are indicated. In that chapter it is concluded that the pathology in muscle lacking acid 1-4 $\alpha$-glucosidase is multifactorial. Analysing the data from the studies carried out in this thesis and comparing them with results obtained by other groups aiming to develop therapeutic interventions for GSD II it is felt that a point of no return might be present in the patho-physiological process of acid 1-4 $\alpha$-glucosidase deficiency. This would imply that to be most successful, therapeutic interventions should take place early in the disease process. Close monitoring of new-borns is thus essential. In the future, more experimental studies should be performed, delineating the mechanisms of muscle wasting and the regenerative capacity of the affected muscle in order to reduce the detrimental effects of muscle atrophy. Finally, it is suggested that apart from the enzyme replacement therapy that is presently developed, additional therapeutic measures such as mild exercise programmes or addition of muscle growth stimulating agents should be explored. 

Samenvatting 


\section{Samenvatting}

Erfelijke enzym deficiënties in spierweefsel hebben vaak een verminderd functioneren van het spierweefsel tot gevolg. Als gevolg hiervan is de capaciteit van deze patiënten om te bewegen afgenomen, en in veel gevallen sterven patiënten aan een verminderde cardio-respiratoire functie. Glycogeen stapeling ziekte type II, ook wel ziekte van Pompe genoemd, is een aandoening die autosomaal recessief overert, en waarin de patiënten een te lage activiteit van het lysosomale enzym zure 1-4 $\alpha$-glucosidase hebben. Als gevolg hiervan ontstaat stapeling van glycogeen in de lysosomen van deze patiënten. Deze stapeling komt in alle weefsels voor, maar heeft de meeste gevolgen voor het spierweefsel, waarvan de functie ernstig verminderd is. Bij de meest ernstige vorm van deze spierziekte overlijden de patienten door functie verlies van hartspier en ademhalingsspieren voor ze 2 jaar oud zijn. De onderzoeken die in dit proefschrift beschreven staan, waren er op gericht inzicht te verwerven in het pathologische proces dat plaatsvindt in spierweefsel zonder werkzaam zure 1-4 $\alpha$-glucosidase. In deze onderzoeken werd een genetisch gemodificeerde muizenstam gebruikt als model voor het humane ziektebeeld. Metingen uitgevoerd aan muizen zonder werkzaam zure 1-4 $\alpha$ glucosidase (AGLU muizen) hadden tot doel meer inzicht te verschaffen in het mechanisme dat het klinische ziektebeeld veroorzaakt, en informatie te verzamelen die de ontwikkeling van therapieën voor de ziekte van Pompe kunnen vergemakkelijken.

Het proefschrift begint met een inleidend hoofdstuk waarin enige algemene informatie over het ziektebeeld gegeven wordt en de onderzoeksdoelen beschreven staan. Het belangrijkste doel van dit proefschrift was een beeld te krijgen van het tijdspad waarin de afname van spierfunctie in zowel isometrische als isokinetische contracties plaatsvindt. Een tweede doel was inzicht te krijgen in een aantal mogelijke mechanismen die een rol spelen bij de verminderde spierfunctie. Hieronder vallen zowel veranderingen in spiermassa als vermindering van de kwaliteit ven het spierweefsel. Omdat een aantal factoren een rol kan spelen bij zowel veranderingen in spiermassa als veranderingen in kwaliteit van het nog aanwezige spierweefsel was een derde doel van dit proefschrift de factoren die een rol spelen bij de afname van spiermassa bij ziekte van Pompe te belichten. Hiervoor werden de eiwit turnover, de activiteit van het ubiquitine proteasoom systeem en de apoptotische activiteit in het spierweefsel van AGLU muizen onderzocht.

Vervolgens wordt in hoofdstuk 2 een literatuuroverzicht gegeven over lysosomale stapelingsziekten. Hierbij is de nadruk gelegd op de ziekte van Pompe. Aan de hand van de literatuur wordt in dit hoofdstuk een aantal mechanismen genoemd die een rol kunnen spelen bij de schade aan weefsels die optreedt bij lysosomale stapelingsziekten. In veruit de meeste van deze aandoeningen is stapeling van lipofuscine een duidelijk herkenbaar fenomeen. Lipofuscine stapeling komt in normale omstandigheden alleen voor in oudere cellen en wordt in verband gebracht met een verminderde functie van de lysosomen. Verder wordt stapeling van lipofuscine in verband gebracht met geprogrammeerde celdood. Hierop werden 2 hypotheses geformuleerd over mogelijke 
mechanismen die de afname van spiermassa bij ziekte van Pompe kunnen veroorzaken. Een eerste oorzaak van de progressieve afname van spiermassa is een combinatie van atrofie door het verminderde gebruik van de spieren en door lipofuscine stapeling veroorzaakte geprogrammeerde celdood. Een tweede hypothese was dat de door glycogeen stapeling gezwollen lysosomen, stapeling van niet contractiel materiaal, en plekken in de spiercel waar de contractiele elementen worden afgebroken de structuur van overgebleven spierweefsel dusdanig verstoord hebben dat doorleiding van krachten in de lengterichting, dat will zeggen naar de pezen, niet meer goed mogelijk is. Dit heeft een verminderde spierfunctie tot gevolg.

In hoofdstuk 3 wordt een onderzoek beschreven bij oudere AGLU* muizen, waarbij de klinische klachten zich al duidelijk hadden ontwikkeld. In dit onderzoek werden de hoeveelheid spiermassa, de spier contractiliteit, de oxidatieve capaciteit, de energie status, de morfologie van de spieren en de hoeveelheid desmine in de spier bepaald. De resultaten van de aangedane muizen werden vergeleken met die van niet aangedane nestgenoten. Spiercontractiliteit werd in situ gemeten in speciaal hiervoor ontworpen meetapparatuur. Het bleek dat aangedane muizen van 18 maand oud $50 \%$ minder koppel kunnen leveren tijdens een eenmalige tetanische spiercontractie dan hun niet aangedane nestgenoten. Deze verminderde spierfunctie ging gepaard met een $20 \%$ verminderde spiermassa. De afname in spierfunctie is dus disproportioneel ten opzichte van de afname in spiermassa. De vermoeibaarheid van de spieren, uitgedrukt als de procentuele afname in geproduceerd koppel tijdens een serie contracties, verschilde niet tussen de AGLU* muizen en de controle dieren. Ook de op spiermassa genormaliseerde waarden van de oxidatieve capaciteit, energie status en het eiwit gehalte vertoonden geen verschillen. De morfologie van de spieren van AGLU muizen verschilde wel wezenlijk van die van niet aangedane controle dieren. De celstructuur was duidelijk verstoord door aanwezigheid van met glycogeen gevulde lysosomen en door grote gebieden centraal in de spiercellen waar celmateriaal zich had afgezet. Analyse van de hoeveelheid desmine en $\alpha$-actinine in het spierweefsel toonde aan dat in de spieren van AGLU\% muizen duidelijk meer desmine aanwezig was dan in de controle dieren, terwijl de hoeveelheden $\alpha$-actinine gelijk waren. Omdat het waarschijnlijk is dat de grote hoeveelheden niet-contractiel materiaal in de spiercellen van de AGLU* muizen de longitudinale kracht doorleiding beinvloedt, is het aannemelijk dat de verhoogde hoeveelheid desmine in aangedane muizen een aanpassing is aan de veranderde intracellulaire krachten.

Hoofdstuk 4 beschrijt een onderzoek dat werd uitgevoerd op muizen in 3 verschillende leeftijdsgroepen (6-10 maand, 12-16 maand en 18-24 maand). Deze verschillende leeftijden komen overeen met verschillende stadia van het ziekteproces bij de muizen. Gegevens over de mechanische prestaties van de spier werden gerelateerd aan de mate van spiermassa verlies, eiwit gehalte van de spier en glycogeen gehalte van de spier. Op deze manier werd inzicht verkregen in de mate waarin deze pathologische factoren afzonderlijk bijdragen aan het verlies van spierfunctie. 
Het progressieve karakter van de ziekte kwam tot uiting in een voortschrijdende afname van het geleverd maximaal koppel en maximaal vermogen ten opzichte controle dieren van gelijke leeftijd. Ook blijkt uit de gegevens dat de spierfunctie tijdens isokinetische contracties eerder is aangedaan dan tijdens isometrische contracties. Progressief spiermassa verlies trad op vanaf de leeftijd 12-16 maand. De op spiermassa genormaliseerde afname van het geproduceerd vermogen werd progressief minder in alle leeftijdsgroepen, terwijl het geleverd koppel niet meer afnam na 12-16 maand. De optimale contractie snelheid lag ongeveer $25 \%$ lager in de AGLU $\%$ dieren. Dit was niet afhankelijk van de leeftijd. Omdat het geleverd vermogen mede afhankelijk is van de contractie snelheid kan deze vermindering een substantiële bijdrage geleverd hebben aan het verminderd maximaal vermogen in de AGLU* muizen. De stapeling van glycogeen was in AGLU* dieren van 6-10 maand al zeer duidelijk, en nam na die leeftijd niet significant toe. Hieruit werd geconcludeerd dat in de jongste muizen (6-12 maand) de glycogeen stapeling een belangrijke factor kan zijn in het verlies van spierfunctie. Het is echter niet waarschijnlijk dat in het verdere verloop van de pathologie de glycogeen stapeling per sé een cruciale factor is in de progressieve afname van spier massa en spierfunctie.

In hoofdstuk 5 wordt verder ingegaan op de effecten die de lysosomale glycogeen stapeling kan hebben op de structuur van de spiercel. In de spieren van aangedane en controle muizen van dezelfde leeftijdsgroepen als in hoofdstuk 4 werden de morfologische en structurele eigenschappen geanalyseerd. In de jongste AGLU*- dieren toonde een PAS kleuring de met glycogeen gevulde lysosomen als duidelijk afgebakende plekken in de spiercel. In de oudere dieren wordt de sterk georganiseerde indeling van de spiercel ook nog verstoord door grote velden met afzettingen van celmateriaal. In deze afzettingen komt regelmatig lipofuscine voor, wat erop duidt dat het lysosomaal systeem niet meer in staat is om macromoleculen af te breken. Parallel aan het verschijnen van de afzettingen van cel-materiaal zijn veranderingen in de structuur van het cytoskelet waar te nemen. Deze beginnen met een toename van titine aan de randen van de intracellulaire afzettingen. Deze observatie heeft tot de hypothese geleid dat de lokaal verhoogde titine afzetting tot doel heeft de doorleiding van krachten langs de grote insluitsels te bevorderen, en op die manier de functie van de spiercel te behouden. In de AGLU muizen werd een progressieve toename in de hoeveelheid desmine gevonden en kleuringen toonden aan dat deze verhoogde desmine expressie niet beperkt was tot de gebieden in de buurt van de inclusies. De functionele betekenis van de toename in desmine is nog niet duidelijk. In de latere fases van het ziekteproces zijn de verstoringen in de celstructuur steeds groter en is in individuele cellen een verminderde hoeveelheid titine en niet-functionele desmine te zien.

Uit de gegevens van hoofdstuk 4 en 5 bleek dat in de jonge AGLU dieren de lysosomale stapeling van glycogeen de meest bepalende factor voor spierfunctie verlies zou kunnen zijn. Daarom is in hoofdstuk 6 de bijdrage van intracellulaire inclusies van gezwollen lysosomen aan de verminderde spierfunctie gekwantificeerd met behulp van een eindige elementen model. De berekeningen werden uitgevoerd op een isometrisch 
contraherende plak spier, bij verschillende inclusie dichtheden en verdelingen. De resultaten van de berekeningen werden vergeleken met resultaten van in situ koppel metingen aan de dorsaalflexoren van 6 maand oude AGLU muizen en inclusie dichtheid bij deze dieren. Het berekend koppel verlies was bijna geheel afhankelijk van de inclusie dichtheid, en niet van de verdeling van de inclusies. De uitkomsten van het model ( $6 \%$ krachtsverlies bij een inclusie dichtheid van 3.3\%) kwamen goed overeen met de waarden gevonden bij in situ metingen (7\% koppelverlies). Uit de analyses bleek dat de interactie tussen de niet-contractiele insluitsels en de direct aangrenzende myofibrillen een belangrijke factor is in het verlies in spiertunctie in de eerste fase van het pathologisch proces bij AGLU muizen. Omdat de stapeling bij patiënten met ziekte van Pompe veel sterker is dan de stapeling bij de AGLU* muizen is het waarschijnlijk dat dit fenomeen in patiênten een nog prominentere rol speelt.

In hoofdstuk 7 wordt in meer detail ingegaan op mogelijke mechanismen van spiermassa verlies bij AGLU muizen. Hierbij is een aantal technieken gebruikt om zowel afbraak als opbouw van spiereiwit te kunnen meten. Muizen uit dezelfde leeftijdsgroepen als in hoofdstukken 4 en 5 werden onderzocht. In de oudste 2 groepen was de spiermassa in AGLU muizen lager dan die van controle dieren. In de leeftijdsgroep 12-16 maand werd de eiwit synthese snelheid bepaald door de inbouwsnelheid van L-[ring- $\left.{ }^{13} \mathrm{C}_{6}\right]$-phenylalanine in de spier. De proteolytische activiteit van het ubiquitine proteasoom systeem werd in alle leeftijdscategorieèn gemeten in spier homogenaten. Ten slotte werd op coupes van spierweefsel van dieren uit alle leeftijdsgroepen zowel de lokalisatie van het 19S deel van het proteasoom complex als de apoptotische activiteit in de spiercellen bepaald. De uitkomsten van de verschillende metingen toonden aan dat in AGLU muizen van 12-16 maand de eiwitsynthese activiteit ten minste 3 keer hoger is dan in controle dieren, terwijl ook de activiteit van het ubiquitine proteasoom systeem verhoogd is en er meer 19S subunit in de cel aanwezig is. Ook in de 6-10 maand oude AGLU- dieren zijn de markers voor proteolyse verhoogd, hoewel de spiermassa niet verschilt met controle dieren. In de oudste dieren tenslotte is de activiteit van het proteasoom systeem verminderd, terwijl er wel duidelijk afname van spiermassa in AGLU dieren is. Dit is ook de enige groep dieren waarin een klein percentage $(1.5 \%)$ van de celkernen apoptose lijkt te ondergaan. Uit deze gegevens wordt geconcludeerd dat de verstoring van de myofibrillaire structuur in de eerste fase van het ziekteproces een verhoogde activiteit van het proteasoom systeem tot gevolg heeft, waardoor de beschadigde celdelen worden opgeruimd. Activatie van satellietcellen kan voor een snelle regeneratie van het verloren gegane spierweefsel zorgen en de oorzaak zijn van de hoge eiwit synthese activiteit. Door deze hoge turnover worden beschadigde cel delen snel vervangen en is het zichtbaar verlies van spierstructuur minimaal. Aan het eind van dit hoofdstuk wordt de hypothese geformuleerd dat in de oudere dieren de regeneratieve capaciteit verminderd kan zijn vanwege een tekort aan satelliet cellen. De eiwit synthese snelheid zal dan afnemen. Om een te snel verlies van spierweefsel tegen te gaan daalt de proteolytische activiteit in deze oude dieren. 
Hoofdstuk 8 is een algemene discussie waarin alle gegevens uit de voorgaande hoofdstukken worden besproken en mogelijke toekomstige onderzoeksvelden aangegeven. Er wordt geconcludeerd dat het ziekteproces in spieren met een verlaagde activiteit van zure 1-4 $\alpha$-glucosidase een mulitfactorieel proces is. Verder wordt, na analyse van de resultaten uit de studies in dit proefschrift en die verkregen uit onderzoek door anderen, gesuggereerd dat er in het ziekteproces een 'point of no return' zou kunnen zijn. Dit impliceert dat een therapeutische interventie zo vroeg mogelijk in het ziekteproces plaats moet vinden om het grootste effect te hebben. Hiervoor is een goede screening van pasgeborenen essentieel. Toekomstige studies zouden zich moeten richten op de mechanismen van spiermassa verlies en de regeneratieve capaciteit bij ziekte van Pompe. Dit dient te gebeuren om de zeer nadelige effecten van spiermassa verlies tegen te kunnen gaan. Het hoofdstuk sluit af met de suggestie dat naast de enzym vervangende therapie die momenteel ontwikkeld wordt ook onderzoek gedaan dient te worden naar ondersteunende therapieën. Voorbeelden hiervan zijn aangepaste trainingsprogramma's of het toedienen van stoffen die de spiergroei stimuleren. 
Dankwoord 


\section{Dankwoord}

Het dankwoord is een raar iets. Het is het laatste dat je van je proefschrift schrijtt, en het eerste dat iedereen leest. Het enige onderdeel van je proefschrift waar begeleiders geen commentaar meer op leveren is het onderdeel dat het meest kritisch door de meerderheid van de lezers bekeken wordt. Wat heb ik de afgelopen 4,5 jaar gedaan, wie hebben me daarbij geholpen, op welke manier, en in welke volgorde moet ik ze daarvoor bedanken?

De meeste hulp heb ik zonder enige twijfel ontvangen van mijn promotores en mijn copromotor. Ger, Ton en Maarten, onze werkoverleggen waren vaak intensief, lang en vruchtbaar. Ik heb er veel geleerd, we hebben veel gediscussieerd en het proefschrift is er beter door geworden. Ton, jij hebt aan het begin van het project gestaan, en je hebt er voor gezorgd dat het ook tot een eind is gekomen. Ik had graag meer onderzoek gedaan naar de eiwithuishouding in AGLU* muizen, maar er lagen andere vragen, die eerst behandeld moesten worden. Je brede kennis, je enthousiasme voor onderzoek en je betrokkenheid heb ik altijd als zeer plezierig en stimulerend ervaren. Ik hoop dat we in de toekomst nog eens samen kunnen werken. Ger, de inzet die je hebt in de begeleiding van je Aio's is ongelofelijk. Ik heb wel eens het gevoel gehad dat ik na het aanleveren van weer een versie van een manuscript moest zorgen dat ik snel weer op mijn kamer was, omdat het anders met correcties al weer op mijn bureau lag voordat ik er was. Het feit dat het manuscript bij de commissie lag voordat ik aan mijn nieuwe baan begon is vrijwel geheel aan jou te danken. Je grote fysiologische kennis en je altijd kritische houding hebben er voor gezorgd dat er een kwalitatief goed proefschrift ligt. Maarten, ik besef me dat ik het je zo nu en dan erg lastig heb gemaakt met mijn eigenwijsheid. Je niet te stuiten optimisme wat betreft de mogelijkheid om allerlei technieken te optimaliseren is vaak waar gebleken. Hoewel ik je liefde voor biomechanica niet deel, heb ik door jou wel geleerd om op een mechanische manier naar spieren te kijken.

Mede dankzij de inzet van de Pompe onderzoeksgroep in Rotterdam is het mogelijk geweest dit onderzoek uit te voeren. Zonder de inbreng van Arnold Reuser en Ans van der Ploeg was het project waarschijnlijk nooit van de grond gekomen. Het is jammer dat de samenwerking niet intensiever is geweest. De bijeenkomsten met Arnold, Ans, Joep Kamphoven en andere mensen van het Pompe team in Rotterdam staan mij bij als zeer verhelderend en vruchtbaar. Ik wil Amold graag bedanken voor zijn enthousiasme voor onze onderzoekslijn, zijn encyclopedische kennis over de ziekte van Pompe die mij in het begin van mijn onderzoek zeer welkom was, en het feit dat hij ons de mogelijkheid gaf een eigen fok met AGLU muizen te beginnen in Maastricht. Ans wil ik speciaal bedanken voor de uitgebreide en kritische manier waarop ze als lid van de leescommissie het manuscript heeft doorgenomen.

Op de vakgroep BW zijn er veel mensen geweest die aan de studies hebben bijgedragen. Ten eerste Marchel Gorselink, die me leerde met de muizen statometer om te gaan en me de kunst van het aanhaken van zenuwen bijbracht. Onze eerste metingen, 10 dagen nadat mijn aanstelling was ingegaan, in quarantaine, tijdens carnaval, staan mij nog helder voor de geest. Een andere erfenis van jou is het feit dat ik 
nog altijd nadat ik mijn computer even alleen heb gelaten alle openstaande documenten scan om te zien of niet een of andere onverlaat toevallig 'Gors rules' tussen de regels gezet heeft.

Zonder analisten is elke Aio een stumper. Naast hun professionele bijdrage aan kleuringen en bepalingen van enzym activiteiten moet ik Gert Schaart en Gerrit van Kranenburg bedanken voor het feit dat ze, ieder op geheel eigen wijze, het werken op het analytisch lab van BW een belevenis maakten. Gert, de plaatjes in mijn proefschrift bewijzen dat je een stuk beter bent met antilichamen dan met schaatsen, en dat is maar goed ook. Gerrit, ik heb vaak gepoogd te volgen wat je doet tijdens je analyses. Hoewel onnavolgbaar zijn de resultaten meestal reproduceerbaar en correct. Esther Cornips ben ik veel dank verschuldigd voor de eindeloze aantallen PCR analyses die ze in 3-voud uitvoerde, waardoor ik wist welke muizen ik moest meten. Met Joan Senden heb ik met veel plezier gefietst, gelopen, in de Schotse Hooglanden op schapen gejaagd en eiwitanalyses gedaan.

A special word of thanks for the people at the INRA in Clermont Ferrand, where I spent 6 weeks doing research together with Ronnie Minnaard. Didier Attaix contributed much to my understanding of proteolysis by the ubiquitine proteasome system. Didier, I hope you have not regretted too much your decision to put two noisy Dutch PhD students in the room immediately next to your office. Also many thanks to the people at your lab, especially Lydie Combaret, whose expert knowledge of the analysis methods were invaluable. Also Daniel, Sophie, Marie-Noel, Agnes, Daniel and Amina, thanks for your hospitality, having us around and helping us out whenever we came across a problem.

Ronnie, we hebben het er best goed afgebracht die 6 weken dacht ik zo. Onze loopjes, onze lunchen, onze mooie roze buffers, ik denk er met plezier aan terug. Succes met de laatste fase van je onderzoek.

Mijn kamergenoten hebben veel uren met mij doorgebracht. Olivier de Hon was de eerste met wie ik een kamer deelde. We hebben het tijdens, tussen, voor en na werk over van alles en nog wat gehad. Sport was een gedeelde interesse, en je hebt de La Chouffe Tourpool in Maastricht geïntroduceerd Behalve daarvoor, vooral veel dank voor het feit dat je een goede vriend en een fijne kamergenoot was. Na Olivier deelde ik de kamer met Ron Keulen. Vele koppen koffie, kletskwartiertjes over van alles en nog wat, pogingen onze kamer op te ruimen en gedeelde Aio frustraties hebben er uiteindelijk toe geleid dat we beide bezig zijn ons proefschrift af te ronden. Ron, bedankt dat je mijn nukken hebt kunnen verdragen de laatste jaren, en succes met jouw laatste loodjes.

Alle leden van de vakgroep BW met wie ik de afgelopen 4,5 jaar vlaai gegeten heb, die ik met balletjes bekogeld heb, die mijn gefluit op de gang hebben moeten aanhoren, die commentaar gaven bij vakgroepspraatjes, allemaal hartelijk dank. Speciaal dank voor Harry voor het elke keer weer aan de praat knijgen van computers die ik opgegeven had, en voor Paul die onoplosbare Matlab problemen in een middag oplost.

En dan is er een hele groep mensen die niet direct onder een noemer te vangen is, maar die essentieei zijn geweest voor het feit dat ik elke dag met plezier naar de uni ging. Freddy is mijn paranimf, vriend, praatpaal, koffieleut en uiteraard onvermoeibare 
trainingsmaat. De uren die ik op de fiets amechtig hijgend in je achterwiel heb doorgebracht zijn onderhand niet meer te tellen, maar ik heb er lol aan. Uiteraard dank voor de Orgie ${ }^{\infty}$, bestaand uit Freddy, Joost en Patrick. Altijd goed voor het organiseren van de HB Tourpool en daaraan gelieerde bezigheden. Het feit dat het reglement van soms deed denken aan dat van Calvin Ball (The only rule in Calvin Ball is that you can not have the same rule twice. Calvin \& Hobbes) heeft de pret alleen verhoogd. Marja, Ronnie, Robert-Jan, Marco en Joan, bedankt voor de donderdagmiddag loopjes. Stelling 10 is mede daarop geïnspireerd. Ondertussen al lang van uit Maastricht verdwenen zijn Mirjam, Lars, René, Marchel, en Anette. leder op hun eigen manier zorgden ze voor een goede werksfeer op de vakgroep.

Matthijs, broer, paranimf, bedankt voor je hulp, raad, geduld en het feit dat je er altijd bent.

Anique, onze proefschriften zijn op heel verschillende manieren tot stand gekomen. Jouw relativeringen en het feit dat je me liet uitrazen als het weer niet ging zo als ik wilde zijn er een belangrijke oorzaak van dat ik nu mijn dankwoord schrijf. We kennen elkaar al lang en goed, en dat is me veel waard. Onze reizen, van de Butterfly Lodge in Pokhara tot de noodhut op Hornstrandir, waren heerlijke rustpunten in de afgelopen jaren. Dank daarvoor.

Ons nieuwe avontuur heet Merlijn. Klein mannetje, misschien heb ik de afgelopen weken meer tijd in je gestoken dan goed was voor mijn proefschrift, maar ik heb van geen seconde spijt. 
List of Publications 


\section{Full papers}

Gorselink, M., Drost, M.R., Coumans, W.A., Van Kranenburg, G.P.J., Hesselink, R.P. and Van der Vusse, G.J. (2001) Impaired muscular contractile performance and adenine nucleotide handling in creatine kinase deficient mice. Pflugers Arch, 17, 164-169

Hesselink, R.P., Gorselink, M., Schaart, G., Wagenmakers, A.J.M., Kamphoven, J., Reuser, A.J.J., Van der Vusse, G.J. and Drost, M.R. (2002) Impaired performance of skeletal muscle in acid $\alpha$-glucosidase knockout mice; Muscle \& Nerve, $25 ; 873-883$

Hesselink, R.P., Drost, M.R., Wagenmakers, A.J.M. and Van der Vusse, G.J. (2003) Lysosomal dysfunction in muscle with special reference to glycogen storage disease type II; Biochimica Biophysica Acta, 1637; 164-170

Drost, M.R., Hesselink, R.P., Oomens, C.W. and Van der Vusse, G.J. Effects of noncontractile inclusions on mechanical performance of skeletal muscle Submitted to Biomechanical Journal

Hesselink, R.P., Van Kranenburg, G.P.J., Wagenmakers, A.J.M., Van der Vusse, G.J. and Drost, M.R. Progression of muscle dysfunction in acid 1-4 $\alpha$-glucosidase knockout mice during isometric and shortening contractions Submitted to Muscle \& Nerve

\section{Published abstracts}

Hesselink, R.P., Gorselink, M., Wagenmakers, A.J.M., Drost, M.R. and Van der Vusse, G.J. (1999) Characterisation of isometric muscle contractions of $\alpha$-glucosidase knockout mice; J Mus Res Cel Mot

Hesselink, R.P., Gorselink, M., Schaart, G., Wagenmakers, A.J.M., Kamphoven, J., Van der Vusse, G.J. and Drost, M.R. (2001) Cytoskeletal changes and impaired isokenetic muscle performance in $\alpha$-glucosidase knockout mice; J Mus Res Cel Mot 
Curriculum Vitae 


\section{Curriculum Vitae}

Reinout Hesselink werd op 14 juni 1973 geboren te Enschede. Hij behaalde daar in 1990 zijn HAVO diploma aan het Jacobus College, en in 1992 zijn VWO diploma. Aansluitend studeerde hij Gezondheidswetenschappen aan de Universiteit Maastricht, alwaar hij in februari 1997 zijn doctoraal diploma haalde in de afstudeerrichting Bewegingswetenschappen. Zijn afstudeer stage over de effecten van leucine op glutamaat dehydrogenase werd begeleid door Prof. dr. A. Wagenmakers, capaciteitsgroep Humane Biologie. Na zijn afstuderen was hij enige tijd werkzaam als onderzoeks-assistent bij de vakgroep Humane biologie en als onderwijs-assistent bij de vakgroep Anatomie. Daarnaast schreef hij mee aan een voorstel voor onderzoek naar de ziekte van Pompe. In februari 1998 werd hij aan de Universteit Maastricht assistent in opleiding op dit onderzoek, onder leiding van Prof. dr. G. van der Vusse (Fysiologie), Prof. dr. A. Wagenmakers (Humane Biologie) en dr. M. Drost (Bewegingswetenschappen). Sinds 1 september 2003 werkt hij als docent Biomedische Wetenschappen aan de Fontys Sporthogeschool. 
Appendix 


\section{Color figures}

Figure 3.3: PAS staining of longitudinal (upper panels) and transverse (lower panels) sections of the gastrocnemius muscle of control (A \& C) and AGLU mice (B \& D). Arrows indicate a number of nuclei co-located with the darkly coloured glycogen storage vacuoles in the muscle of AGLU $\%$ mice (panel B). Open arrowheads indicate the central location of the non-contractile material in the muscle cell (panel D).
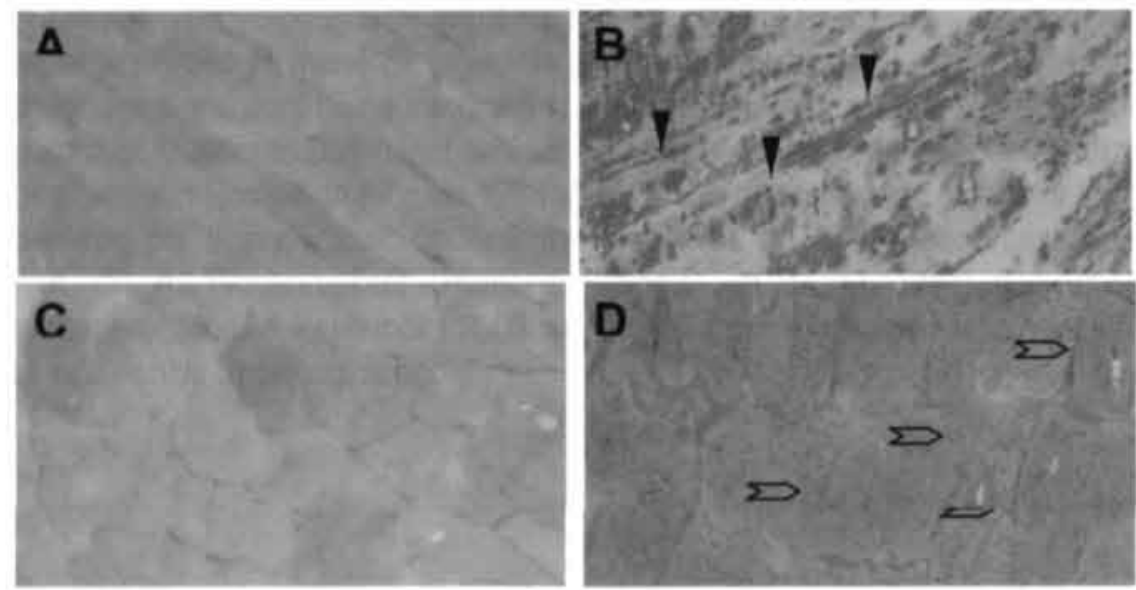

Figure 5.1: PAS staining of longitudinal sections of fibres of dorsal flexor muscle of AGLU* and control mice. Upper panels show control muscle tissue of mice in age groups 6-10 months (A), 12-16 months (B) and 18-24 months (C). Lower panels ( $D, E$ and $F$ ) show muscle tissue of AGLU animals of corresponding age groups.
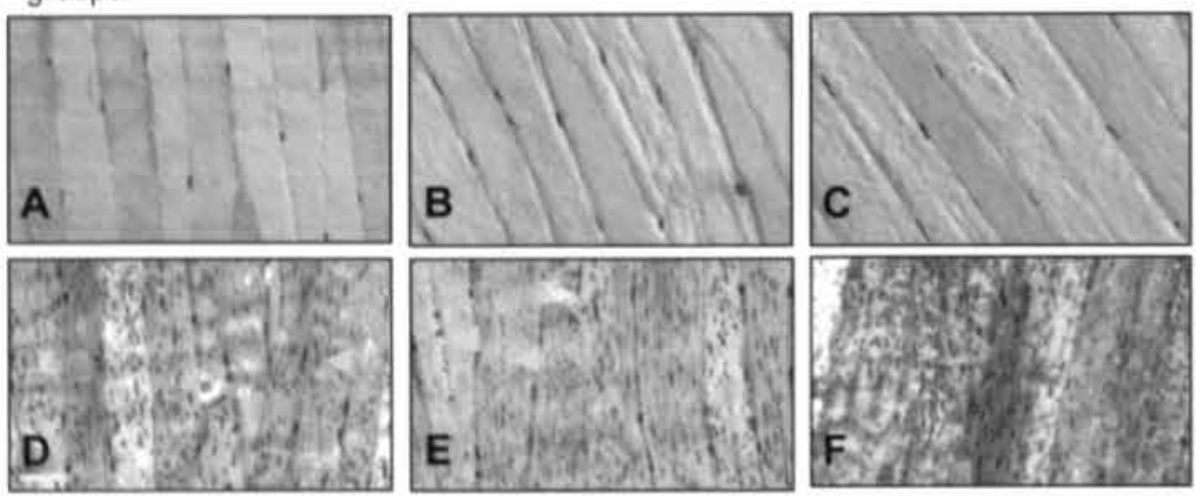

In 5.1D a yellow arrowhead indicates an example of a glycogen filled lysosome showing as an intensely crimson stained focal dot. In $5.1 \mathrm{E}$ the arrowheads indicate the central cores of cellular debris showing as dark blue dots on a row in the centre of the fibre. In $5.1 \mathrm{~F}$ individual muscle fibres are no longer clearly distinguishable. 
Figure 5.2: Micrograph showing immuno-fluorescence staining of desmin (green) and auto-fluorescence of lipofuscin (red) in a longitudinal section of fibres of dorsal flexor muscle of a 20 month old AGLU- mouse.

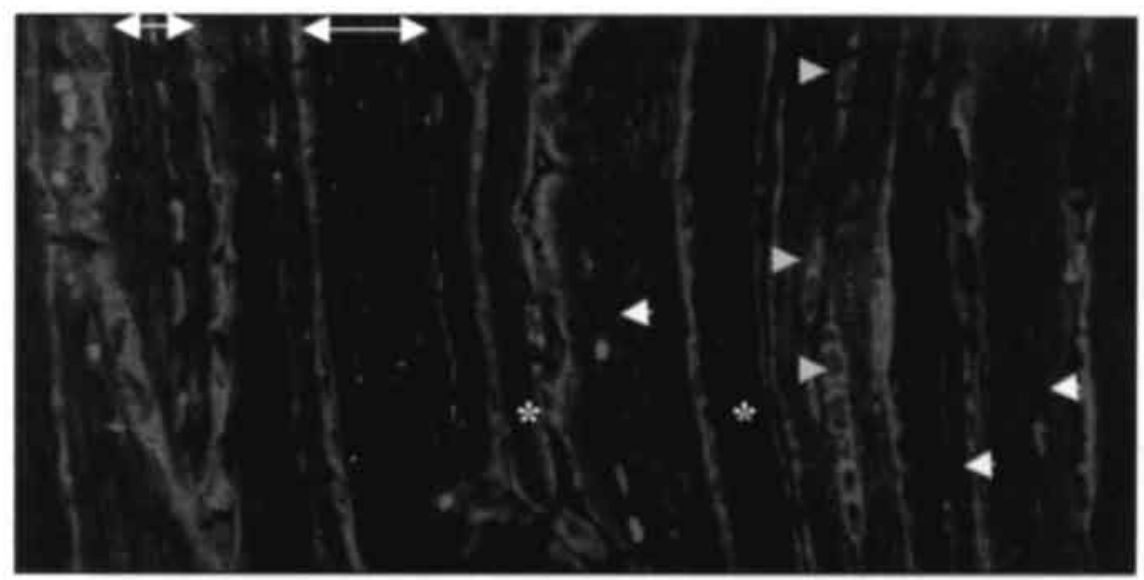

Accumulation of lipofuscin shows as intense red dots on a row centrally in the fibre (single white arrowheads). In some fibres (examples indicated by double white arrowheads) also a more diffuse, continuous lipofuscin signal can be seen. Numerous nuclei (blue), some centrally located in the fibre (yellow arrowheads) are visible. Note that both fibres with severe structural damage and undamaged fibres can be observed (compare fibres indicated with asterisk).

Figure 5.3: Immuno-fluorescent staining of titin in longitudinal sections of fibres of dorsal flexor muscle of control and AGLU\% mice. Upper panels show control tissue of mice in age groups 6-10 months (A), 12-16 months (B) and 18-24 months (C). Lower panels (D, $E$ and F) show tissue of AGLU* animals of corresponding age groups.
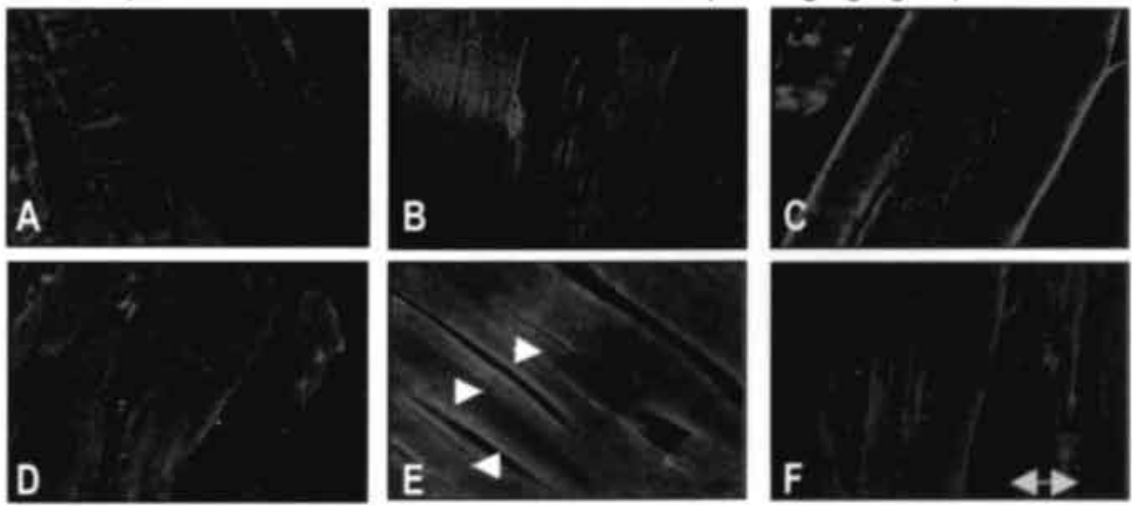

White arrowheads in panel $\mathrm{E}$ indicate the large central inclusions. The outlines of the cell can be appreciated by the nuclei in blue. The yellow arrow in Figure $5.3 \mathrm{~F}$ is placed at the same spot as in Figure $5.4 \mathrm{~F}$ indicating the difference in pattern of titin and desmin staining. In panel $\mathrm{D}$ sectioning 
was not entirely parallel to the fibre direction, resulting in a slightly oblique appearance of the muscle fibres.

Figure 5.4: Immuno-fluorescent staining of desmin in longitudinal sections of fibres of dorsal flexor muscle of control and AGLU* mice. Upper panels show control tissue of mice in age groups 6-10 months (A), 12-16 months (B) and 18-24 months (C). Lower panels $(D, E$ and $F)$ show tissue of $A G L U *$ animals of corresponding age groups.
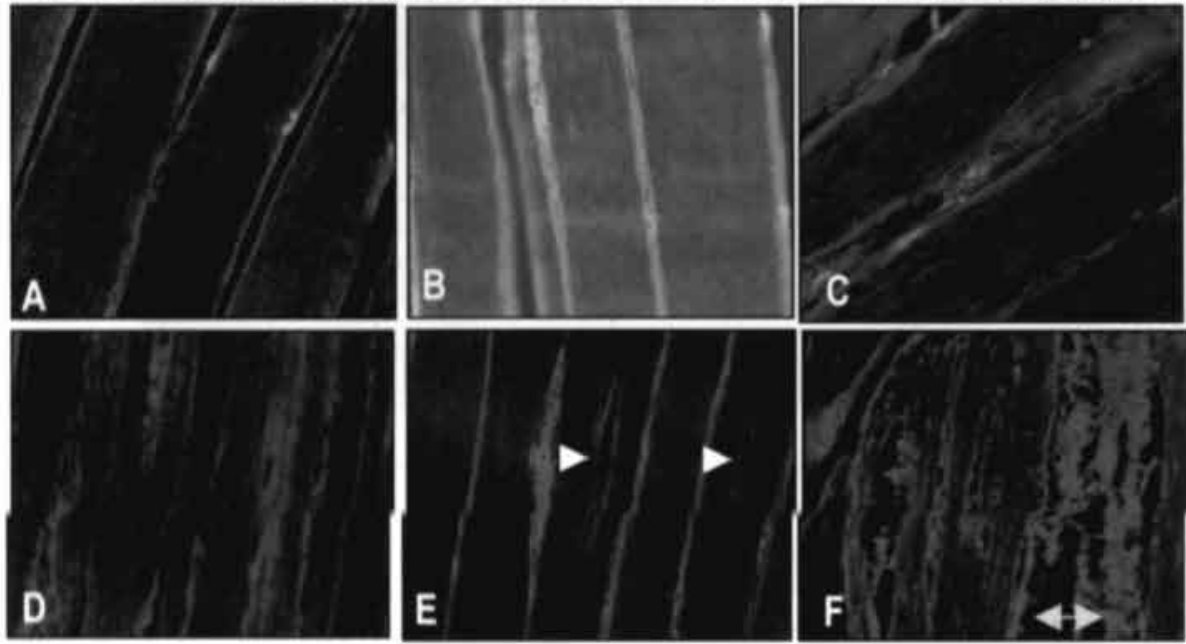

White arrowheads in panel $\mathrm{E}$ indicate the large central inclusions. The yellow arrow in Figure 5.4F is placed at the same spot as in Figure 5.3F emphasising the difference in pattern of desmin and titin staining.

Figure 6.2: Distribution of the longitudinal strain, given as elongation factor $\lambda[-](2 A)$ and longitudinal stress [kPa] $(2 \mathrm{~B})$ of the contractile tissue during the plateau phase of an isometric contraction in the deformed calculation area (regular distribution, $10^{*} 6 \mu \mathrm{m}$, inclusion density $2.6 \%$ ). Stresses and strains inside the inclusion are not shown.

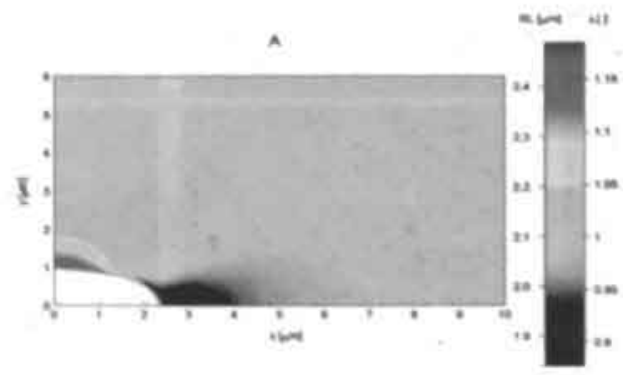




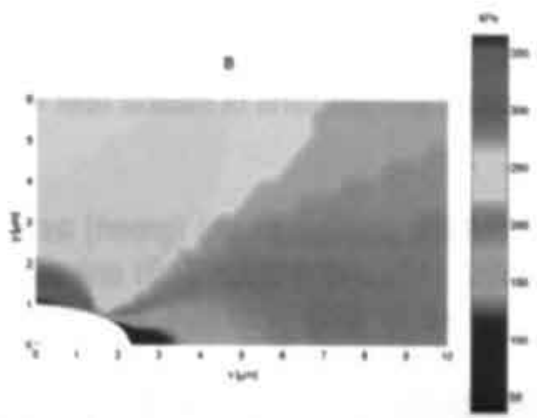

A) Elongation factors of the contractile tissue $(\lambda)$, i.e. actual length divided by length in the resting situation are given to the right of the colour-bar, values less than one indicate shortening, more than one elongation. In the resting condition the sarcomere length was assumed to be at its optimal length $(2.1 \mu \mathrm{m})$. For the sake of clarity, also the scale for lengths of sarcomeres (SL) is shown to the left of the colour-bar.

Longitudinal shortening occurred mainly in front ( $x$-direction) of the inclusion. The shortening area (bluish) becomes wider with increasing $x$-position while the magnitude of the shortening becomes less ( $\lambda$ closer to 1$)$. The inclusion elongated by approximately $20 \%$. The elongating area (green, yellow and red) was lateral to the inclusion and lateral to the shortening area. Maximal elongation (red) in the contractile tissue occurs directly lateral (y-direction) to the inclusion.

B) Stresses are given in $\mathrm{kPa}$. Longitudinal stresses are low in front of the inclusion (bluish) and high adjacent to the inclusion (yellow and red). Over a large area (green) stresses hardly deviate from the stress without inclusion $(223 \mathrm{kPa})$.

Figure 7.3: Immuno-fluorescent staining of the regulatory 19S unit of the proteasome complex (red), laminin (green) and nuclei (blue) in longitudinal sections of the dorsal flexor muscles of 2 control ( $3 \mathrm{~A}$ and $3 \mathrm{C}$ ) and 2 AGLU $\%$ animals ( $3 \mathrm{~B}$ and $3 \mathrm{D}$ ) at 12 months of age.
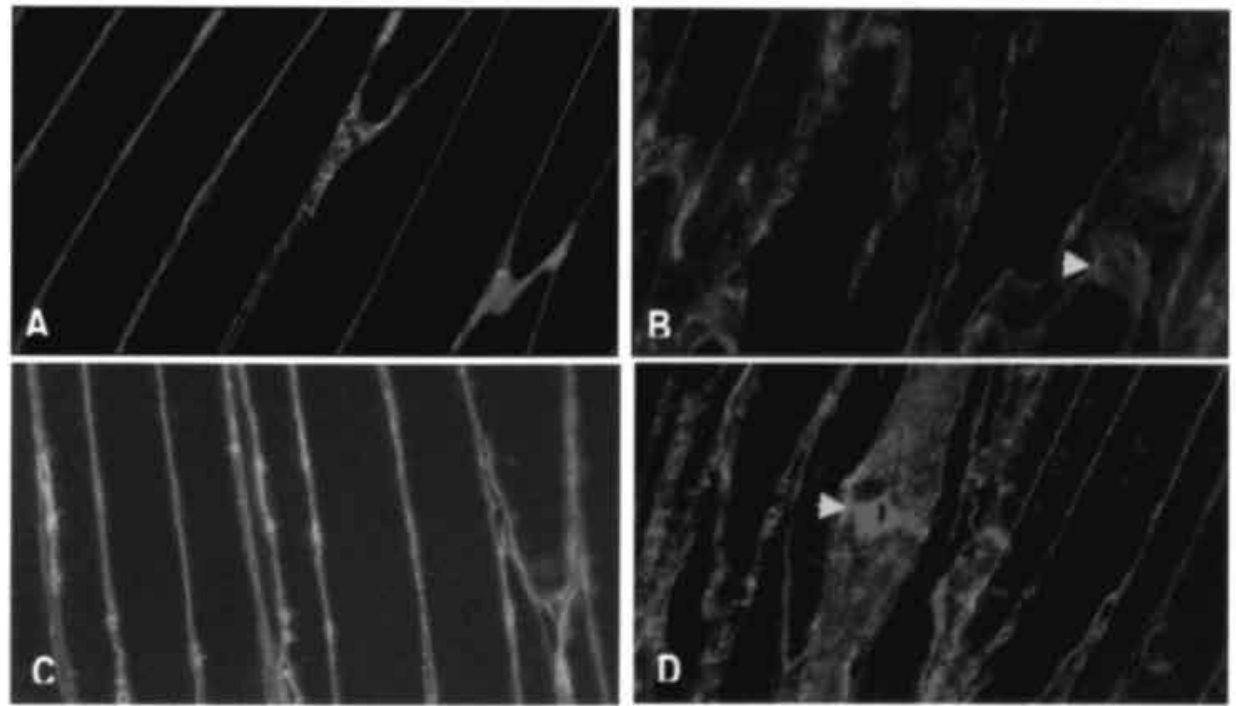
Note the increased signal of the 19S unit in the AGLU+ animals. The laminin staining of the muscle membrane is less distinct, and the number of nuclei is increased in the affected muscle fibres. Yellow arrowheads indicate damaged parts of muscle fiber with intense signal of the $19 \mathrm{~S}$ unit.

Figure 7.4: Localisation of TUNEL positive nuclei (green) as a indicator of apoptosis in dorsal flexor muscles of control (4A) and AGLU $\%(4 B)$ animals at 18-24 months of age. Non-apoptotic nuclei are stained in blue. Laminin is stained in red to highlight the outlines of the myocyte.
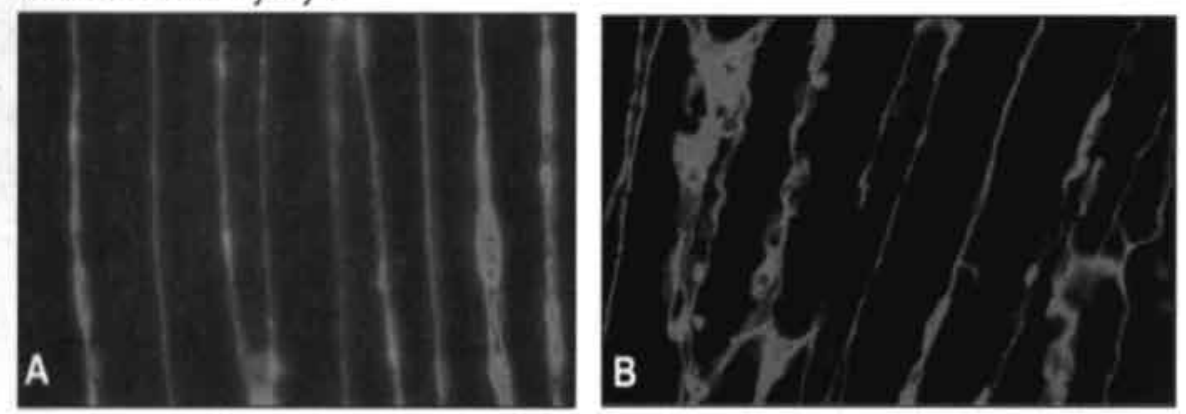

In figure $7.4 \mathrm{~B}$ apoptotic nuclei are identified in green. There, the laminin staining of the muscle membrane is less distinct, and the number of nuclei is increased. 

